\title{
ANÁLISE DE SINAIS DE VOZ POR PADRÕES VISUAIS DE DINÂMICA VOCAL
}

Tese apresentada à Escola de Engenharia de São Carlos, da Universidade de São Paulo, para obtenção do Título de Doutor em Ciências (Programa de Engenharia Elétrica).

Área de Concentração: Processamento de Sinais e Instrumentação

Orientador: Prof. Tit. Dr. José Carlos Pereira

São Carlos 


\section{FOLHA DE JULGAMENTO}

Candidato(a): Fonoaudióloga MARIA EUGENIA DÁJER.

Tese defendida e julgada em 30/07/2010 perante a Comissão Julgadora:

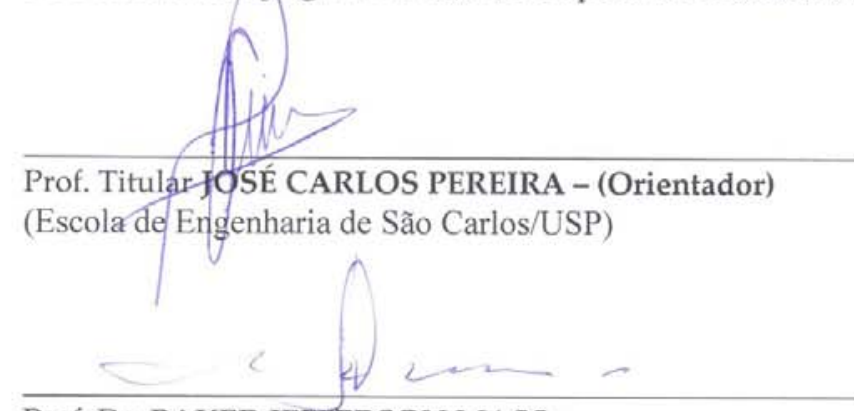

Prof. Dr. BAKER JEFFERSON MASS

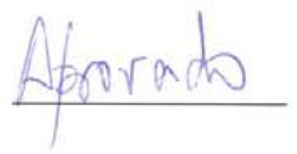

(Escola de Engenharia de São Carlos/USP)
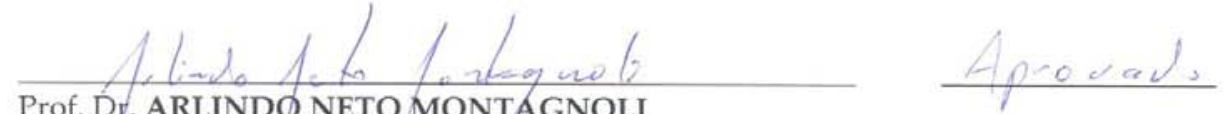

Prof. Dy. ARLINDO NETO MONTAGNOLI

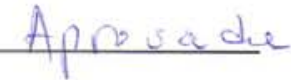

(Universidade Federal de São Carlos/UFSCar)

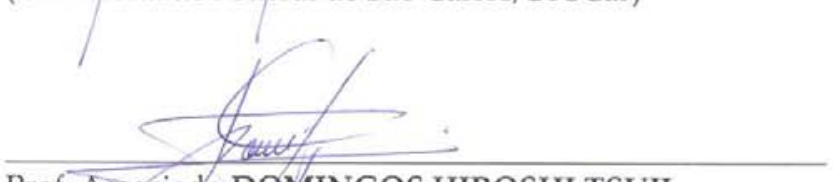

Prof. Associado DOMINGOS HIROSHI TSUII

(Faculdade de Medicina/USP)

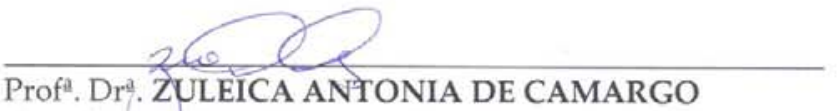

(Pontificia Universidade Católica/PUC/Campus de São Paulo)

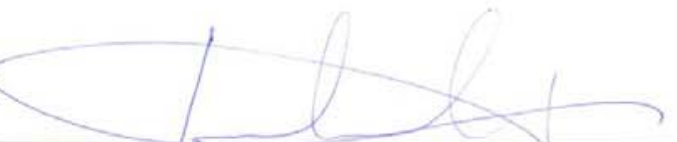

Prof. Titular GERALDO ROBERTO MARTINS DA COSTA

Coordenador do Programa de/Pós-Graduação em Engenharia Elétrica e

Presidente da Comissão de Pós-Graduação 
DEDICATORIA

A mis padres, Angelita y Ricardo, porque la certeza de su presencia es mi fortaleza, mi luz y mi alegría. 


\section{AGRADECIMENTOS}

Tenho muito a agradecer, porque só eu sou responsável pelas minhas quedas; mas compartilho minhas vitórias com muita gente. Sempre caminhei com minhas próprias pernas, mas nunca estive sozinha. Por isso agradeço a DEUS em primeiro lugar por tem-me abençoado com tantas pessoas incríveis ao longo do caminho.

Agradeço a meus pais, pelo amor e apoio constante; e por ensinar-me desde muito cedo o valor da amizade e a importância de saber sonhar.

Ao Prof. José Carlos Pereira, por todos estes anos de trabalho conjunto, de apoio, de guia, de paciência. Pela confiança, a generosidade e a oportunidade. E por ser um exemplo de vida e de profissional.

Ao Silvio A. Souza ( $X u$ hermoso), por ser meu amor, meu parceiro, meu amigo; por me dar forças e apoio nos momentos mais difíceis, e pela PACIÊNCIA para agüentar as crises e choros.

Quero agradecer especialmente a um grupo humano incrível, diversificado, divertido, nobre, íntegro, com quem tive a honra de compartilhar longas horas de trabalho ano após ano; com quem aprendi grandes lições sobre determinação, esforço, trabalho, responsabilidade e companheirismo. Daiane "Macuca" de Bem, Edwin Villanueva e Soledad Espezúa, Julián Villamarín, Rafael "Capacetão" Christ, Paulo Scalassara, Vinicius "Vinão" Guimarães, Fernando Araújo, Lianet Sepúlveda, Jamille Marrara, Regina Pimenta e Alan Petrônio muitíssimo obrigada!!!!!! Também quero agradecer a uma pessoa muito especial, que compartilhou apenas um semestre com a gente, mas que fez diferença em nossas vidas. Anderson!! (vulgo: Forex, Dandi ou "Tou de boa"), muito obrigada pela mensagem, pela alegria e pela amizade. 
Ao Dr. Paulo Scalassara, um grande companheiro e amigo, por toda ajuda recebida e por todo o trabalho compartilhado nestes quatro anos; a sua linda esposa Melissa pelo carinho e amizade.

A “La Pequeña Cubana", por ensinar-me que é possível ser forte, determinada e lutadora, sem perder a alegria e a grandeza d'alma. Pela amizade incondicional e por compartilhar angústias e alegrias como uma verdadeira irmã. Obrigada a Esperanza, Felipe, Lian, Orieta e Indara por receber-me com tanto carinho e tantos mojitos!!!!.

A meus "queridos Maricas"! Amilcar Querubini, Giovani Pozzebón e Guido Gomez, pelos mates, os cafezinhos, os happy-hours, churras e companhia, mas principalmente pela amizade generosa e desinteressada, vocês são meus anjos guardiães! E um agradecimento especial ao Prof. Ricardo Quadros e a sua esposa Rita, pelo apoio e carinho, e por incorporarme como mais uma ao grupo.

A Regina, Jamille, Fernando, Paula, Felipe e Filipe por permitir-me tão generosamente compartilhar e dar palpites em seus trabalhos. Vocês são os responsáveis por eu querer ser "palpitera profissional”!!!

A minhas queridas amigas Carol, Lie, Aline, Lilian, Sabrina, Camila, Cris, Sheila e Alinezinha por tantos momentos de "terapia de grupo", fofocas e risadas. Vocês são tuuudo de bom!! A todos os amigos do departamento: Kustela, Janison, Monaro, Marcel, Suetake, Marcelo, Perninha, Moussa e Leandro, por fazerem minha vida mais leve com as risadas, conversas e momentos de relax.

Ao pessoal de secretaria, Jussara, Marisa, Cidinha e Zé, e ao pessoal de apoio técnico, Roseli, Fernanda, Gerson e João, por estar sempre prontos para resolver pepinos e porque seu trabalho constante faz possível o trabalho de todos nós. A Vera pelo cafezinho "salvador" das 2 das tarde!! A Dair e Rui, pelo serviço técnico, o pronto socorro e pela cordialidade de todos estes anos. 
A Kátia, Tatyana e Marcelo, do serviço de convênios, por toda a assistência, ajuda e paciência para orientar-me com tanta papelada!!

Ao Prof. Arlindo Montagnoli pela colaboração, por tantas contribuições teóricas e práticas, e pela paciência e confiança.

A todos os professores que contribuíram de diferente forma com minha formação humana e profissional, Prof. Rodrigo Guido, Prof. Mara Behlau, Prof. Domingos Tsuji, Prof. Marcelo BJ, Prof. Vilma, Prof. Zucoloto, Prof. José Marcos, Prof. Lidia Teles, Prof. Baker, Prof. Geraldo, Prof. Luciana Montanari, Prof Nelson Silva, Prof. Maciel e ao Programa de Engenharia Elétrica que aceitou o desafio de receber um profissional de outra área.

Ao Programa de Estudante-Convênio de Pós-Graduação (PEC-PG) e à Coordenação de Aperfeiçoamento de Pessoal de Nível Superior (CAPES) por financiar este projeto.

A Mónica, Abudi, Nati e Tami Sultani, pelo carinho e a torcida. A meus primos, Claudio Dajer e família, Laura García e família, e Andrea Vides e família, por torcer por mim a distância!!!

A meus "hermanos del corazón": Ceci Pellegrini, Fede Ferrari, Marisa Zorrilla, Pichi Funes e "Tutis" María Cruz e Tomás; Viky Rivas, Cesar Demonte, Virginia De Arriba, Tomás e Robert Easdale e Hernán Bracamonte por mostrarme que não existe tempo nem distância.

A minha família materna, Matilde Rubín, Graciela e família, Mirta e família, e David e família, por ensinar-me que amizade é uma das melhores heranças.

A meu Brother Fernando Castro e toda sua família, por receber-me de braços abertos com tanto carinho. Ao trio Thais Perez Vanzella, Silvia Pinto e Ava Brandão, pela amizade e o companheirismo, e por conservar intata uma 
época maraviSHosa, que ficará para sempre no meu coração. A meus amigos Josi, Elton e André, pelo carinho e a amizade de todos estes anos.

A dona Judith e as meninas da pensão, Bruna, Patrícia e Simone.

A todos e cada uma destas pessoas por contribuir com gestos, palavras, criticas, apoio, amizade e ter-me acompanhado nesta longa caminhada. 
“Ó Deus, Criador do Universo e meu Pai, concedei-me uma boa idéia, que esteja de acordo com o meu talento e que beneficie o maior número possível de pessoas. E concedei-me a força vital capaz de realizar essa boa idéia". 


\section{SUMÁRIO}

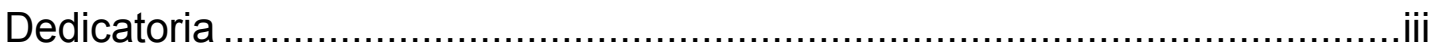

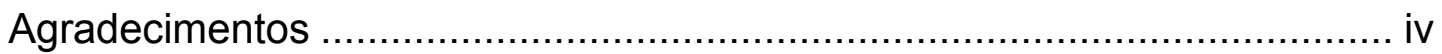

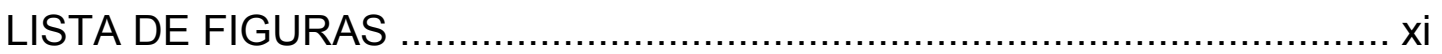

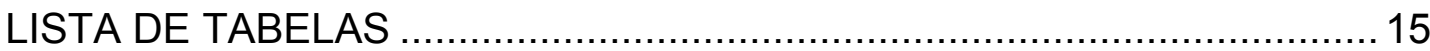

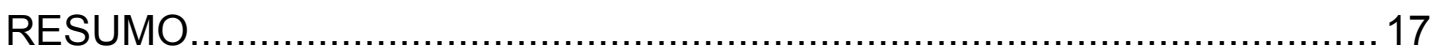

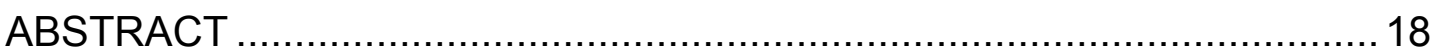

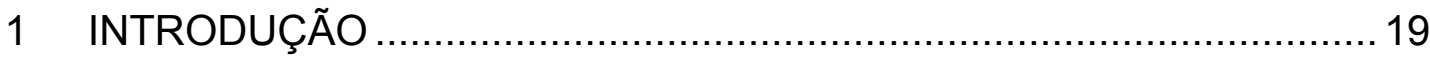

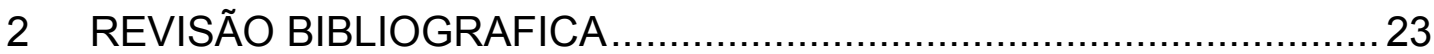

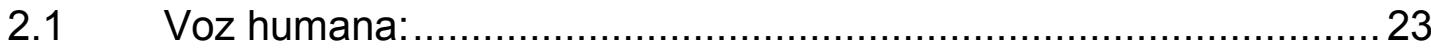

2.1.1 Voz fenômeno multidimensional e evolutivo. ........................ 36

2.1.2 Voz relacionada com transtornos posturais ........................ 37

2.1.3 Alterações vocais ou voz disfônica. ................................... 38

2.2 Avaliação dos sinais de voz ............................................... 40

2.2.1 Avaliação perceptivo-auditiva ........................................ 41

2.2.2 Avaliação acústica ................................................... 44

2.2.3 Abordagens baseadas em modelos de dinâmica não linear... 47

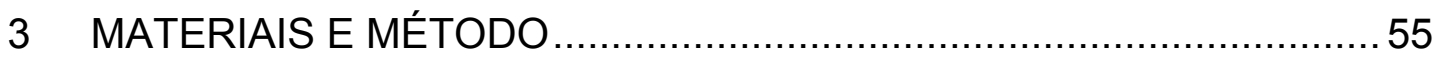

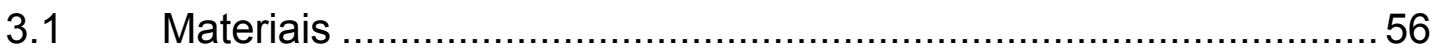

3.1.1 Grupo 1. Sinais de voz sem alteração vocal ou vozes saudáveis 56 
3.1.2 Grupo 2. Sinais de voz com disfonia.............................. 58

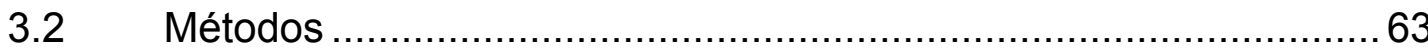

3.2.1 Avaliação perceptivo-auditiva ..................................... 63

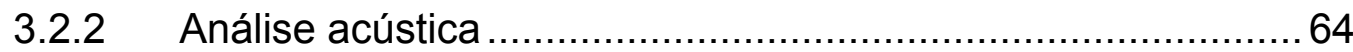

3.2.3 Análise qualitativa dos padrões visuais da dinâmica vocal PVDV 66

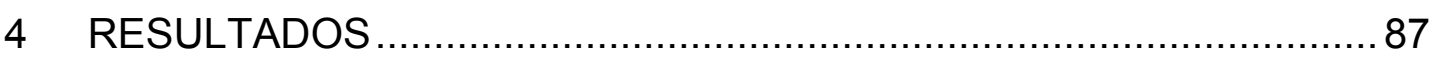

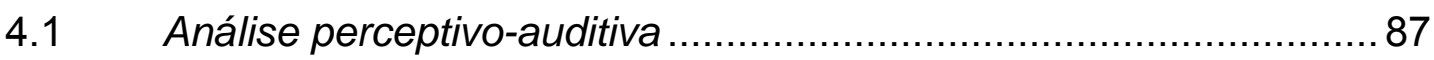

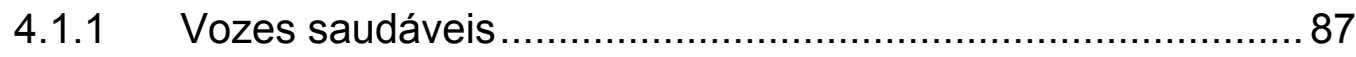

4.1.2 Voz normal com mudanças posturais ............................ 88

4.1.3 Vozes patológicas ..........................................................90

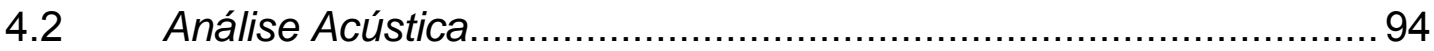

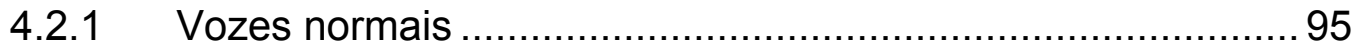

4.2.2 Normais com diferentes posturas ...................................96

4.2.3 Vozes patológicas ...................................................... 100

4.3 Análise qualitativa dos Padrões Visuais da Dinâmica Vocal......... 105

4.3.1 Vozes normais ........................................................ 105

4.3.2 Voz normal com mudanças posturais ............................ 109

4.3.3 Vozes patológicas ............................................... 116

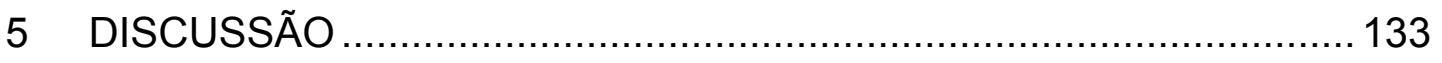

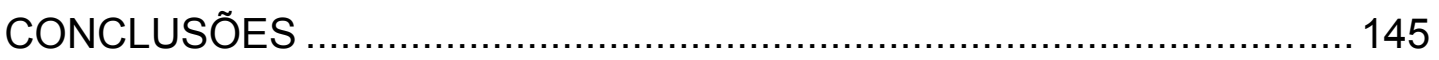

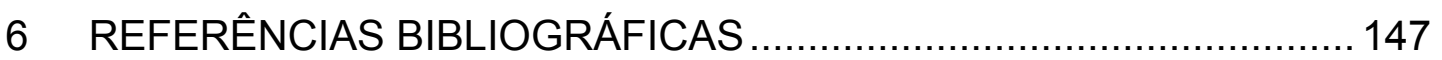




\section{LISTA DE FIGURAS}

Figura 2.1: Desenho esquemático dos sistemas e órgãos envolvidos na produção dos sinais de voz e do modelo linear de fonte-filtro proposto por FANT (1970). 24

Figura 2.2: Esquema da localização da laringe no trato respiratório. Figura modificada de: http:/medimages.healthopedia.com/ large/larynx.jpg ........ 25

Figura 2.3: Visão anterior e posterior das principais estruturas laríngeas (cartilagens, ligamentos, membranas laríngeas, osso Hióde e traquéia. Figura modificada de Netter (1997).

Figura 2.4: Desenho esquemático da visão posterior (a) e da visão lateral (b) dos músculos intrínsecos da laringe. Figura modificada de Netter (1997) 28

Figura 2.5: Desenho esquemático de um corte transversal da laringe. Músculos Tiroaritenóideo (TA) e interaritenóideo (IA) ......................................... 29

Figura 2.6: Esquema de um corte longitudinal de uma prega vocal. 31

Figura 2.7: Desenho esquemático do mecanismo das pregas vocais na produção do pulso glótico. Onde To= período completo; $\mathrm{t} 1=$ começo de fase de abertura; t2= abertura máxima; $t 3=$ inicio de fase fechada e t4= fechamento completo.

Figura 2.8: (A) Desenho esquemático do espectro de freqüências do som fundamental sem amplificação. (B) Curvas de ressonância do trato vocal. (C) Espectro resultante da freqüência fundamental mais as ressonâncias do trato vocal. 34

Figura 3.1: Grupos e sub-grupos das amostras de sinais de voz avaliadas. ... 56

Figura 3.2: Imagens das pregas vocais saudáveis. Imagens extraídas do banco de dados do Laboratório de Processamento de Sinais. 58

Figura 3.3: Imagem das pregas vocais de um paciente com edema de Reinke. Imagem extraída do sitio web: http://www.gbmc.org/body.cfm?id=450.... 60

Figura 3.4: Imagem das pregas vocais de um paciente com nódulos vocais bilaterais. Imagem extraída de Behlau, M. Voz - O Livro do Especialista. 61 
Figura 3.5: Imagem das pregas vocais de um paciente com disfonia de origem neurológico, portador de paralise unilateral. Imagem extraída do sitio web: http://www.gbmc.org/body.cfm?id=450

Figura 3.6: Imagem da versão 2009 do programa Análise de Voz (MONTAGNOLI, 2009).

Figura 3.7: (A) Sinal completo da vogal sustentada /a/. (B) trecho de 200 milissegundos. (C) trecho de 10 ciclos selecionado para análise.

Figura 3.8: Curva de informação mútua por atraso de amostras para o sinal apresentado na figura 3.7C (10 ciclos).

Figura 3.9: Exemplo de um PVDV bidimensional de uma vogal sustentada /e/ do sinal apresentado na figura 3.7C (10 ciclos) com atraso de 13 amostras.

Figura 3.10: Exemplo do PVDV tridimensional (eixos $x, y, z$ ) do sinal de 10 ciclos apresentado na figura $3.7 \mathrm{C}$ com atraso de 13 amostras.

Figura 3.11: Exemplo do PVDV em função do tempo do sinal de 10 ciclos apresentado na figura $3.7 \mathrm{C}$ com atraso de 13 amostras.

Figura 3.12: Exemplo do PVDV de um sinal simulado de uma única freqüência.

Figura 3.13: Exemplo do PVDV de um sinal simulado de uma única freqüência e com acréscimo de $1 \%$ de jitter e $1 \%$ de shimmer . 74

Figura 3.14: Exemplo do PVDV de um sinal de voz, de uma vogal /i/ sustentada de um sujeito sem queixa ou alteração vocal.

Figura 3.15: Exemplo de uma vogal /a/ no tempo com seu respectivo PVDV de um sujeito sem queixa ou alteração vocal.

Figura 3.16: Exemplos de graus de loops dos PVDV. Grau 4- para configurações com mais de 3 loops; grau 3- para três loops ; grau 2- para dois loops; grau 1- para um loop e grau 0 - para número indefinido.

Figura 3.17: Exemplo de um sinal de vogal la/ no tempo (superior) e o respectivo PVDV de um sujeito com alteração vocal (inferior). 80

Figura 3.18: Exemplos dos graus de regularidade de traçados. Grau 5- traçado regulares em todo o percurso; grau 4- traçados regulares com uma porção de irregularidade; grau 3- regularidade intermitente; grau 2 - traçados levemente irregulares; grau 1- traçados levemente irregulares com região de irregularidade, e grau 0- para traçados irregulares em todo o percurso. 
Figura 3.19: Exemplo de uma vogal /e/ no tempo com seu respectivo Padrão Visual da Dinâmica Vocal de um sujeito com alteração vocal.

Figura 3.20: Exemplos de PVDV com os 5 graus de convergência de trajetórias para sinais de voz da vogal sustentada /a/. Onde o grau 4- apresenta uma forte convergência da trajetória das órbitas e o grau 0- uma convergência fraca. Os graus 1, 2 e 3 são intermediários e mostram uma dinâmica de convergência mista. 84

Figura 3.21: Exemplo de avaliação qualitativa de um Padrão Visual da Dinâmica Vocal de um trecho de voz de 200 milissegundos de um voluntário sem patologia ou queixa vocal. 86

Figura 4.1: Gráfico de distribuição de valores de jitter para: 1- Postura neutra, 2- postura com anteriorização de cabeça com extensão do pescoço e 3 postura com aumento da cifose toráxica com anteriorização de cabeça. . 97

Figura 4.2: Gráfico de distribuição de valores de shimmer para: 1- Postura neutra, 2- postura com anteriorização de cabeça com extensão do pescoço e 3 postura com aumento da cifose toráxica com anteriorização de cabeça.

Figura 4.3: Gráfico de distribuição de valores de freqüência fundamenta F0 para: 1- Postura neutra, 2- postura com anteriorização de cabeça com extensão do pescoço e 3 postura com aumento da cifose toráxica com anteriorização de cabeça. 100

Figura 4.4: Gráfico de distribuição de valores de jitter para: grupo 1- vozes sem alteração ou queixa vocal, grupo 2- edema de Reinke; grupo 3- nódulos vocais e grupo 4- disfonia orgânica de origem neurológico. 104

Figura 4.5: Gráfico de distribuição de valores de shimmer para: grupo 1- vozes sem alteração ou queixa vocal, grupo 2- edema de Reinke; grupo 3nódulos vocais e grupo 4- disfonia orgânica de origem neurológico....... 105

Figura 4.6: Exemplos de PVDV de trechos de 200 milissegundos da vogal sustentada /a/ de sujeitos de ambos os gêneros sem queixa ou alteração vocal. 108

Figura 4.7: PVDV para as três posturas avaliadas. 1- Postura neutra, 2- postura com anteriorização de cabeça com extensão do pescoço e 3- postura com aumento da cifose toráxica com anteriorização de cabeça. 110

Figura 4.8: Exemplos de PVDV para a postura 1 ou Postura neutra correspondentes as amostras dos dias 1, 5, 7 e 9 . 111

Figura 4.9: Exemplos de PVDV para a postura 2 ou postura com anteriorização de cabeça e com extensão do pescoço. Os quatro PVDV correspondem aos dias $1,5,7$ e 9 . 
Figura 4.10: Exemplos de PVDV para a postura 3 ou postura com aumento da cifose toráxica. Os PVDV correspondem aos dias 1, 5, 7 e 9.

Figura 4.11: Exemplos de PVDV de seis sinais de voz com edema de Reinke.

Figura 4.12: Exemplo 09 e uma aproximação de PVDV de uma voz com edema de Reinke.

Figura 4.13: Exemplo 07 e uma aproximação de PVDV de uma voz com edema de Reinke.

Figura 4.14: Exemplos de PVDV de seis vozes com nódulos vocais. 123

Figura 4.15: Exemplos de PVDV de seis vozes com nódulos vocais. 124

Figura 4.16: Exemplos de PVDV de seis vozes com nódulos vocais. 125

Figura 4.17: Exemplos de PVDV de vozes de pacientes com alterações neurológicas.

Figura 4.18: Exemplo 11 e uma aproximação de PVDV de uma voz com disfonia de origem neurológica. 128

Figura 4.19: Exemplo 12 e uma aproximação de PVDV de uma voz com disfonia de origem neurológica. 


\section{LISTA DE TABELAS}

Tabela 3-1: Relação de gênero e idade do grupo de vozes saudáveis 57

Tabela 3-2: Relação de gênero e idade do grupo de pacientes com edema de Reinke. 59

Tabela 3-3: Relação de gênero e idade do grupo de pacientes com nódulo vocal. 60

Tabela 3-4: Relação de diagnóstico e idade do grupo de pacientes com disfonia de origem neurológica.

Tabela 4-1: Resultados da avaliação perceptivo-auditiva dos sinais saudáveis. 88

Tabela 4-2: Avaliação perceptivo-auditiva dos sinais de voz com três posturas nos 10 dias de coleta.

Tabela 4-3: Avaliação perceptivo-auditiva das vozes com edema de Reinke.. 91

Tabela 4-4: Resultados da avaliação perceptivo-auditiva dos sinais com nódulo vocal.

Tabela 4-5: Avaliação perceptivo-auditiva das vozes com disfonia neurológica. 93

Tabela 4-6: Resultados de jitter, shimmer e Fo das 16 vozes saudáveis. 95

Tabela 4-7: Valores médios de jitter (\%) das amostras de voz nas três posturas. 96

Tabela 4-8: Valores médios de shimmer (\%) das amostras de voz nas três posturas.

Tabela 4-9: Valores da Freqüência fundamental F0 $(\mathrm{Hz})$ das vozes nas três posturas.

Tabela 4-10: Valores médios dos parâmetros acústicos jitter, shimmer, e F0 para os 16 sinais de voz com edema de Reinke.

Tabela 4-11: Valores médios de jitter, shimmer, e Fo dos 15 sinais com nódulos vocais. 
Tabela 4-12: Valores médios de jitter, shimmer e freqüência fundamental de vozes de pacientes com disfonia neurológica. 103

Tabela 4-13: Avaliação qualitativa dos PVDV das vozes saudáveis 106

Tabela 4-14: Avaliação em graus da configuração de loops, regularidade e convergência dos traçados dos PVDV nas diferentes posturas.

Tabela 4-15: Resultados da avaliação dos PVDV das vozes com edema de Reinke. 118

Tabela 4-16: Resultados qualitativos dos PVDV das vozes com nódulos vocais.

Tabela 4-17: Avaliação qualitativa dos PVDV das vozes com disfonia neurológica. 126

Tabela 4-18: Comparação de porcentagens de graus de loops das vozes dos 4 grupos

Tabela 4-19: Comparação de porcentagens de graus de regularidade de traçados dos sinais de voz dos quatro grupos 130

Tabela 4-20: Comparação de porcentagens de graus de convergência para os 4 grupos

Tabela 4-21: Coeficiente de correlação das variáveis das três técnicas usadas para os 91 sinais de voz 


\section{RESUMO}

\section{DAJER, M. E. Análise de sinais de voz por padrões visuais de dinâmica} vocal. 2010. pp. 154. Tese (Doutorado) - Escola de Engenharia de São Carlos, Universidade de São Paulo, São Carlos, 2010.

O objetivo deste trabalho foi avaliar vozes saudáveis e com alterações patológicas aplicando análise de Padrões Visuais de Dinâmica Vocal (PVDV) em conjunto com análise acústica e análise perceptivo-auditiva. Foram avaliadas 91 vozes da vogal sustentada /a/ do português do Brasil, de sujeitos de ambos os gêneros com idades entre 21 e 88 anos. As vozes foram gravadas com taxa de amostragem de $22.050 \mathrm{~Hz}, 16$ bits, mono canal e formato WAV. Foram obtidos valores de jitter, shimmer e freqüência fundamental. Para análise perceptivo-auditiva foram avaliadas rugosidade, soprosidade, tensão e instabilidade. Para descrever a dinâmica dos sinais de voz dos PVDV foi utilizada a técnica de reconstrução de espaço de fase e foram analisados qualitativamente os parâmetros de loops, regularidade e convergência de traçados. Foram aplicados testes estatísticos paramétricos e não paramétricos. Os resultados demonstram que jitter apresenta uma correlação negativa com loop, regularidade e convergência dos traçados; e que shimmer tem correlação negativa com convergência e loops. As características de rugosidade e soprosidade estão correlacionadas negativamente com os três parâmetros dinâmicos. A análise qualitativa dos PVDV é uma técnica promissora, por considerar os componentes caótico e determinístico da voz. É sugerido que não substitui as técnicas existentes, embora possa aperfeiçoar e complementar os métodos usados por profissionais fonoaudiólogos e otorrinolaringologistas.

Palavras - chave: Voz; Análise de Voz; Padrão Visual de Dinâmica Vocal, Reconstrução de Espaço de Fase; Análise Não Linear. 
ABSTRACT

\section{DAJER, M. E. Voice signal analysis using Vocal Dynamic Visual Patterns.} 2010. pp.154. Ph.D. Thesis - Escola de Engenharia de São Carlos, Universidade de São Paulo, São Carlos, 2010.

The aim of this research was to analyze healthy and pathologic voices using Vocal Dynamic Visual Patterns (VDVP) in combination with acoustical and perceptual analysis. Ninety one voice signals of sustained vowel /a/ from Brazilian Portuguese, from male and female patients, were analyzed using acoustical analysis, perceptual analysis and Vocal Dynamic Visual Patterns (VDVP) analysis. All voice samples were quantized in amplitude with16 bits and recorded in mono-channel WAV format. The sampling frequency was $22050 \mathrm{~Hz}$. Acoustical values for jitter, shimmer and fundamental frequency were obtained. Roughness, breathiness, strain and irregularity were analyzed for perceptual analysis. Phase space reconstruction technique was performed in order to describe the voice signal nonlinear characteristics by Vocal Dynamic Visual Patterns. Results showed negative correlation for jitter and the 3 dynamic parameters, as well as, for shimmer with convergence and loops. Roughness and breathiness were negative correlated with dynamical parameters. Vocal Dynamic Visual Pattern analysis is a promising technique for voice evaluation; including voice chaotic and deterministic components. It is suggested that visual pattern analysis do not replace the existing voice analysis techniques, although it complements and improves the voice evaluation methods available for speech therapist and laryngologists.

Keywords: Voice, Voice analysis, Vocal Dynamic Visual Pattern, Phase Space Reconstruction, Nonlinear Analysis. 


\section{$1 \quad$ INTRODUÇÃO}

A importância da voz em nosso dia a dia é inquestionável. A voz - única para cada pessoa - é um meio rápido, eficiente e econômico que nos permite comunicar e transmitir idéias, expressar emoções, exercer uma profissão, e manter-nos inseridos num contexto social. Conseqüentemente, distúrbios de voz podem produzir um impacto na qualidade de vida de uma pessoa, limitando a comunicação no trabalho, assim como em outros aspectos da vida social. Por tanto, a manifestação de uma alteração vocal deve ser rapidamente diagnosticada e tratada. O diagnóstico de uma alteração vocal é um processo extenso que precisa combinar diversas técnicas de avaliação e análise para contemplar a complexidade da dinâmica vocal (BEHLAU, 2008).

Com o intuito de aperfeiçoar o processo de avaliação na clínica vocal, nas últimas décadas diversas áreas da ciência, principalmente a medicina e a engenharia, desenvolveram pesquisas referentes à fisiologia normal da voz humana e suas alterações patológicas. Destes estudos sugiram diversas medidas, técnicas e ferramentas de análise como videolaringoscopia, glotografia, análise acústica e análise perceptivo-auditiva. Todos estes recursos desenvolvidos ao longo dos anos têm como objetivo proporcionar informações e dados úteis tanto para clínica como para a pesquisa na área da voz, mas em contrapartida apresentam uma série de desvantagens. 
As técnicas de avaliação laríngea (videolaringoscopia, laringoscopia, videofluoroscopia, etc.), usadas fundamentalmente para avaliação e diagnóstico laríngeo proporcionam um acesso direto para observar as estruturas e as características vibratórias das pregas vocais, mas em contrapartida são consideradas de alto custo e de caráter invasivo. A glotografia, embora não invasiva, é uma técnica pouco usada na clínica e apresenta uma baixa resolução, além de inserir um filtro passa baixas (eletrodos localizados no pescoço) antes da captação do sinal.

As técnicas de análise acústica são amplamente utilizadas tanto na clínica como na pesquisa, e têm demonstrado serem ferramentas auxiliares úteis e não invasivas. Por outro lado as medidas acústicas fornecem valores médios para os parâmetros acústicos, que na maioria dos casos dependem da determinação da freqüência fundamental. No estudo de ESPANHOL (2004) foi demonstrado que os "determinadores" disponíveis não apresentam a robustez necessária. E segundo UMAPATHY ET AL (2005) embora seja uma das ferramentas de análise da voz mais utilizada, ainda não existe consenso a respeito da utilidade e confiabilidade destas medidas na discriminação de vozes normais e patológicas. Grandes diferenças são encontradas nos valores dos parâmetros nos diferentes softwares comercializados, devido à implementação de algoritmos diferentes para cálculo desses valores (SMITS; CEUPPENS; DE BODT, 2005)0, ou a presença de ruído (CARSON; INGRISANO; EGGLESTON, 2003). 
Por último, a análise perceptivo-auditiva pode ser considerada o método de avaliação da voz mais utilizado na clínica fonoaudiológica diária (OATES, 2009), mas por ser um método subjetivo depende de fatores tais como: treinamento do avaliador (EADIE; BAYLOR, 2006) e (CHAN; YIU, 2005); das diferenças individuais do ouvinte e do consenso a respeito da terminologia para definir os parâmetros a serem avaliados (SHRIVASTAV, 2005), e em alguns casos, os parâmetros auditivos podem ser difíceis de correlacionar com os parâmetros acústicos. (BHUTA; PATRICK; GARNETT, 2004) (MARYN ET AL, 2009).

Nas últimas décadas a dinâmica não linear tem introduzido uma nova perspectiva para a análise de sistemas que evoluem no tempo e são sensíveis as condições inicias, e embora determinísticos apresentam comportamentos aperiódicos. Esta nova abordagem tem contribuído em diversas áreas da ciência, desde a física e a engenharia, até a biologia e a medicina. A partir dos primeiros estudos nos anos 90 (TEAGER,H; TEAGER, S, 1990); (BAKEN, 1990) (TITZE, BAKEN, HERZEL, 1993), (HERZEL, BERRY, TITZE, SALEH, 1994), diversas ferramentas baseadas em dinâmica não linear vem sendo aplicadas na análise de sinais voz. Desde esta perspectiva um sinal de voz pode ser considerado uma série temporal representada por uma trajetória no espaço de fase reconstruído aplicando a técnica de tempo de atraso PACKARD ET AL (1980) e TAKENS (1981). Por tanto, um ciclo vibratório das pregas vocais em função do tempo, será representado como uma trajetória no espaço de fase, evidenciando o comportamento dinâmico do sistema de produção vocal. Se o sinal for periódico, a trajetória será fechada e regular; 
mas no caso de sinais aperiódicos a trajetória será aberta e irregular. Considerando que a produção vocal é um sistema que evolui no tempo, tende ao equilíbrio e apresenta ciclos de repetição, porem pode apresentar simultaneamente mudanças e comportamentos irregulares, parece apropriado escolher ferramentas baseadas em dinâmica não linear para análise de sinais de voz.

A necessidade na clínica e na pesquisa, de uma técnica de análise que permita a visualização da dinâmica do sistema vocal com uma melhor resolução de dados, que não dependa da determinação da freqüência fundamental, e que seja de baixo custo e de caráter não invasivo, foram as principais motivações para desenvolver uma ferramenta de fácil implementação para o especialista em voz. A ferramenta proposta permite estabelecer padrões visuais dinâmicos capazes de refletir a dinâmica da produção vocal de forma rápida, econômica, precisa, não invasiva, fornecendo dados complementares que aumentam a eficiência na avaliação e diagnóstico. Também permite o acompanhamento temporal das condições do paciente, avaliando sua melhora ou não no decorrer de uma terapia vocal. Portanto, o objetivo deste trabalho foi avaliar vozes saudáveis e com alterações patológicas aplicando análise de Padrões Visuais de Dinâmica Vocal (PVDV) em conjunto com análise acústica e análise perceptivo-auditiva e estabelecer correlações entre as técnicas. 


\section{REVISÃO BIBLIOGRAFICA}

Este capítulo apresenta alguns dos principais conceitos referentes à produção de voz sem alterações e com alterações patológicas na seção 2.1. $\mathrm{Na}$ seção 2.2 apresentam-se os métodos empregados na clínica fonoaudiológica para avaliação dos sinais de voz, e na subseção 2.2 .3 são introduzidos alguns conceitos sobre técnicas de avaliação dinâmica da voz.

\section{$2.1 \quad$ Voz humana:}

A voz humana, considerada principal ferramenta de comunicação, é uma emissão acústica voluntária, de alta complexidade e com inúmeros fatores envolvidos na sua produção. Para produzir um sinal de voz, é necessária a sincronia de diferentes sistemas e órgãos, cada um deles com diferentes funções primárias. Em outras palavras, do ponto de vista anatômico não existe um sistema de produção de voz, senão, vários sistemas de órgãos trabalhando coordenadamente para realizar uma função secundária, desenvolvida ao longo da evolução humana. Estes sistemas envolvidos na produção de voz são:

- $\quad$ Respiratório $\rightarrow$ Fonte de Energia (pulmões)

- $\quad$ Fonatório $\rightarrow$ Fonte Vibratória (pregas vocais)

- $\quad$ Ressonância $\rightarrow$ Fonte de Ressonância (cavidade oral e nasal) 
- $\quad$ Articulatório $\rightarrow$ Articuladores (língua, lábios, mandíbula, palato, dentes)

- Sistema Nervoso Central e Periférico $\rightarrow$ Coordenação. (Córtex, estruturas sub-corticais e nervos).

A partir do ponto de vista anatômico-fisiológico é possível considerar um modelo mecânico-matemático para podermos representar o sistema de produção de voz. Segundo o modelo linear de fonte-filtro de FANT (1970) as pregas vocais são consideradas a fonte sonora e o trato vocal atua como um filtro acústico. Este modelo aperfeiçoado por FLANAGAN (1972) continua sendo muito empregado na área de processamento de sinais. A figura 2.1 ilustra um modelo fisiológico dos sistemas envolvidos na produção de voz, assim também como a correlação com o modelo linear de fonte-filtro proposto por FANT (1970).

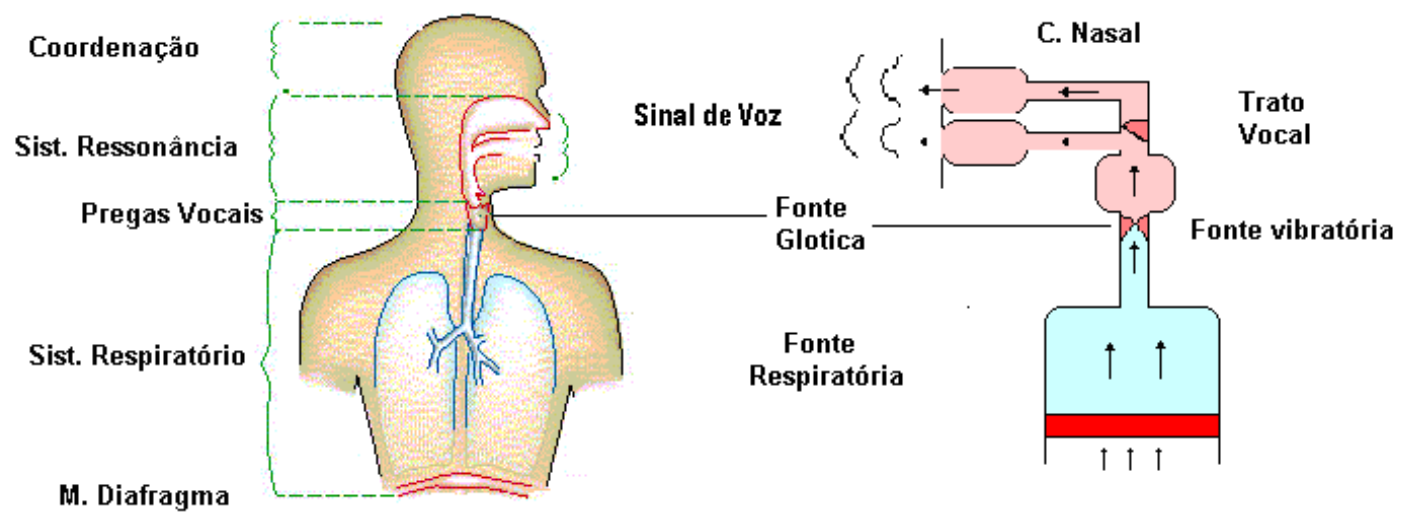

Figura 2.1: Desenho esquemático dos sistemas e órgãos envolvidos na produção dos sinais de voz e do modelo linear de fonte-filtro proposto por FANT (1970).

O sinal resultante desta complexa interação será o sinal acústico de voz humana. (RABINER; JUANG; 1993). As pregas vocais encontram-se na laringe, a vibração destas estruturas é considerada a fonte sonora ou pulso 
glotal, responsável pela freqüência fundamental de uma voz. A laringe é um órgão do sistema respiratório, se encontra na parte anterior do pescoço, tem formato de tubo alongado, e comunica a faringe e a traquéia. A figura 2.2 ilustra a localização anatômica da laringe humana.

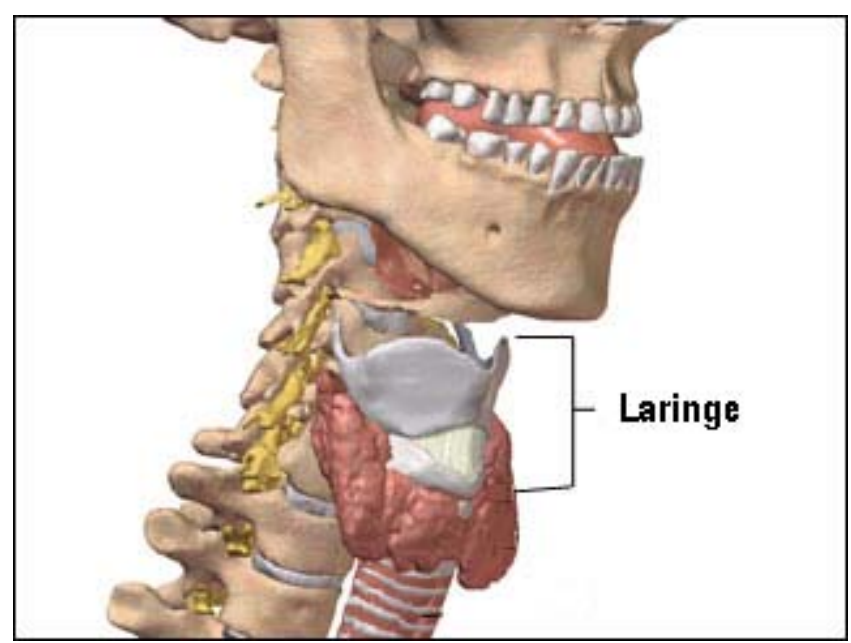

Figura 2.2: Esquema da localização da laringe no trato respiratório. Figura modificada de: http:/medimages.healthopedia.com/ large/larynx.jpg

A laringe está constituída por cartilagens, músculos, membranas e mucosa. As cartilagens laríngeas são nove no total e podem ser classificadas em pares e impares. As três cartilagens impares são: a tireóidea, a cricóidea e a epiglote; e as cartilagens pares são: as aritenóideas, consideradas principais, as corniculadas e as cuneiformes, estas últimas, consideradas acessórias ou secundárias. Estas cartilagens estão sustentadas principalmente pelo osso hióde, que tem a particularidade de ser o único que não se articula com outros ossos, e serve de ponto de inserção para os músculos e ligamentos da laringe, língua e outros órgãos. A figura 2.3, modificada de Netter (1997), apresenta de forma esquemática uma visão anterior e posterior de algumas das principais estruturas da laringe. 

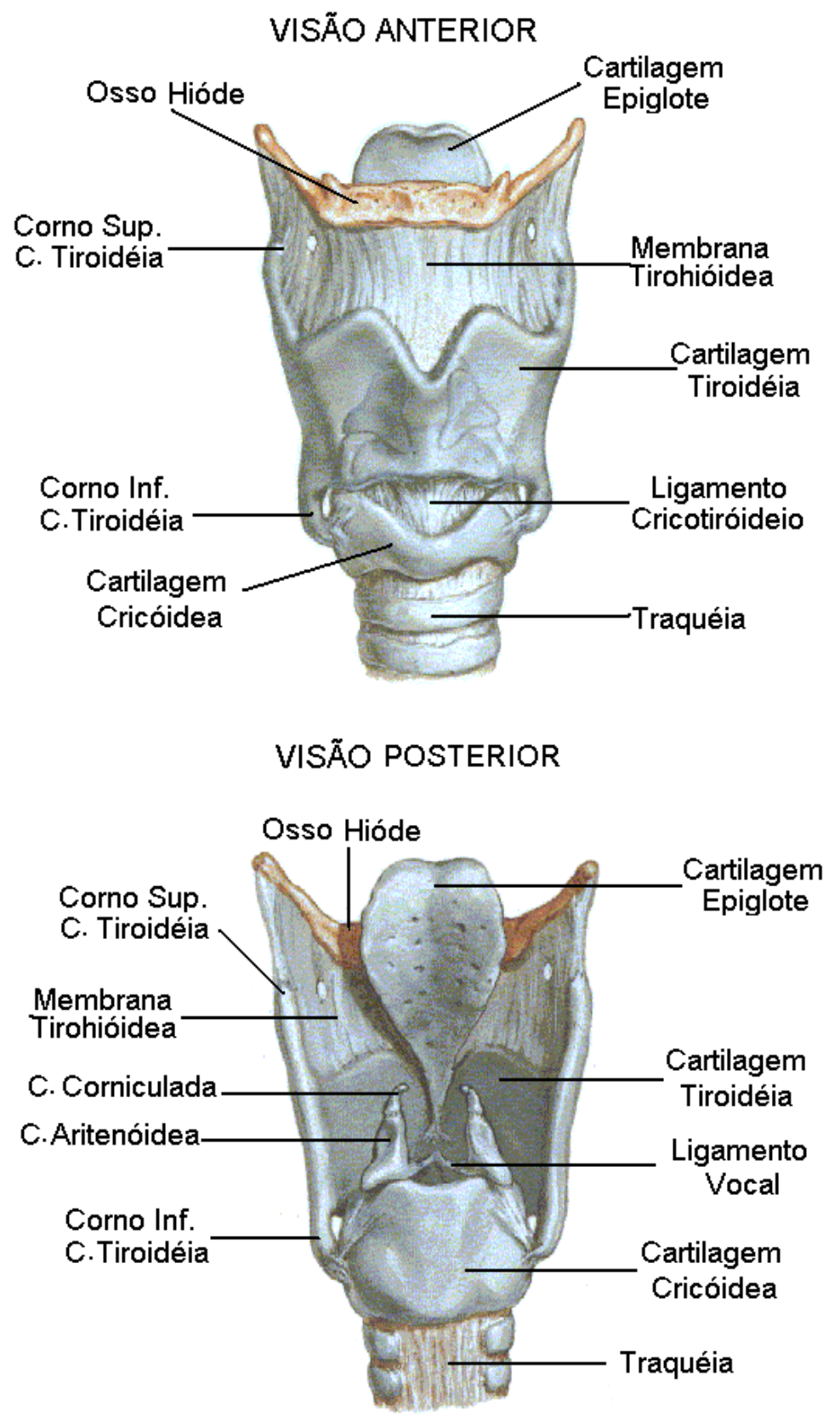

Figura 2.3: Visão anterior e posterior das principais estruturas laríngeas (cartilagens, ligamentos, membranas laríngeas, osso Hióde e traquéia. Figura modificada de Netter (1997). 
Os músculos da laringe podem ser classificados segundo o tipo de inserção. Aqueles que têm origem e inserção na laringe são denominados músculos intrínsecos; e os músculos com inserção na laringe e em estruturas externas, são denominados extrínsecos. (TUCKER, 1993). Os músculos intrínsecos estão relacionados diretamente à produção de voz e têm maior proporção de fibras musculares tipo IIA que outros músculos do corpo, estas fibras são de contração rápida e altamente resistentes à fadiga (HENICK, SATALOFF, 1997). A musculatura intrínseca participa ativamente nas funções de respiração, esfíncter e fonação; também é responsável pela adução, a abdução e a tensão das pregas vocais.

Existem seis pares de músculos intrínsecos: o Tiroaritenóideo (TA), o Cricoaritenóideo Posterior (CAP), o Cricoaritenóideo Lateral (CAL), o Cricotiróideo (CT), o Ariepiglótico (AE) e o Tireoepiglótico (TE). O único músculo impar é o aritenóideo (A) ou interaritenoideo. As figuras 2.4 e 2.5 ilustram de forma esquemática a musculatura intrínseca antes mencionada. (HIRANO,1981). 


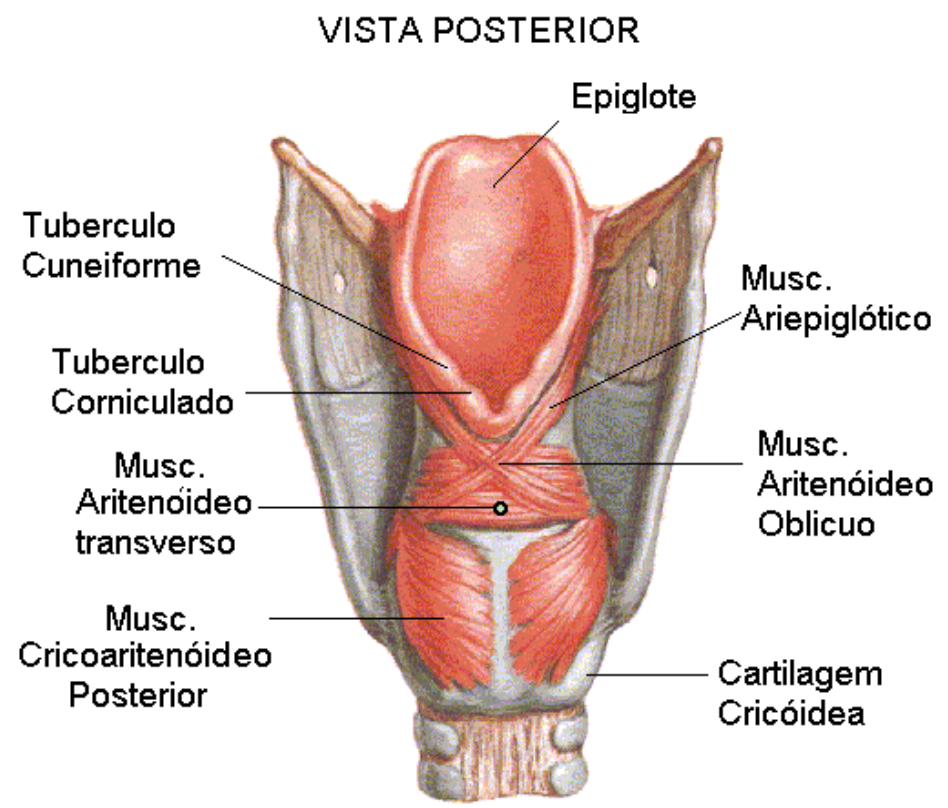

(a)

\section{VISTA LATERAL}

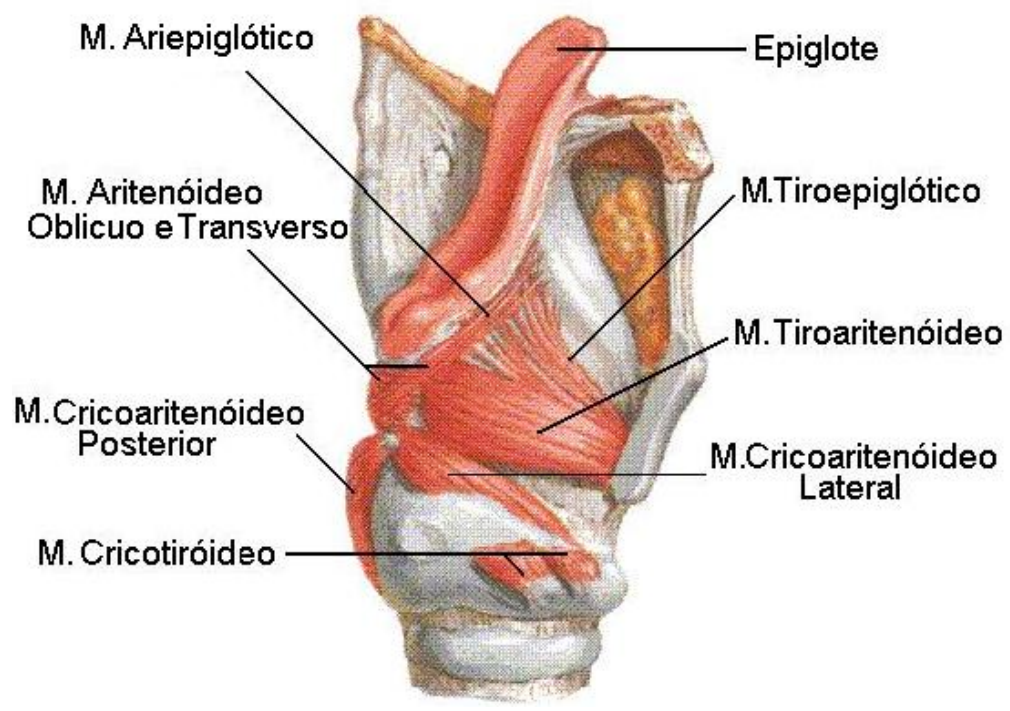

(b)

Figura 2.4: Desenho esquemático da visão posterior (a) e da visão lateral (b) dos músculos intrínsecos da laringe. Figura modificada de Netter (1997) 


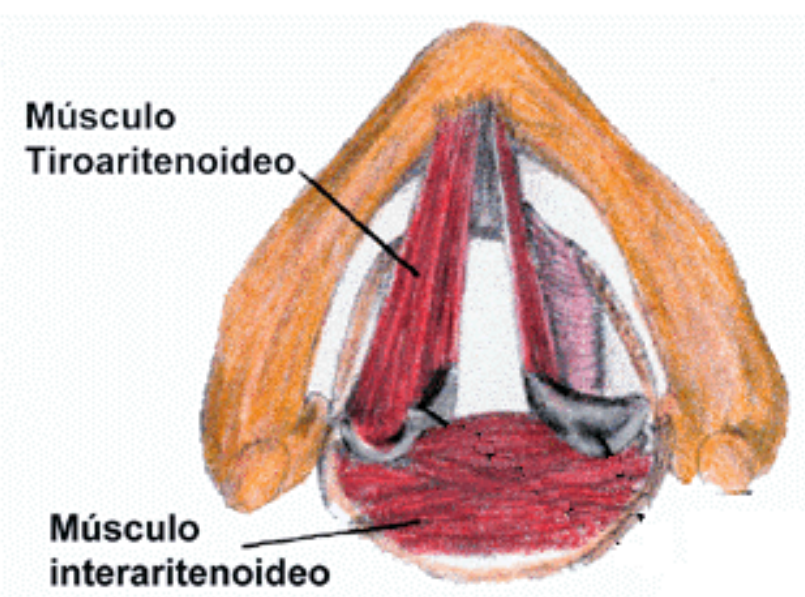

Figura 2.5: Desenho esquemático de um corte transversal da laringe. Músculos Tiroaritenóideo (TA) e interaritenóideo (IA)

Figura modificada de: escuela.med.puc.cll...I AnatLaringea09.gif

Os músculos extrínsecos têm como função principal manter e proporcionar estabilidade à laringe nas estruturas do pescoço. Participam de forma indireta na fonação, mas são considerados importantes por serem os responsáveis do mecanismo secundário de controle de freqüência (LE HUCH; ALLALI, 1993). Estes grupos musculares podem ser classificados segundo sua localização em relação ao osso hióide em músculos supra-hióideos, que elevam a laringe no pescoço; e em músculos infra-hióideos, que abaixam a laringe.

As cartilagens e músculos laríngeos encontram-se interconectados por ligamentos e membranas intrínsecos e extrínsecos, estes tecidos têm como função básica a interligação das estruturas laríngeas. No interior da laringe encontram-se as pregas vestibulares e as pregas vocais. As pregas vestibulares, erroneamente chamadas de falsas pregas vocais, são duas dobras de tecido espesso e mole com glândulas internas que se localizam por cima das pregas vocais (HIRANO, 1996). 
Em seus detalhados trabalhos histológicos, Hirano demonstrou que a estrutura das pregas vocais é organizada em camadas, e que cada camada tem propriedades mecânicas diferentes. A análise da organização estrutural das pregas vocais mostra que há uma variação gradativa na rigidez de cada camada, sendo mais maleáveis na superfície e tornando-se cada vez mais rígidas em direção ao músculo vocal (TSUJI, INAMURA; UBIRAJARA, 2006).

Baseado nessa estrutura em camadas surgiu o modelo de "corpo e cobertura" (do termo em inglês cover-body) proposto por Hirano no começo dos anos 70. Neste modelo as pregas vocais são duas estruturas multilaminadas, formadas basicamente por músculo e mucosa, constituídas por camadas que se encontram localizadas em posição horizontal dentro da laringe e em sentido ântero-posterior. Segundo Hirano a prega vocal esta dividida em: mucosa, por sua vez, subdividida em duas camadas, o epitélio e lâmina própria; e o músculo constituído pelo músculo vocal (HIRANO; KAKITA,1985).

O epitélio da mucosa das pregas vocais está formado por tecido escamoso e estratificado e sua função é cobrir e manter a forma da prega vocal. A lâmina própria subdivide-se em três camadas: superficial, intermediária e profunda, onde cada uma delas apresenta características diferentes. $\mathrm{Na}$ figura 2.6 pode-se observar um esquema das diferentes camadas histológicas das pregas vocais segundo o modelo proposto por (HIRANO, KAKITA, 1985). 


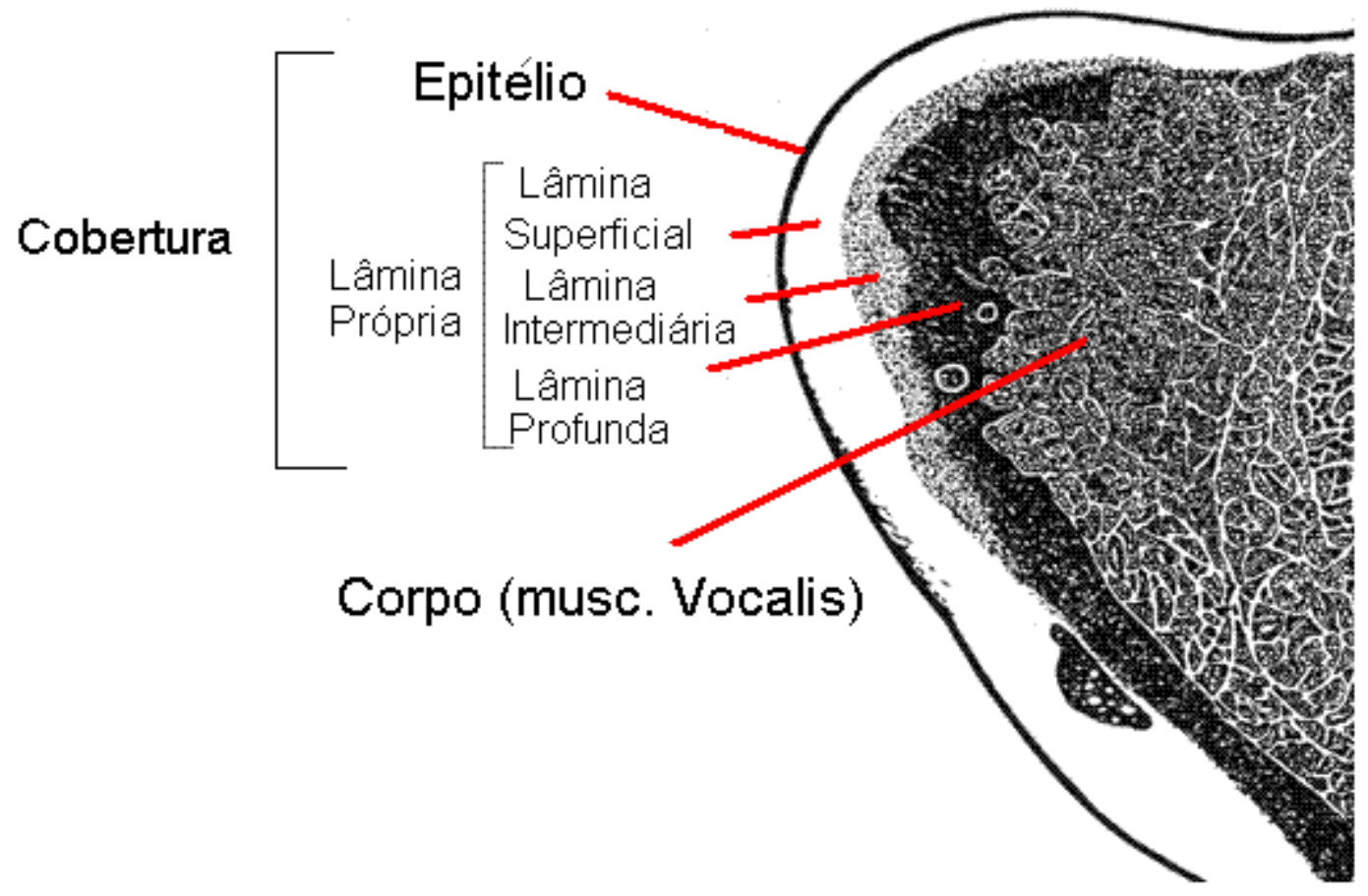

Figura 2.6: Esquema de um corte longitudinal de uma prega vocal. Apresenta as diferentes camadas histológicas; cobertura (epitélio, camadas da lâmina própria) e corpo (músculo vocalis) segundo o modelo de "corpo e cobertura" de Hirano. Figura modificada de: www.british-voice-association.com

A camada superficial da lâmina própria (CSLP), também chamada de espaço de Reinke, se apresenta como um tecido gelatinoso, solto e flexível; esta característica permite um descolamento acentuado, sendo a camada que vibra mais intensamente durante a fonação. A camada intermediaria da lâmina própria (CILP) está composta por um grande número de fibras elásticas e caracteriza-se por ser uma camada com maior densidade. A camada profunda da lâmina própria (CPLP) é constituída por maior quantidade de fibras colágenas que proporcionam maior rigidez. Não existe um limite bem definido entre as camadas intermediaria (CILP) e profunda (CPLP), mas pode-se observar a diminuição de fibras elásticas e o aumento de fibras colágenas à medida que os tecidos se aproximam do corpo da prega vocal (HIRANO; KAKITA, 1985), (HIRANO, 1996). 
O corpo da prega vocal está constituído pelo músculo vocal ou músculo tiroaritenóideo, e funciona como um feixe elástico rígido no momento da contração muscular. É composto por fibras elásticas, fibras colágenas e fibras musculares distribuídas longitudinal e paralelamente à borda livre da prega vocal. O limite entre a camada profunda da lâmina própria (CPLP) e o músculo vocal é difuso, sendo que algumas fibras da camada profunda inserem-se no músculo (GRAY, HIRANO, SATO, 1993), como se pode observar na figura 2.6.

De acordo com o modelo de corpo e cobertura as cinco camadas descritas podem ser agrupadas segundo sua estrutura e propriedades mecânicas em três seções: cobertura (epitélio e CSLP), transição (CILP) e corpo (músculo vocal). Hirano observou em estudos com luz estroboscópica, que durante a fonação na cobertura da prega vocal ocorre um deslocamento intenso e fluido em direção contraria a gravidade, enquanto o corpo oferece estabilidade e tono muscular de base. Por sua vez, a camada de transição tem a função de acoplamento entre a camada superficial da lâmina própria e o músculo vocal (HIRANO; 1996).

Portanto, segundo este modelo, a passagem do fluxo aéreo procedente dos pulmões e a diferença de pressões da cavidade (efeito Bernoulli) associadas às propriedades mioelásticas e mecânicas das pregas vocais produzem a vibração da cobertura, gerando o som vocal ou pulso glótico. A figura 2.7 mostra de forma esquemática a geração do pulso glótico pela vibração das pregas vocais. 


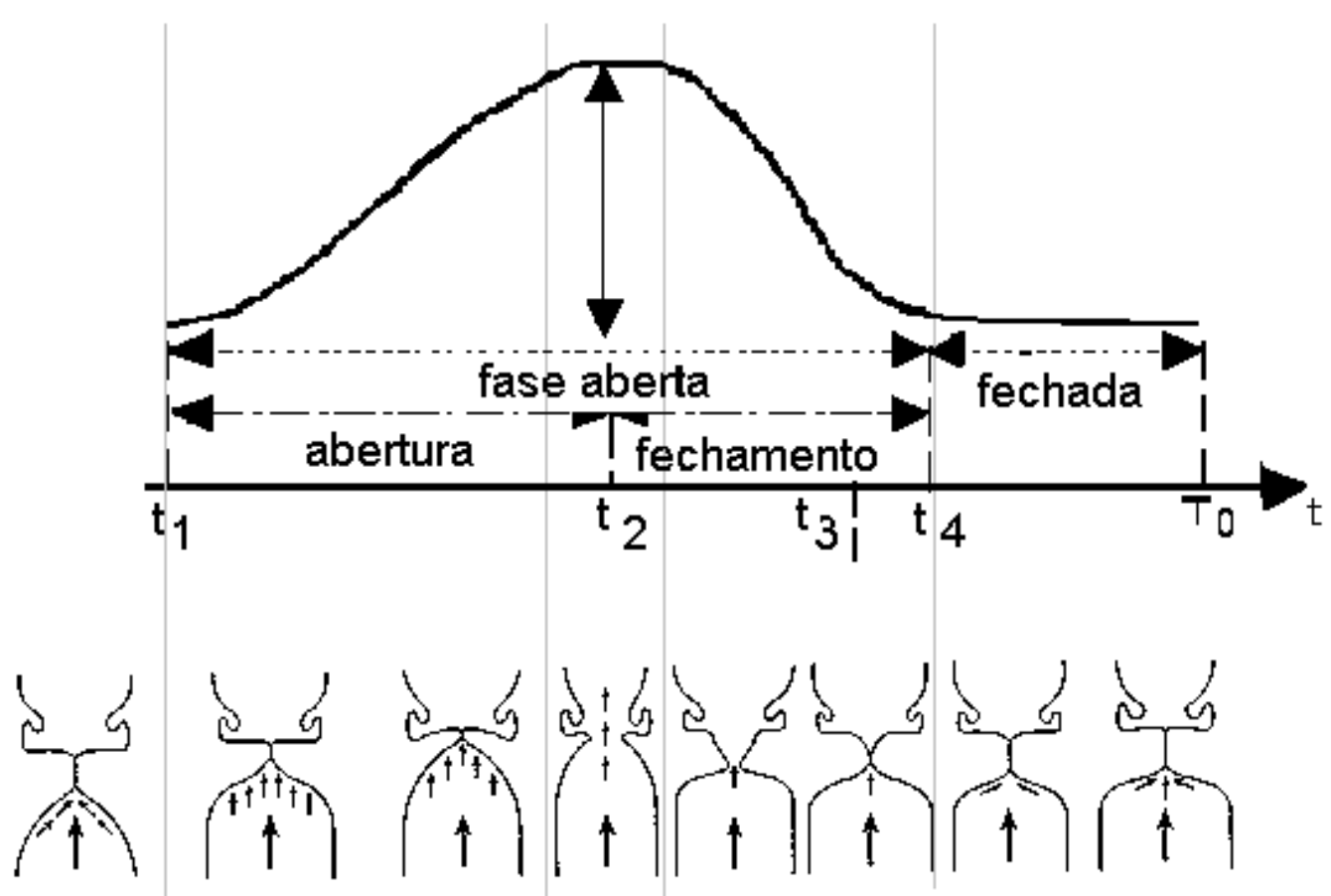

Figura 2.7: Desenho esquemático do mecanismo das pregas vocais na produção do pulso glótico. Onde To= período completo; $\mathrm{t} 1=$ começo de fase de abertura; $\mathrm{t} 2=$ abertura máxima; $\mathrm{t} 3=$ inicio de fase fechada e t4= fechamento completo.

Pelas características particulares da fonte produtora do som, observarse certa variabilidade de ciclo a ciclo vibratório. Em outras palavras, os ciclos vibratórios podem ser considerados similares, mas não idênticos; o que faz com que o sinal de voz humano seja considerado um sinal acústico quaseperiódico (TOSI, 1979). Essas variações próprias do som fundamental podem ocorrer como perturbações na freqüência, denominada jitter, ou perturbações na amplitude, shimmer (BAKEN, ORLIKOFF, 2000).

O som fundamental gerado pelos ciclos vibratórios da mucosa das pregas vocais tem uma intensidade muito baixa e freqüência fundamental com seus harmônicos sem amplificação. Na figura 2.8A visualiza-se uma ilustração 
do espectro do pulso glótico com uma intensidade que decresce $12 \mathrm{~dB}$ por oitava.
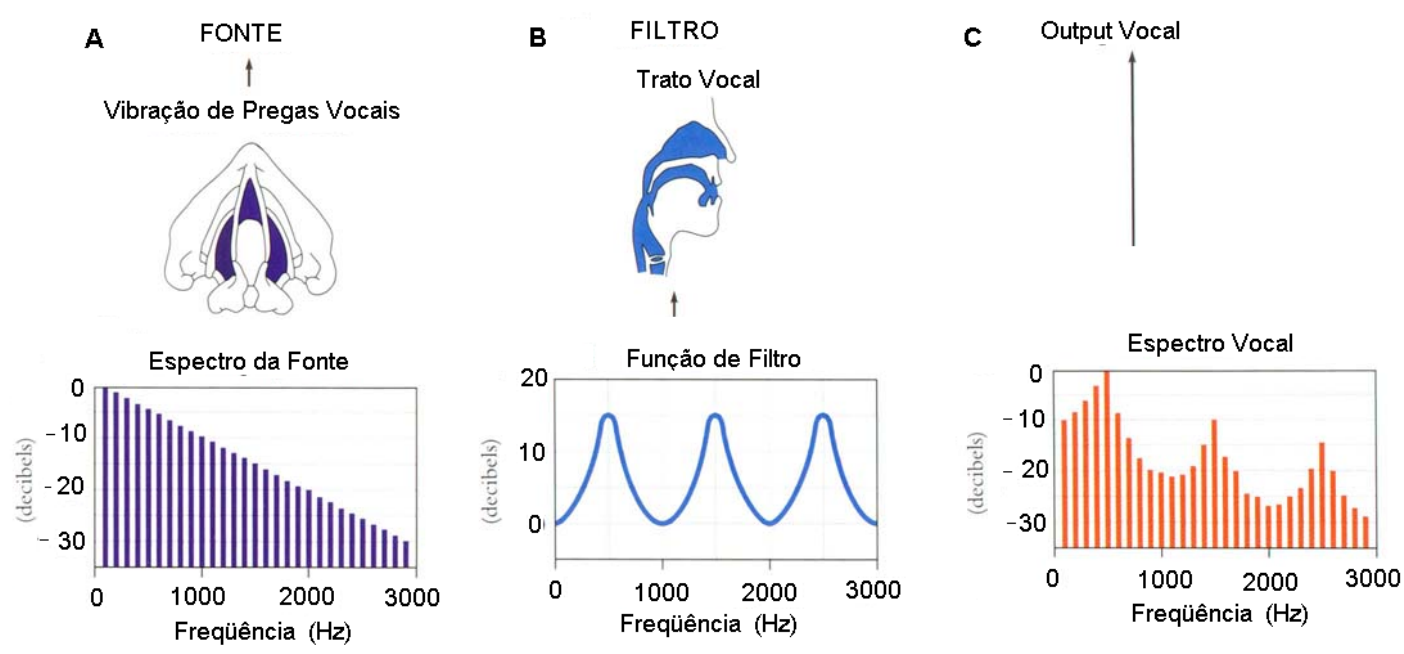

Figura 2.8: (A) Desenho esquemático do espectro de freqüências do som fundamental sem amplificação. (B) Curvas de ressonância do trato vocal. (C) Espectro resultante da freqüência fundamental mais as ressonâncias do trato vocal.

Figura modificada de: www.spectrum.uni-bielefeld.de/ thies/HTHS WiS...

No entanto, a voz humana como resultado final é muito mais complexo que esse pulso glótico gerado nas pregas vocais. O pulso glótico é modificado e amplificado ao longo do trato vocal. O trato vocal atua como um verdadeiro filtro (equalizador), realçando ou atenuando as componentes de freqüências contidas no pulso glótico. Em outras palavras, o som básico da vibração da mucosa das pregas vocais será modificado pelo fenômeno de ressonância provocado pelo trato vocal, que consiste na amplificação de certas faixas de freqüência, e no amortecimento de outras dependendo das características de cada ressonador ou freqüências naturais de ressonância (TITZE, 2000). A figura 2.8B ilustra de forma esquemática as curvas de ressonância do trato vocal. 
Devido às características do sistema de ressonância do trato vocal existem inúmeras possibilidades na estrutura tridimensional, revestimento das paredes que geram diversas curvas de resposta traduzida como infinitas qualidades vocais, ou seja, cada voz é única e individual. O trato vocal também é responsável pela articulação dos sons da fala; palato, língua, dentes e lábios modificam o som laríngeo formando as vogais e as consoantes, elementos básicos da fala. A figura $2.8 \mathrm{C}$ apresenta um esquema do espectro de freqüências do pulso vocal modificado pelas cavidades de ressonância do trato vocal.

Resumindo, os espectros de som e as curvas de ressonância de uma voz dependem de fatores evolutivos, características anatômicas e funcionais das estruturas fonatórias, assim como da conjunção das dinâmicas dos diferentes sistemas envolvidos no processo de produção de voz. Cabe mencionar que determinadas opções de amplificação e ressonância dependem das escolhas de base psico-emocional do falante, que se evidenciam no padrão articulatório e de ressonância (ROSEN; SATALOFF, 1997). Deve-se lembrar que a qualidade de uma voz não depende simplesmente do desempenho e coordenação de diferentes subsistemas, depende também da atividade de todos os músculos envolvidos na produção da voz, e da integridade de todos os tecidos do aparelho fonador e do sistema nervoso central e periférico (BEHLAU, 2001). 


\subsubsection{Voz fenômeno multidimensional e evolutivo.}

A laringe é um órgão extremamente complexo, responsável por diversas e importantes atividades fisiológicas. (TSUJI; INAMURA; UBIRAJARA, 2006). Esta sofre transformações fisiológicas ao longo da vida que são facilmente perceptíveis na voz. As mudanças da voz acompanham e representam o desenvolvimento do indivíduo, tanto do ponto de vista físico como psicológico e social. (BEHLAU, 2001).

A voz manifesta-se desde o primeiro momento de vida, com o primeiro choro; e após o nascimento com o crescimento do trato vocal, onde ocorre uma série de mudanças nas configurações geométricas do tubo. Portanto, a voz humana pode ser estudada em diversas etapas da vida: infância, puberdade, fase adulta e senescência. Essa diferenciação se deve as modificações das estruturas que produzem a voz que ocorrem ao longo do tempo.

Levando em consideração que estas mudanças fazem parte de um processo fisiológico evolutivo, associado a características sócio-culturais e psicológicas, falar de voz normal e disfônica parece um tanto simplista. BEHLAU, (2001) afirmou que o conceito de voz normal é altamente negociável, e depende de diversos fatores intrínsecos e extrínsecos; e propõe uma série de conceitos entre normal e disfônico, como os de voz saudável e voz preferida.

Chama-se de voz saudável quando a voz não apresenta alterações e está adaptada às situações nas quais a qualidade é aceitável socialmente, não interfere na inteligibilidade da fala, permite o desenvolvimento profissional, 
apresenta freqüência, intensidade, modulação e projeção apropriadas para o gênero e idade do falante e transmite a mensagem emocional do discurso. No caso da voz profissional, BELHAU (2001) propõe o termo de voz preferida, que considera fatores culturais, modismos e estilos das diferentes profissões que usam a voz como ferramenta de trabalho. Este tipo de enfoque favorece a compreensão da voz como fenômeno dinâmico e de múltiplas dimensões, considerando os diversos aspectos relacionados à produção e à função da voz.

\subsubsection{Voz relacionada com transtornos posturais}

Existe um consenso geral da estreita relação entre postura corporal e voz. Vários autores afirmam que um bom alinhamento postural é um importante elemento na otimização da função vocal (SCHNEIDER, DENNEHY; SAXON; 1997), (RUBIN; MATHIESON; BLAKE, 2004) e (BHEMAN-ACKAH, 2005), (CARNEIRO ET.AL, 2008). Segundo BEHMAN (2005) a maioria dos fonoaudiólogos, que trabalham com pacientes com alterações vocais consideram a importância de uma boa postura corporal para obtenção de uma melhor produção de voz.

Nos últimos anos tem-se incrementado o interesse dos profissionais da voz a fim de compreender os mecanismos fisiológicos subjacentes às recomendações posturais feitas para os pacientes e estudantes de voz. De acordo com SCHNEIDER, DENNEHY; SAXON (1997) a postura incorreta da cabeça e o pescoço levam a mudanças adaptativas dos músculos desequilíbrio muscular - que eleva a laringe e comprometem o controle da 
freqüência e da ressonância da voz. Outros estudos associaram a modificação da postura corporal com mudanças no formato dos tecidos moles da faringe e a conseqüente alteração da ressonância vocal. Assim, como o desequilíbrio na musculatura é um fator de risco na prática de esportes, no caso da voz, o desequilíbrio muscular oriundo de uma postura corporal inadequada, representa também um alto risco para desenvolver uma patologia vocal principalmente para pessoas com uso profissional ou ocupacional da voz.

Estes dados mencionados na literatura nos fazem refletir sobre a complexidade do fenômeno da produção de voz e considerar que mesmo em vozes sem alterações patológicas, os fatores intrínsecos como a postura, os movimentos corporais e o desequilíbrio da musculatura influenciam diretamente o output vocal.

\subsubsection{Alterações vocais ou voz disfônica.}

Se partirmos do conceito de que a voz saudável requer um consenso entre o falante e o ouvinte, podemos definir uma alteração vocal quando um ou mais parâmetros vocais são percebidos como alterados por falante e/ou ouvinte, produzindo um sinal de voz não adaptado. Quando se fala de uma alteração da voz, independente de sua etiologia, geralmente refere-se a uma disfonia. BEHLAU (2001) define disfonia como um distúrbio da comunicação oral, no qual a voz não consegue cumprir seu papel básico de transmissão da mensagem verbal e emocional do falante. A autora afirma que esta disfonia pode manifestar-se de diversas formas, como desvio da qualidade vocal, 
emissão com esforço, fadiga, perda de controle da freqüência fundamental, sensações desagradáveis na emissão, entre outras.

Considerando a voz como fenômeno multidimensional e a grande variedade de alterações de voz, observamos que também existem vários critérios para a classificação das disfonias. PONTES, BEHLAU, BRASIL, (2000) classificaram as disfonias segundo o envolvimento do comportamento vocal no surgimento da alteração vocal; eles classificam as disfonias em três grupos: funcionais; organofuncionais e orgânicas.

Seguindo este critério, as disfonias funcionais podem subdividir-se em primárias por uso incorreto da voz; secundárias por inadaptações vocais e funcionais por alterações psicogênicas. São exemplos deste tipo de disfonias: compressão glótica excessiva ou insuficiente, alterações miodinâmicas laríngeas e disfonia de conversão, respectivamente. As disfonias organofuncionais englobam aquelas disfonias com lesões secundárias, com base funcional, como nódulos e edema de Reinke, para mencionar alguns. A terceira categoria de disfonias orgânicas pode ter diferentes causas, e não estão relacionadas com o uso da voz; e podem ser subdivididas em orgânicas por alterações nos órgãos da comunicação e orgânicas por doenças com origem em outros órgãos ou aparelhos. Diafragma laríngeo, neoplasias, disfonias por desordens neurológicas, como Parkinson e esclerose lateral amiotrófica (ELA) são exemplos de disfonias orgânicas (BEHLAU, 2001). 
É importante destacar que esta classificação, assim como outras, tem como objetivo facilitar o raciocínio clínico e terapêutico organizando um vasto conjunto de dados em categorias; mas nem sempre é possível encontrar categorias fechadas devido à complexidade fisiopatológica da voz. (BEHLAU, 2001).

\section{$2.2 \quad$ Avaliação dos sinais de voz}

Do mesmo modo que consideramos a produção de voz como um fenômeno complexo e multidimensional, a instância de avaliação de voz resulta igualmente complexa, e precisa considerar diferentes dimensões de análise para abarcar os diversos aspectos do sinal de voz. Portanto, a avaliação de voz é um processo clínico, geralmente multidisciplinar, com uma série de instâncias e procedimentos que devem ser considerados. Este processo serve para compreender o mecanismo normal e fisiopatológico da produção de voz, a significância de um transtorno vocal e planejar as medidas terapêuticas necessárias para restabelecer a organização funcional do sistema de produção de voz.

Segundo BEHLAU, (2008) a avaliação dos sinais de voz pode-se dividir em 5 dimensões: 1) análise perceptivo-auditiva (escalas analógicas e numéricas), 2) auto-avaliação da voz e seu impacto (medir o grau do desvio e como interfere), 3) dados aerodinâmicos e acústicos (medidas fonatórias e medidas acústicas; 4) perfil de extensão vocal e 5) análise visual da laringe. 
Neste trabalho, serão abordados alguns conceitos chaves referentes à primeira dimensão, de análise perceptivo-auditiva com escala numérica; e a terceira dimensão, com dados de análise acústica. Ambas as ferramentas serão empregas no presente trabalho e são consideradas essenciais, embora controversas, na clínica e na pesquisa para análise da qualidade vocal (OATES, 2009), (MARYN, 2009). Ambos os tópicos serão abordados nas subseções seguintes.

\subsubsection{Avaliação perceptivo-auditiva}

A avaliação perceptivo-auditiva é uma das ferramentas mais usadas na clínica vocal, e geralmente é considerada padrão ouro (OATES, 2009), principalmente por a voz ser um fenômeno perceptivo em resposta á um estímulo acústico (EADIE, TAYLOR, 2006). Este tipo de avaliação tem como objetivo definir as características vocais. De modo geral, os métodos de avaliação perceptivo-auditiva são ferramentas importantes na clínica fonoaudiológica, pois permitem avaliar qualitativamente possíveis transtornos ou desvios vocais, e ainda podem se empregados para validar outras ferramentas de avaliação de voz, consideradas mais objetivas (MARTIN; FITCH; WOLFE, 1995) e (SÖDERSTEN ET AL., 1991).

Este tipo de análise faz parte da prática profissional dos fonoaudiólogos e é objeto de estudo e aprimoramento, e por sua característica de subjetividade ou grau de confiabilidade tem sido questionado por diversos pesquisadores (EADIE, BAYLOR, 2006), (GERRATT, KREIMAN, 2001), (CARDING; 
CARLSON; EPSTEIN; MATHIESON; SHEWELL, 2000), (OATES, 2009), mas continua sendo a ferramenta âncora na avaliação fonoaudiológica de voz.

Existem diversos protocolos e escalas normalizadas reconhecidas internacionalmente como o "Modelo Fonético de Descrição da Qualidade Vocal - Fonte e Filtro" (LAVER, 1980), para avaliação global da voz, e a escala "GRBAS", criada pelo Comitê para Testes de Função Fonatória da Sociedade Japonesa de Logopedia e Foniatria (SJLF) em 1969. Escalas foram adaptadas para uma determinada comunidade como a Escala de Avaliação Perceptivoauditiva da Fonte Glótica: RASAT (PINHO; PONTES, 2002). Assim também existem simultaneamente escalas informais com nomenclatura e graus diferentes, customizadas por cada fonoaudiólogo. Isto aporta inúmeros termos e gradientes para descrever e valorar a qualidade vocal de um sinal de voz.

A qualidade vocal é uma interação entre um sinal acústico de voz e um ouvinte; o sinal de voz não possui em si mesmo uma qualidade, mas evoca no ouvinte uma determinada qualidade (KREIMAN; GERRATT, 1998). Portanto, pode-se considerar que a qualidade vocal é o produto da percepção do ouvinte e depende mais do sistema de referência interno do ouvinte - envolve diversos fatores e varia de sujeito a sujeito - que do próprio sinal de voz. Por exemplo, o adequado estado das pregas vocais, sua densidade muscular, o estado da mucosa que as reveste permitem que ambas sejam aduzidas otimamente, e possibilita a criação de uma condição ideal de pressão e velocidade volumétrica do fluxo de ar, gerando assim o sinal quase-periódico que evocará no ouvinte a sensação de qualidade vocal normal ou sem alteração. 
Os termos utilizados na maioria de escalas de avaliação perceptivoauditiva para descrever desvios na qualidade vocal, são: rouquidão, aspereza e soprosidade. Diversos autores definiram os termos usados com maior freqüência, a fim de chegar num consenso e simplificar a troca de informações entre pesquisadores (OATES, 2009).

Isshiki (ISSHIKI, 1980) define a rouquidão como uma irregularidade vibratória da mucosa das pregas vocais durante a fonação, causada por uma fenda glótica maior ou igual a $0,5 \mathrm{~mm}^{2}$. Segundo (HIRANO; YOSHIDA; TANAKA; HIBI, 1990) e (HAMMARBERG, 2000) a rouquidão provoca ruídos de baixa freqüência que mascaram o traçado espectrográfico dos harmônicos inferiores. Esta característica pode ser encontrada em patologias como nódulos vocais, edemas e hiperemias que apresentam um sinal de voz irregular com ruído similar ao som de uma bandeira tremulando ao vento forte.

O termo aspereza é empregado para descrever uma característica vocal associada à rigidez de mucosa, provocada por certa irregularidade vibratória dependendo da presença ou não de fenda glótica e de associações com outras alterações laríngeas. Segundo autores como (HIRANO; YOSHIDA; TANAKA; HIBI, 1990), (HAMMARBERG; GAUFFIN. 1995), (HAMMARBERG, 2000) a característica perceptiva de aspereza apresenta ruídos de alta freqüência na análise acústica e espectral. Isto se explica funcionalmente devido ao grande vazamento de ar provocado pela vibração de uma mucosa enrijecida. Se a característica de rigidez predomina, a qualidade vocal parece uma voz seca e sem projeção. O exemplo clássico de voz áspera por rigidez de mucosa é 
encontrado nos casos de sulco vocal. Cistos, pontes mucosas e bolsas geralmente apresentam voz áspera associada à rouquidão mais intensa, devido à presença de edema que freqüentemente os acompanha.

Um funcionamento inadequado de qualquer músculo, principalmente intrínseco, acarretará uma vocalização soprosa (SHRIVASTAV, 2005). Ao ocorrer uma superadução prolongada das pregas vocais, estas ficam passíveis de originarem uma fenda na região posterior, também causando escape de ar. Qualquer interferência nas bordas de aproximação das pregas vocais resultará em disfonias e ruído turbulento, ou seja, aparecimento de soprosidade na avaliação perceptivo-auditiva (EADIE; BAYLOR, 2005). ISSHIKI, alerta para o fato que, devido à complexa estrutura de funcionamento do sistema produtor da fala, patologias com características soprosas podem ser confundidas com as percentualmente definidas como roucas.

\subsubsection{Avaliação acústica}

Os métodos não invasivos de avaliação da função fonatória, como a análise acústica, embora tenham um papel secundário no diagnóstico diferencial de distúrbios laríngeos, têm a vantagem de propiciar, as chamadas medidas objetivas, isto é, dados quantitativos extraídos automaticamente, por meio de um processamento computacional adequado, além de utilizar instrumentos relativamente simples e baratos (NUNES; COSTA, 2006). 
Pode-se considerar que a história da análise acústica da voz começou em 1920 quando surgiu o oscilograma, que foi o primeiro instrumento para representar um sinal contínuo num gráfico da amplitude em relação ao tempo. Posteriormente, entre as décadas de 40's e 50's, surgiram a análise de Fourier e a espectrografia. A partir da metade do século $X X$ surgiram várias teorias para explicar o fenômeno de produção de voz, desde a teoria mioeslásticaaerodinâmica de Van Den Berg em 1954 até a mais recente e bem aceita, teoria do caos de Titze, Baken e Herzel (1993).

A partir de 1970 o processamento digital de sinais trouxe um aumento gradativo de estudos voltados à análise objetiva da voz e ao desenvolvimento de inúmeros laboratórios de voz. A implementação da análise acústica no processamento de sinais de voz permitiu definir os parâmetros e medidas acústicas usadas na atualidade na clínica de voz. Segundo FUKUYAMA (2001) os principais parâmetros são: Medidas de freqüência fundamental, medidas de perturbação e medidas de ruído.

- $\quad$ Medidas de Freqüência fundamental (FO) ou freqüência glótica: é o número de ciclos vibratórios completos da mucosa das pregas vocais por segundo. De acordo com BEHLAU, TOSI; PONTES (1995) para o português brasileiro, os valores normais médios são de 80 a $150 \mathrm{~Hz}$ com média de $113 \mathrm{~Hz}$ para os homens; de 150 a $250 \mathrm{~Hz}$ com média de $204 \mathrm{~Hz}$ para as mulheres, e média de $235,8 \mathrm{~Hz}$ para as crianças. Pode-se observar que a freqüência fundamental esta relacionada fortemente com o gênero e a idade. 
- $\quad$ Medidas de perturbação: A vibração das pregas vocais produz um pulso de ar glótico quase-periódico, esta quase-periodicidade embora normal no funcionamento da laringe, está limitada a certos valores. As medidas de perturbação de um sinal referem-se a quanto um determinado período de vibração diferença-se do outro que o sucede (FUKUYAMA, 2001), e por meio destas pode-se discriminar casos patológicos dos normais. Várias medidas na perturbação de freqüência e amplitude foram propostas na literatura. De forma genérica, o jitter representa a perturbação do período (freqüência), e o shimmer à perturbação na amplitude do sinal.

- Medidas de Ruído: avaliam o ruído em diferentes faixas de freqüência do espectro. O ruído é um sinal acústico sem periodicidade, originado da superposição de vários movimentos de vibração com diferentes freqüências as quais não apresentam relação entre si (FUKUYAMA, 2001). Da mesma forma que as medidas de perturbação, vários algoritmos foram propostos na literatura, como por exemplo: Relação Harmônico/Ruído (HNR); Intensidade Relativa de Harmônicas (Hr), Harmônicas Relativas (Ra), Nível Espectral de Ruído (SNL), para mencionar algum deles.

A avaliação acústica clínica, introduzida na década de 1990, na realidade brasileira, tem sido cada vez mais presente na realidade fonoaudiológica (BEHLAU, 2001). Segundo Nunes e Costa (2006) este tipo de análise é uma ferramenta valiosa na clínica, pois: 
- No diagnóstico, apóiam as observações subjetivas nas imagens de videlaringoestrobospia,

- Em campanhas de triagem podem potencialmente ser utilizadas para detectar níveis de perturbação fonatória acima dos valores de referência de uma população não disfônica.

- $\quad$ Podem auxiliar o monitoramento terapêutico.

- As imagens e gráficos destas análises permitem ao pacientes uma maior compreensão do problema vocal.

- Registros e medidas acústicas podem servir em perícias onde há questionamento da eficácia de tratamentos vocais.

Em síntese, a análise acústica fornece informações e medidas relativas ao bloco patológico que originou uma determinada alteração vocal e modificação acústica no sinal de voz; possibilitam a obtenção de dados normativos; oferecem uma documentação e monitoram a eficácia de um tratamento. Embora o uso confiável requeira ainda cuidados na gravação dos sinais e conhecimento sobre as capacidades e limitações e fragilidades dos algoritmos computacionais (NUNES, COSTA, 2006).

\subsubsection{Abordagens baseadas em modelos de dinâmica não linear}

$\mathrm{Na}$ área clínica, assim como na pesquisa, a análise acústica tem sido muito utilizada para avaliar objetivamente a voz, medindo as propriedades de sinais de voz de vogais sustentadas, tanto patológicas como saudáveis. Se os 
sinais forem quase-periódicos, as flutuações em curto prazo podem ser quantificadas usando medidas de perturbação (jitter e shimmer). Mas segundo RAHN ET AL (2007) empregar este tipo de medida para determinar o grau de patologia em vozes com alterações, pode ser difícil porque o período não pode ser extraído de forma consistente.

Nos últimos anos, no campo da medicina, os estudos têm focalizado na análise das propriedades caóticas em EEG, sistema respiratório, ritmos cardíacos, (POON; MERRILL, 1997), (RICHTER; SCHREIBER, 1998), (HORNERO; ALONSO; JIMENO; JIMENO; LOPEZ, 1999), (SATALOFF; HAWKSHAW, 2001) e vibração das pregas vocais, (AWREJCEWICZ, 1990), (HERZEL ET AL, 1994), (BERRY; HERZEL; TITZE; KRISCHER, 1994), (JIANG; ZHANG, 2001), (JIANG; ZHANG, 2002), (MAC CALLUM ET AL, 2009). Esses sistemas têm uma característica em comum, não podem ser categorizados como aleatórios, embora sigam determinados padrões próprios e o resultado seja muitas vezes altamente imprevisível.

Segundo TITZE, BAKEN, HERZEL (1993) os sinais de voz humana possuem manifestações de dinâmica não linear. Alguns exemplos são: voz rouca, voz crepitante, ou as quebras de voz. Existem três trabalhos que podem considerar-se como os pioneiros em demonstrar a não linearidade na vibração das pregas vocais. Um deles é o modelo matemático desenvolvido por AWREJCEWICZ (1990) que desvia a dificuldade de conduzir experimentos fisiológicos numa laringe em fonação e demonstra a função laríngea através de um modelo matemático. Outro trabalho foi realizado por (MENDEL, HERZEL, 
WERMKE, 1990) que evidenciou que o choro de recém nascidos é uma fonte rica de características raras e desconhecidas na voz do adulto, que apresenta "quebra dos sub-harmônicos" e turbulência, que envolvem duplicação de período e aperiodicidade respectivamente. O último estudo é o realizado por (BAKEN, 1990) que comparou as vibrações das pregas vocais entre pessoas normais e pessoas com patologia laríngea comprovada.

Do mesmo modo, a análise não linear tem mostrado ser uma valiosa ferramenta para estudar segmentos aperiódicos de voz (HERZEL, BERRY, TITZE, SALEH, 1994) e (ZHANG ET AL. 2005). A aplicação deste tipo de ferramentas fornece informações complementares à análise acústica no estudo objetivo da voz. Conseqüentemente, a análise da dinâmica não linear em combinação com medidas de perturbação pode melhorar a capacidade de descrever e diagnosticar vozes com alterações patológicas (TITZE, BAKEN, HERZEL, 1993), (ZHANG, JIANG, 2004), (DAJER, MACIEL, PEREIRA, 2007), (MAC CALLUM ET AL, 2009).

Algumas das técnicas não lineares aplicadas para analisar sinais com aperiodicidades como é o sinal de voz são: reconstrução de espaço de fase, mapa de Pointcaré, dimensão fractal, dimensão de correlação, entropia de Kolmogorov e Expoente de Lyapunov. Estas técnicas são capazes de descrever um sistema determinístico, mas que apresentam comportamentos não lineares. 
O Mapa de Poincaré é uma ferramenta desenvolvida a partir da idéia original do físico e matemático francês Henri Poincaré. Segundo este autor, as características de um sistema podem ser imprevisíveis dependendo das condições iniciais e dos parâmetros externos aplicados ao sistema. Essa característica de imprevisibilidade é conhecida como caos determinístico. O mapa de Poincaré é uma ferramenta útil para análise desses fenômenos. Esta técnica descreve a evolução do sistema para valores no tempo discreto e esses mapas são versões discretizadas dos sistemas associados a equações diferenciais ordinárias. (NAYFEH, BALACHANDRAN, 1994), (KANTZ, SCHREIBER, 2003).

A dimensão fractal foi um conceito introduzido por Mandelbrot e é empregado para se referir à forma geométrica da natureza que tem estrutura semelhante. Sinais biológicos com certas flutuações como a EEG e sons vocais são conhecidos por terem componentes que podem ser avaliados pela sua dimensão fractal e relacionados com a propriedade de "auto- afinidade" (KATZ, 1988).

De forma resumida, a dimensão de correlação é uma medida quantitativa que específica o número de graus de liberdade necessários para descrever o sistema dinâmico; um sistema mais complexo tem uma alta dimensão (KANTZ, SCHREIBER, 2003). Um estudo de RAHN ET AL (2005) utilizou a dimensão de correlação e análise da perturbação para descrever as alterações vocais. Este estudo demonstrou que a dimensão de correlação (D2) 
pode quantificar amostras de vozes periódicas e aperiódicas, enquanto que os métodos de perturbação não podem medir precisamente vozes aperiódicas.

O expoente de Lyapunov define as características numéricas de um sistema dinâmico. Este expoente permite classificar o comportamento do sistema de maneira concisa, através da convergência exponencial ou divergência das trajetórias que se originam próximas umas das outras. 0 número do expoente de Lyapunov, que caracteriza o comportamento do sistema dinâmico, é igual a dimensão deste sistema. Para a aplicação prática, é importante conhecer o Máximo Expoente de Lyapunov. Se o máximo valor no espectro do Expoente de Lyapunov é positivo, significa que o expoente é caótico. Se esse valor for igual a zero indica uma dinâmica periódica ou quaseperiódica (KANTZ, SCHREIBER, 2003).

A reconstrução do espaço de fase, baseado no método das coordenadas defasadas, tem provado ser uma poderosa ferramenta na análise de sinais biológicos, como os sinais de voz. As idéias fundamentais sobre esta técnica são creditadas a PACKARD ET AL (1980) e TAKENS (1981), e uma de suas principais características é a preservação dos invariantes geométricos do sistema. Se considerarmos um sinal de voz como uma série temporal, $s(n)$, esta pode ser representada pela trajetória de um dado sistema dinâmico. As séries temporais se caracterizam por terem comprimento e precisão finitos, portanto, a seleção do $\tau$ é importante na reconstrução do espaço de fase. Se $\tau$ for muito baixo, as amostras atrasadas estarão fortemente correlacionadas, e as trajetórias dos atratores estendem-se ao redor de uma linha diagonal no 
espaço de fase reconstruído. Caso contrario, se $\tau$ é muito grande, a trajetória dos atratores reconstruídos no espaço de fase caracteriza-se por uma autointerseção.

Para estimar o tempo de atraso $\tau$, um dos métodos propostos na literatura é o Método de Informação Mutua (FRASER; SWINNEY, 1986), o qual geralmente depende de duas variáveis. FRASER E SWINNEY propõem como critério efetivo para a seleção de um tempo de atraso $\tau$, o primeiro valor mínimo da curva de informação mútua por tempo de atraso $\tau$, e afirmam que esta medida garante que as variáveis defasadas sejam descorrelacionadas.

A idéia básica da técnica é traçar $s(n)$ versus $s(n+\tau)$, onde $\tau$ é uma defasagem no tempo. Este procedimento é motivado pelo fato de que a trajetória representada no espaço de fase reconstruído, possui propriedades similares ao espaço de fase original, sendo topologicamente equivalentes (PACKARD ET AL,1980) e (TAKENS, 1981). A reconstrução do espaço de fase mostra a vibração das pregas vocais em função do tempo, sendo uma trajetória fechada no sinal periódico e uma trajetória irregular quando o sinal é irregular ou caótico, (JIANG, ZHANG, MCGILLIGAN, 2006), (RAHN, 2007) (DAJER, MACIEL, PEREIRA, 2007), (SCALASSARA, ET AL, 2009).

Os diversos trabalhos encontrados na literatura, (GIOVANNI; OUAKNINE; TRIGLIA, 1998), (MATASSINI; HEGGER; KANTZ; MANFREDI, 2000), (JIANG; ZHANG, 2002), (ZHANG; JIANG, 2004), (ZHANG ET AL. 2005), (MACCALLUM ET AL, 2009) confirmam que as técnicas de dinâmica não linear 
têm-se mostrado ferramentas poderosas na área de análise de distúrbios vocais. Estas técnicas consideram as características intrínsecas do sistema de produção vocal; e se empregadas em conjunto conseguem revelar a dinâmica dos sinais de voz, sejam estes normais ou patológicos.

Ainda existe um amplo campo de pesquisa nesta área. Estudos futuros podem ser úteis para confirmar resultados e para desenvolver ferramentas de uso clínico, que permitam contornar as desvantagens dos métodos existentes e proporcionem dados mais precisos para os pesquisadores, profissionais de saúde e os pacientes. 


\section{MATERIAIS E MÉTODO}

A proposta deste trabalho foi analisar sinais de voz sem alterações vocais e com alterações patológicas empregando Padrões Visuais de Dinâmica Vocal- PVDV em conjunto com análise acústica e análise perceptivo-auditiva e estabelecer correlações entre as técnicas. Foram analisadas 91 amostras de sinais de voz da vogal sustentada /a/ do português brasileiro de sujeitos de ambos os gêneros, pertencentes ao banco de vozes do Laboratório de Processamento de Sinais do SEL-EESC-USP. Os sinais de voz foram gravados e digitalizados diretamente em computador com o programa Análise de Voz com $22050 \mathrm{~Hz}$ de taxa de amostragem, mono-canal e 16 bits. Todas as amostras utilizadas neste trabalho foram de pacientes que realizaram videoestroboscopia para corroborar a presença ou ausência de patologia vocal.

Foram selecionados trechos estacionários de 200 milissegundos de cada uma das amostras para serem analisadas com a técnica de padrões visuais da dinâmica vocal (PVDV), conjuntamente com a análise acústica (AA) e a análise perceptivo-auditiva (APA). Os resultados das três análises receberam tratamento estatístico com testes paramétricos para os dados quantitativos e não paramétricos para os dados qualitativos. Foi aplicado o teste de correlação para avaliar a possível associação entre as técnicas. 


\subsection{Materiais}

Os 91 sinais analisados foram classificados em dois grandes grupos: sinais de voz sem alterações vocais, ou saudáveis (46 amostras) e sinais de voz com disfonia (45 amostras); ambos os grupos foram subdivididos, como apresentado na Figura 3.1.

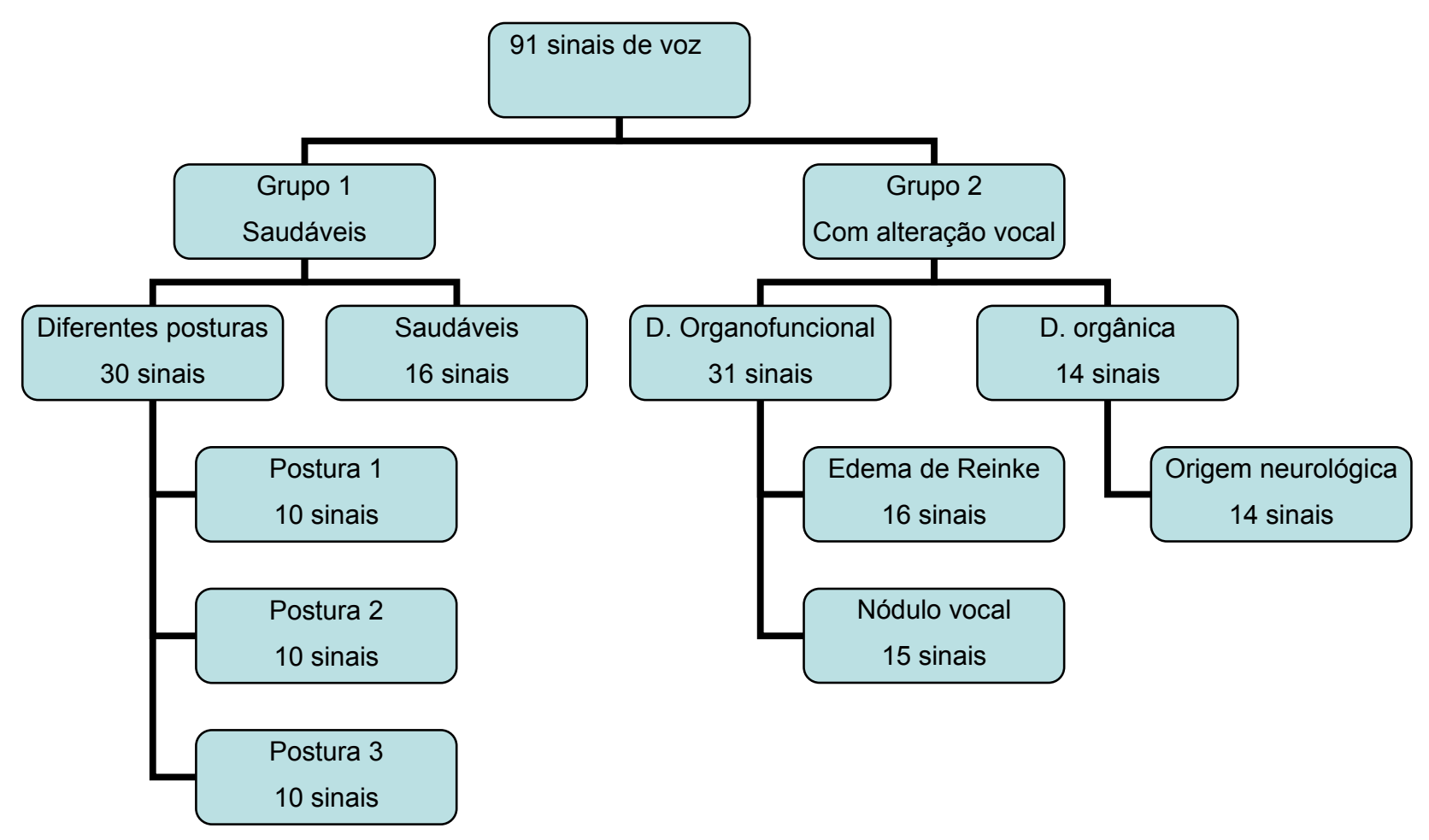

Figura 3.1: Grupos e sub-grupos das amostras de sinais de voz avaliadas.

\subsubsection{Grupo 1. Sinais de voz sem alteração vocal ou vozes saudáveis}

Neste grupo de vozes saudáveis foi incluído o subgrupo de vozes saudáveis com alteração postural. O objetivo desta inclusão foi avaliar mais profundamente a capacidade das ferramentas de análise, de diferenciar alterações sutis, mesmo em vozes sem alteração. Por conseguinte, 
possibilitando uma visão mais precisa das possibilidades e limites de cada uma das ferramentas aplicadas.

Os 46 sinais de voz foram divididos em:

- $\quad$ Saudáveis: 16 sinais de voz da vogal /a/ de adultos jovens com idades entre 21 e 45 anos, idade média de 31,31 anos sem queixa ou alteração vocal, de ambos os gêneros (5 femininos e 11 masculinos); A tabela 3-1 apresenta uma relação segundo o gênero e idade dos sinais de voz deste grupo.

Tabela 3-1: Relação de gênero e idade do grupo de vozes saudáveis

\begin{tabular}{ccc}
\hline Sinal de voz & Gênero & Idade \\
\hline 1 & Masculino & 39 \\
2 & Masculino & 21 \\
3 & Feminino & 41 \\
4 & Feminino & 22 \\
5 & Masculino & 35 \\
6 & Masculino & 23 \\
7 & Masculino & 23 \\
8 & Masculino & 21 \\
9 & Masculino & 43 \\
10 & Masculino & 36 \\
11 & Feminino & 24 \\
12 & Feminino & 45 \\
13 & Masculino & 38 \\
14 & Masculino & 27 \\
15 & Feminino & 21 \\
16 & Masculino & 42 \\
\hline \hline
\end{tabular}

- Saudáveis com diferentes posturas: 30 sinais da vogal /a/ de um mesmo sujeito, masculino de 33 anos em três posturas diferentes: 1) postura neutra, 2) anteriorização de cabeça com extensão do pescoço e 3) aumento da cifose toráxica com anteriorização de cabeça. O participante realizou, na posição 
sentada, a emissão confortável da vogal sustentada /a/ nas três posturas. Os registros vocais foram repetidos, pelo mesmo indivíduo, por dez dias.

A figura 3.2 mostra a imagem de pregas vocais sem alteração em posição aberta ou posição respiratória e fechada ou posição fonatória.

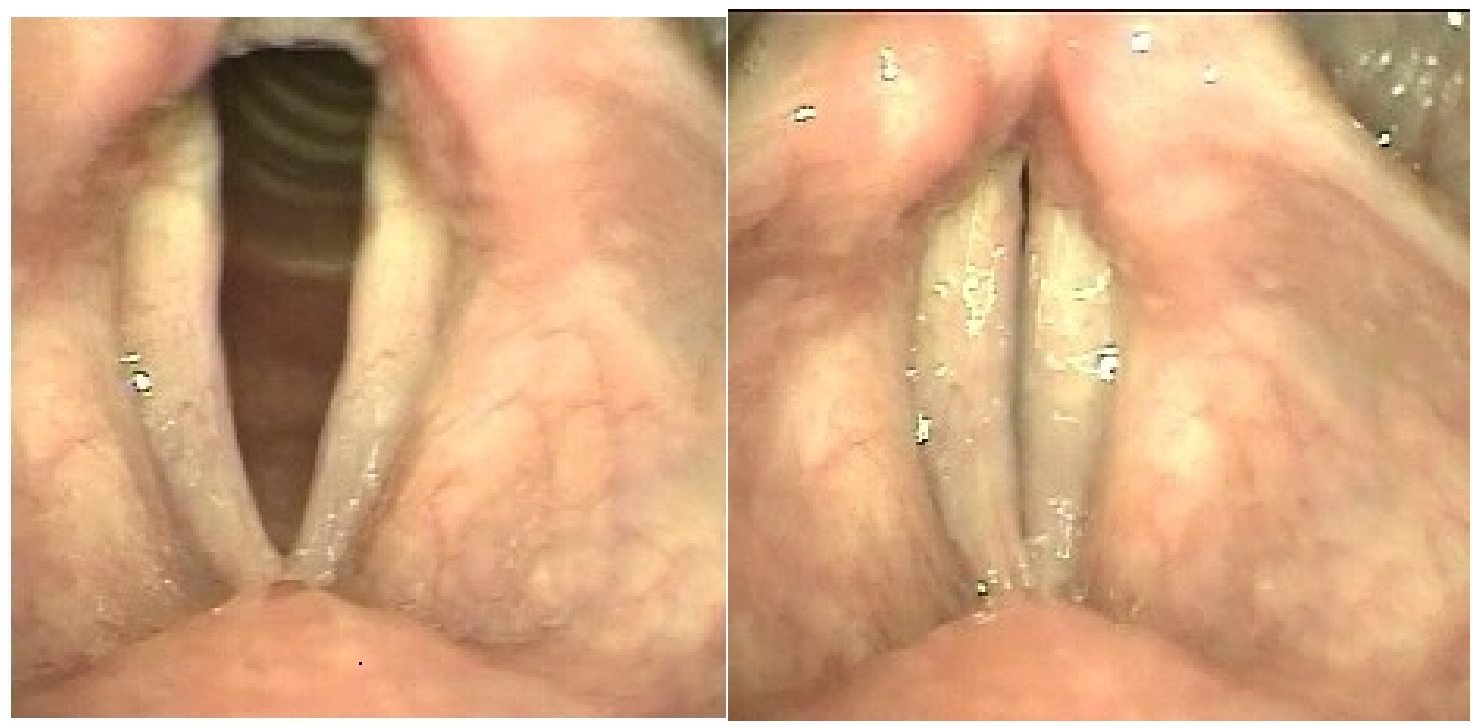

Figura 3.2: Imagens das pregas vocais saudáveis. Imagens extraídas do banco de dados do Laboratório de Processamento de Sinais.

\subsubsection{Grupo 2. Sinais de voz com disfonia}

Consta de 45 sinais de voz de pacientes de ambos os gêneros com alteração patológica de diferente etiologia, divididos segundo o critério de classificação de disfonias (PONTES; BELHAU, 2000), em dois subgrupos:

- $\quad$ Disfonia organofuncional: 16 sinais de voz com Edema de Reinke e 15 sinais com nódulo vocal. 
Edema de Reinke: os 16 sinais de voz pertencem a sujeitos com idades entre 28 e 48, com média de 38,56 anos, de ambos os gêneros (14 femininos e 2 masculinos). Uma relação segundo o gênero e idade dos pacientes deste grupo encontra-se na tabela 3-2.

Tabela 3-2: Relação de gênero e idade do grupo de pacientes com edema de Reinke

\begin{tabular}{ccc}
\hline Sinal de voz & Gênero & Idades \\
\hline Paciente 1 & Feminino & 45 \\
Paciente 2 & Feminino & 36 \\
Paciente 3 & Feminino & 38 \\
Paciente 4 & Feminino & 40 \\
Paciente 5 & Feminino & 41 \\
Paciente 6 & Feminino & 48 \\
Paciente 7 & Feminino & 34 \\
Paciente 8 & Masculino & 28 \\
Paciente 9 & Masculino & 33 \\
Paciente 10 & Feminino & 40 \\
Paciente 11 & Feminino & 29 \\
Paciente 12 & Feminino & 38 \\
Paciente 13 & Feminino & 34 \\
Paciente 14 & Feminino & 42 \\
Paciente 15 & Feminino & 45 \\
Paciente 16 & Feminino & 46 \\
\hline \hline
\end{tabular}

O edema de Reinke se caracteriza pela deposição de material gelatinoso no espaço de Reinke. Apresenta uma grande variabilidade clínica, mas na visão laringoscópica apresenta um aspecto característico geralmente bilateral e assimétrico, que evolui com a distensão gradativa do espaço de Reinke, aumentando a massa e a flacidez das pregas vocais (TSUJI, INAMURA; UBIRAJARA, 2006). A Figura 3.3 mostra a imagem laríngea de pregas vocais com edema de Reinke. 


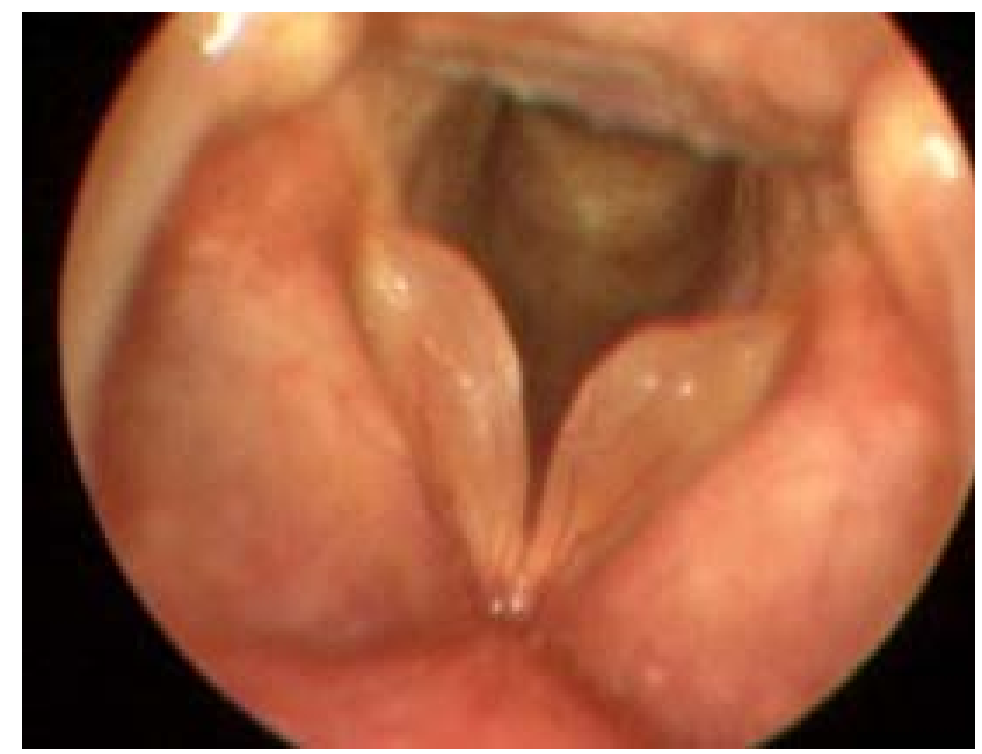

Figura 3.3: Imagem das pregas vocais de um paciente com edema de Reinke. Imagem extraída do sitio web: http://www.gbmc.org/body.cfm?id=450

Nódulo Vocal: os 15 sinais de voz pertencem a sujeitos com idades entre 25 e 48, média de 35,86 anos de ambos os gêneros (13 femininos e 2 masculinos). A relação segundo gênero e idade deste grupo se encontra na tabela 3-3.

Tabela 3-3: Relação de gênero e idade do grupo de pacientes com nódulo vocal

\begin{tabular}{ccc}
\hline Sinal de voz & Gênero & Idade \\
\hline Paciente 1 & Feminino & 28 \\
Paciente 2 & Feminino & 33 \\
Paciente 3 & Feminino & 45 \\
Paciente 4 & Feminino & 26 \\
Paciente 5 & Masculino & 44 \\
Paciente 6 & Feminino & 42 \\
Paciente 7 & Feminino & 38 \\
Paciente 8 & Masculino & 31 \\
Paciente 9 & Feminino & 29 \\
Paciente 10 & Feminino & 35 \\
Paciente 11 & Feminino & 48 \\
Paciente 12 & Feminino & 37 \\
Paciente 13 & Feminino & 32 \\
Paciente 14 & Feminino & 45 \\
Paciente 15 & Feminino & 25 \\
\hline \hline
\end{tabular}


Os nódulos vocais são lesões relativamente comuns e ocorrem em adultos quase exclusivamente em mulheres entre 20 e 40 anos. Apresentam-se em geral bilateralmente na região de transição entre o terço médio para o anterior das pregas vocais e levam a alterações da membrana basal e da camada superficial da lâmina própria das pregas vocais (TSUJI, INAMURA; UBIRAJARA, 2006). A figura 3.4 mostra uma imagem laringoscopica de nódulos vocais bilaterais.

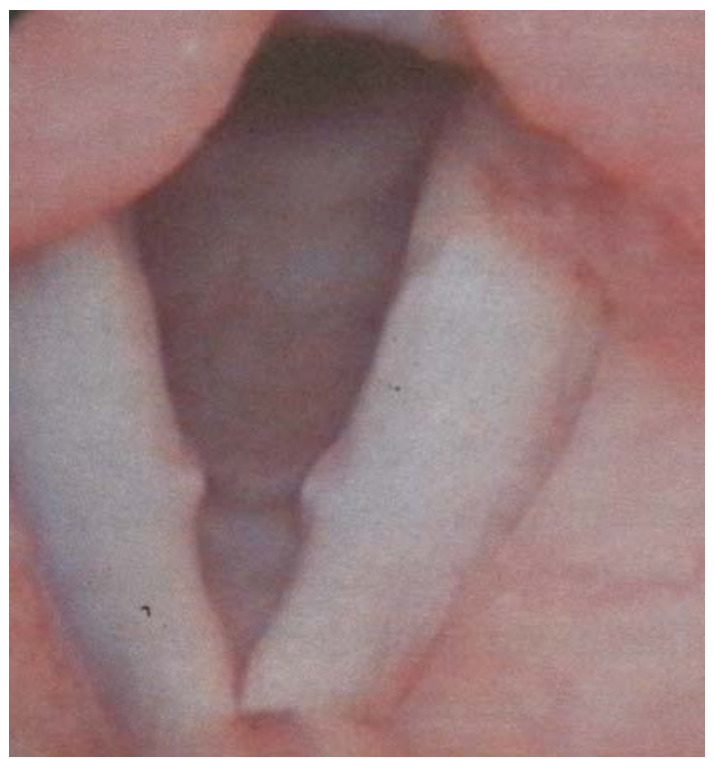

Figura 3.4: Imagem das pregas vocais de um paciente com nódulos vocais bilaterais. Imagem extraída de Behlau, M. Voz - O Livro do Especialista.

- Disfonia orgânica de origem neurológica: o grupo consta de 14 sinais de voz (7 masculinos e 7 femininos) com idades entre 22 a 90 anos, média de 58,5 anos. A tabela 3-4 apresenta a relação respeito à patologia, gênero e idade dos sinais de voz com disfonia orgânica de origem neurológica. 
Tabela 3-4: Relação de diagnóstico e idade do grupo de pacientes com disfonia de origem neurológica.

\begin{tabular}{cccc}
\hline Sinal de voz & Patologia & Gênero & Idade \\
\hline 1 & AVC & Feminino & 90 \\
2 & Doença de Huntington & Masculino & 52 \\
3 & AVC & Masculino & 77 \\
4 & Doença de Parkinson & Masculino & 60 \\
5 & Doença de Parkinson & Feminino & 80 \\
6 & ELA & Masculino & 53 \\
7 & Mononeurite múltipla & Feminino & 59 \\
8 & Mitocondropatia & Masculino & 42 \\
9 & ELA & Feminino & 40 \\
10 & Distrofia de Duchenne & Masculino & 22 \\
11 & ELA & Masculino & 65 \\
12 & Distonia cervical & Feminino & 70 \\
13 & Distonia cervical & Feminino & 70 \\
14 & Distrofia miotônica & Feminino & 39 \\
\hline \hline
\end{tabular}

Legenda: AVC (Acidente Vascular Cerebral); ELA (Esclerose Lateral Amiotrófica)

Segundo Behlau (2005) as disfonias neurológicas são distúrbios vocais que acompanham a lesões ou alterações no sistema nervoso; e embora nem todos os pacientes com transtornos neurológicos apresentam disfonia, muitas vezes um desvio vocal é o primeiro sinal de uma alteração no sistema nervoso. Para ilustrar este tipo de patologia a figura 3.5 apresenta a imagem de uma laringe de um portador de disfonia orgânica de origem neurológica; neste caso de uma paralisia unilateral de prega vocal. 


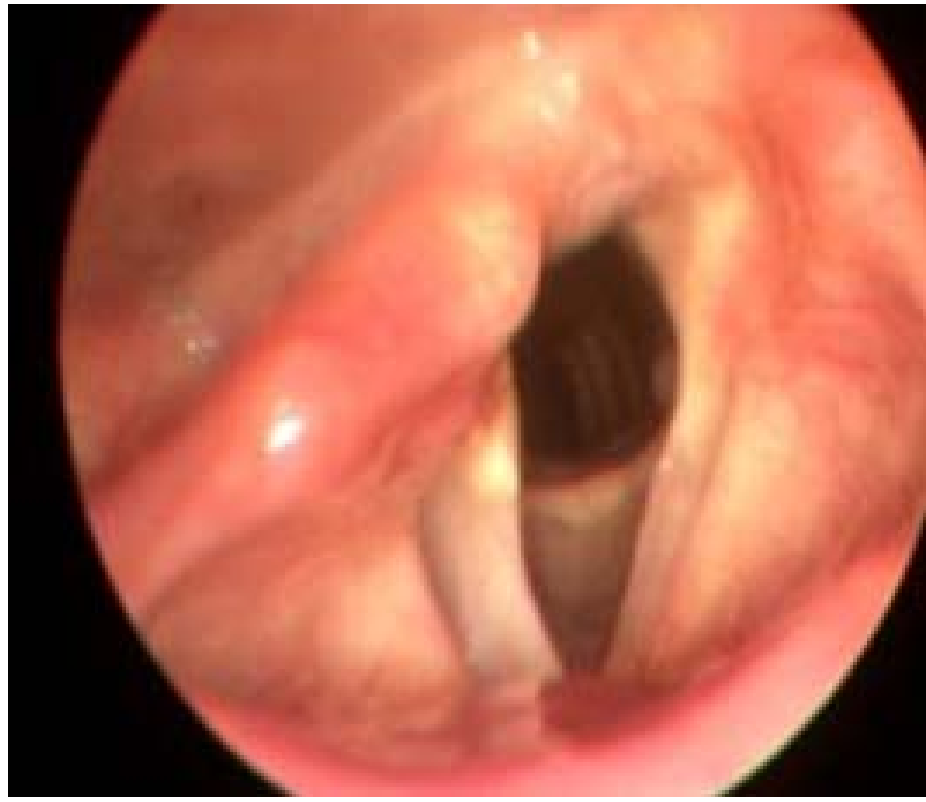

Figura 3.5: Imagem das pregas vocais de um paciente com disfonia de origem neurológico, portador de paralise unilateral. Imagem extraída do sitio web: http://www.gbmc.org/body.cfm?id=450

\subsection{Métodos}

Os dados selecionados para este trabalho foram avaliados por meio de três ferramentas de análise: avaliação perceptivo-auditiva APA, análise acústica tradicional AA e análise qualitativa de Padrões Visuais de Dinâmica Vocal (PVDV).

\subsubsection{Avaliação perceptivo-auditiva}

Para avaliação perceptivo-auditiva das vozes foram contempladas quatro características de qualidade vocal: rugosidade (percepção de irregularidade na fonte sonora), soprosidade (percepção audível de escape de ar na voz), tensão (percepção de esforço vocal) e instabilidade (percepção de oscilação na fonte). Foi empregada uma escala que varia de 0 a 3 para cada 
aspecto avaliado. Sendo que se considera grau 0 (normal ou ausente) quando nenhuma alteração vocal é percebida pelo ouvinte; grau 1 (discreto) para alterações vocais discretas ou, em caso de dúvida, se a alteração está presente ou não; grau 2 (moderado) quando a alteração é evidente e; grau 3 (intenso) para alterações vocais extremas. Esta avaliação foi baseada em conceitos da escala "GRBAS", criada pelo Comitê para Testes de Função Fonatória da Sociedade Japonesa de Logopedia e Foniatria (SJLF, 1969).

A avaliação perceptivo-auditiva foi realizada por uma fonoaudióloga especialista em voz, com mais de 5 anos de experiência que não tinha conhecimento do propósito nem dos dados apresentados neste trabalho. As 91 vozes foram apresentadas aleatoriamente e com $50 \%$ de repetição dos sinais (46 sinais repetidos) - total de 137 sinais de voz. A confiabilidade do avaliador foi de 84,78\%; com 39 sinais de avaliação concordante e 7 sinais avaliadas com diferença de um grau para mais ou para menos.

\subsubsection{Análise acústica}

Para a coleta dos sinais, e análise tradicional de medidas de perturbação acústicas foi utilizado o programa Análise de Voz 6.0. (MONTAGNOLI, 1997). Foram extraídas as medidas de freqüência fundamental e as medidas de perturbação acústica jitter, perturbação da freqüência fundamental e shimmer, perturbação da amplitude. 
As duas medidas de perturbação fornecidas pelo programa, comumente chamadas de Jitter e Shimmer, derivam do cálculo da média de perturbação relativa RAP (KOIKE, 1973), e foi a partir dessas estimativas que Davis em 1976 desenvolveu dois novos parâmetros acústicos denominados de quociente de perturbação de pitch (PPQ) e quociente de perturbação de amplitude (APQ). O parâmetro PPQ ou Jitter indica a perturbação no período do sinal de voz, normalmente ocasionada pela falta de controle das pregas vocais. O parâmetro APQ ou Shimmer muitas vezes está correlacionado a irregularidades nas pregas vocais, como lesões de massas ou redução da resistência glótica.

Nessa nova versão do programa, (MONTAGNOLI, PEREIRA, 2009) utiliza a autocorrelação do sinal de voz ao contrário das versões anteriores, as quais utilizavam o sinal residual da voz para definir esses parâmetros. Este programa nos permite visualizar no lado esquerdo superior da tela, o osciloscópio, que mostra a porção do sinal a ser analisado e do lado direito da figura observamos a autocorrelação do sinal como mostra a figura 3.6. 


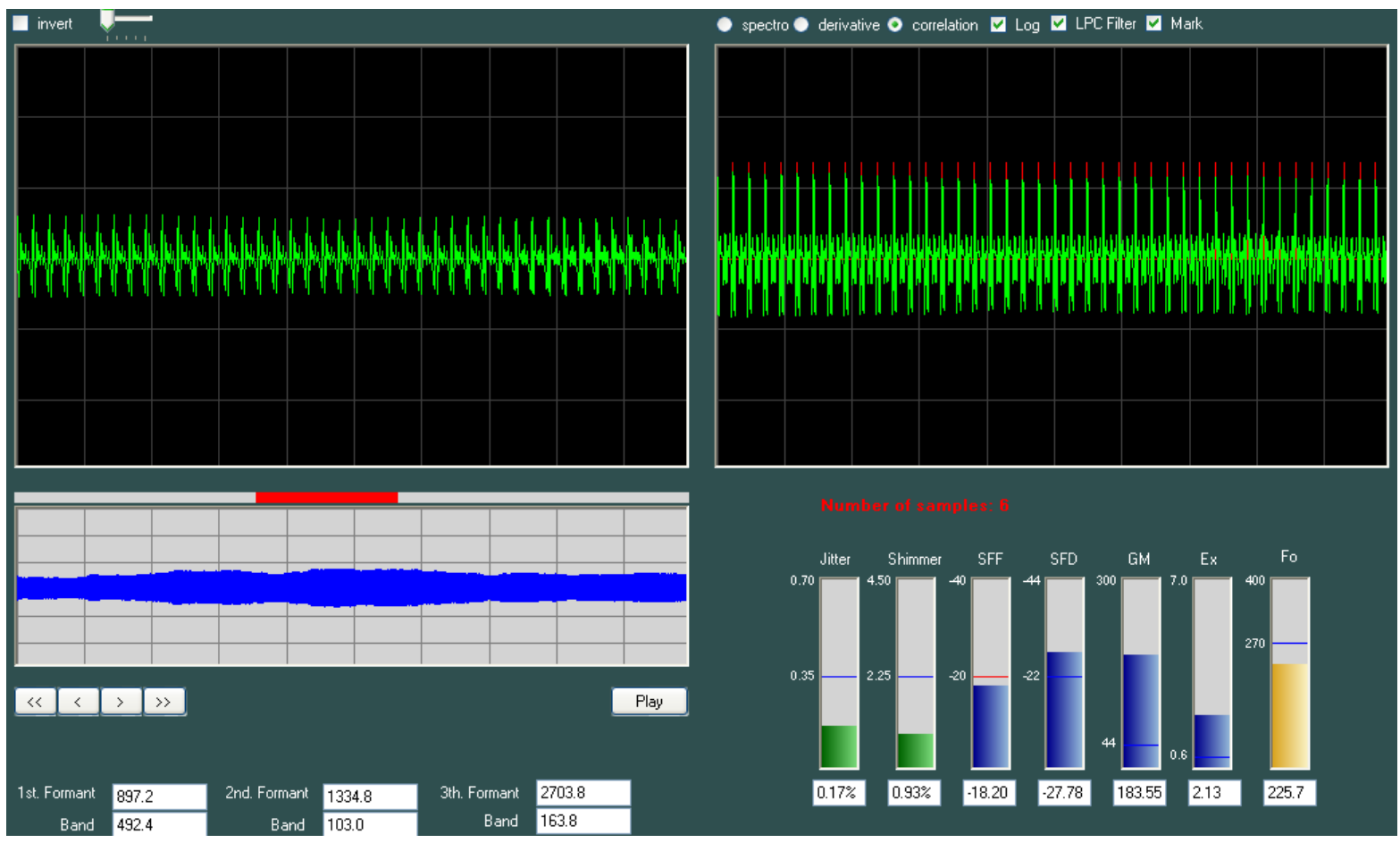

Figura 3.6: Imagem da versão 2009 do programa Análise de Voz.

\subsubsection{Análise qualitativa dos padrões visuais da dinâmica vocal PVDV}

A ferramenta apresentada nesta subseção foi baseada na teoria dos sistemas dinâmicos, que afirma que a evolução no tempo pode ser definida no espaço de fase. Segundo KANTZ e SCHEIBER, (1999) sistemas não lineares exibem caos determinístico, isto é, o ponto de partida natural quando um sinal apresenta irregularidades. Estes autores afirmam que um sinal pode ser representado como uma série temporal, ou em outras palavras, uma seqüência escalar de medidas, que dependem do estado do sistema, tomadas a múltiplos de uma amostragem fixa no tempo. Para converter esta série temporal em vetores de estado é empregado o método de atraso para à reconstrução de espaço de fase. 
A técnica de reconstrução do espaço de fase resulta apropriada no caso dos sinais de voz, já que os ciclos vibratórios das pregas vocais representam um sistema dinâmico, e podem ser descritos como uma trajetória no espaço de fase com evolução no tempo. A análise dos padrões visuais de dinâmica vocal foi baseada na técnica de reconstrução de espaço de fase com técnica de tempo de atraso (FRASER, SWINNEY, 1986). Utilizando o software Matlab 7.0 foi criada uma rotina computacional, chamada de "PVDV" - Padrão Visual de Dinâmica Vocal - desenvolvida a partir do pacote Tisean (HEGGER, KANTZ, SCHREIBER, 1999).

Os PVDV foram baseados na técnica de reconstrução de espaço de fase que representa a vibração das pregas vocais em forma de trajetória num espaço de fase com evolução no tempo. O sinal de voz é representado como uma série temporal simples $x\left(t_{i}\right)=t_{i}=i T$; com $i=1,2, \ldots, N$; onde $N$ é o comprimento do sinal e $T$ é o período de amostragem (KANTZ, SCHREIBER, 2004). O PVDV é realizado plotando a série temporal $x\left(t_{i}\right)$ contra si mesma em um tempo de atraso. Para reconstruir a série temporal $x\left(t_{i}\right)$ foi empregado o método referido por FRASER e SWINNEY (1986) e HEGGER, KANTZ, SCHREIBER (1999). O conjunto de $m$ vetores, chamados de espaço de imersão, são formados por valores de tempo de atraso de $x\left(t_{i}\right)$ como mostra a equação (1)

$$
X\left(t_{i}\right)=\left\{x\left(t_{i}\right) ; x\left(t_{i}-\tau\right), \ldots, x\left(t_{i}-(m-1) \tau\right)\right\}
$$


Quando $m>2 D+1$ o espaço de fase reconstruído é topologicamente equivalente ao espaço de fase original (FRASER E SWINNEY, 1986). Para estimar o tempo de atraso foi utilizado o Método de Informação Mutua (FRASER; SWINNEY, 1986), que propõe como critério de seleção o primeiro valor mínimo da curva de informação mutua por tempo de atraso $\tau$; este critério garante que as variáveis defasadas são geralmente independentes.

Para seleção das amostras de análise se escolhe manualmente um trecho do sinal. Para cada sinal de voz foi escolhido um trecho de 200 milissegundos (que apresentasse maior estabilidade na amplitude de onda) e um trecho menor com 10 ciclos de duração, para análise mais detalhada da dinâmica. A figura 3.7 apresenta a seqüência de pré-processamento dos sinais para escolher os trechos a serem analisados. Na figura 3.7A aparece o sinal de voz completo no domínio do tempo com o trecho selecionado para corte em vermelho. A figura 3.7B mostra o trecho de 200 milissegundos - que será o trecho do sinal avaliado - e em linha pontilhada o trecho a ser cortado de 10 ciclos completos. Finalmente C apresenta a amostra com 10 ciclos, que será o trecho para controle em caso a complexidade da dinâmica apresente duvidas na avaliação. 
A

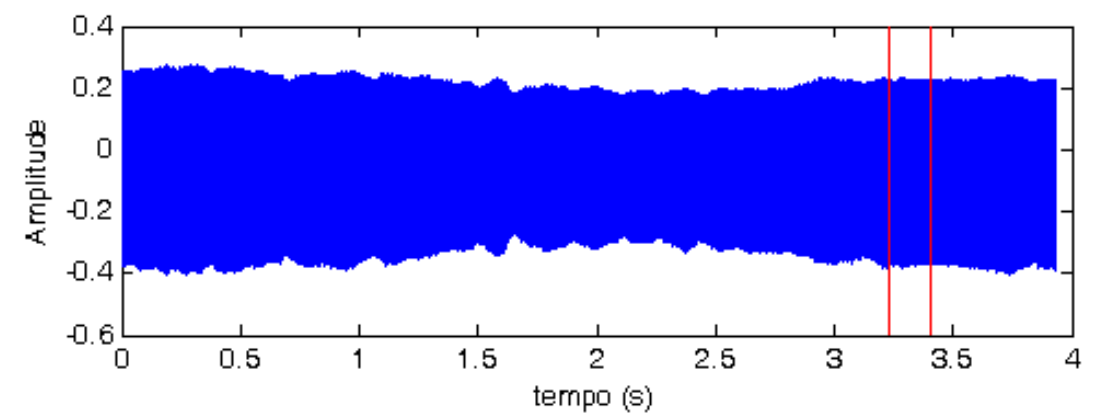

B

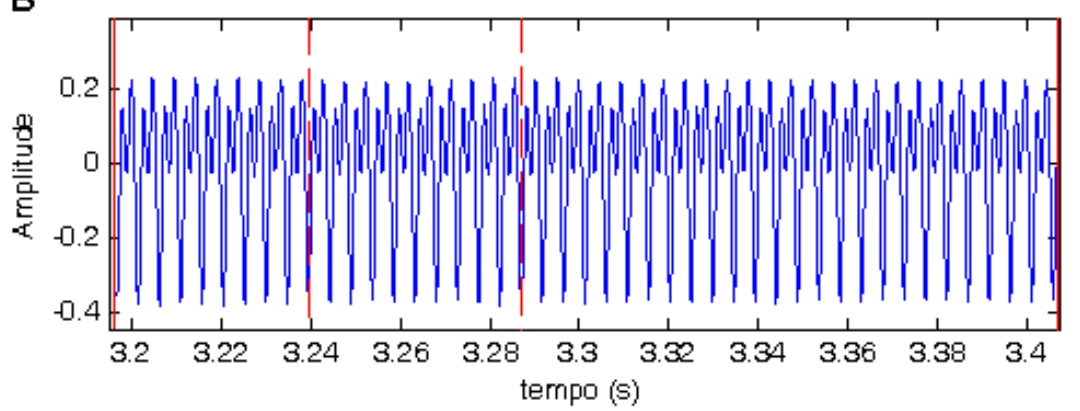

$\mathrm{C}$

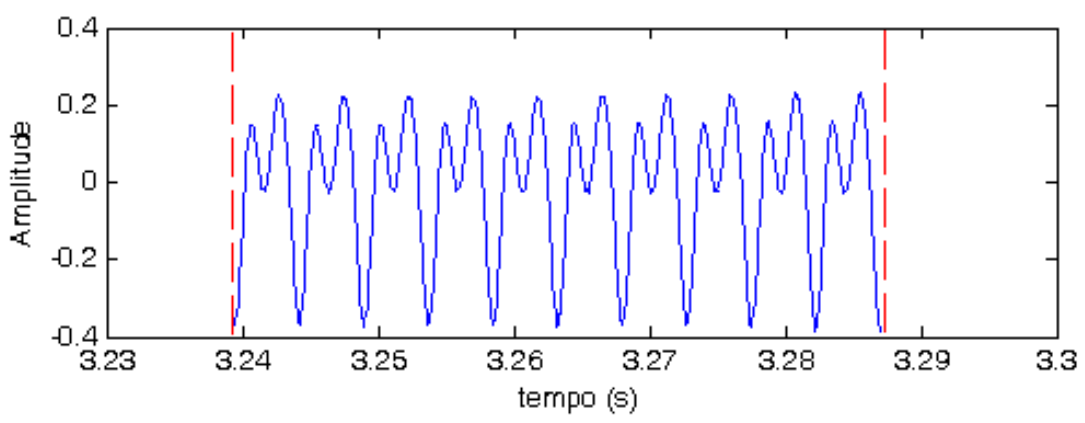

Figura 3.7: (A) Sinal completo da vogal sustentada lal. (B) trecho de 200 milissegundos. (C) trecho de 10 ciclos selecionado para análise.

Depois de escolher as amostras de acordo com o critério proposto por (FRASER; SWINNEY, 1986) é selecionado o primeiro valor mínimo da curva de informação mútua como apresentado na figura 3.8. Este gráfico indica a autocorrelacão da série temporal, realçando a forte similaridade para 26 amostras de atraso e a baixa correlação para 13 amostras. Em outras palavras, ela mede a dependência do sinal consigo mesmo e oferece uma melhor estimativa na eleição de tempo de atraso, realçando a dinâmica aleatória e não determinística do sinal. Na figura 3.8 pode-se observar o gráfico da curva de 
informação mútua em função do tempo de atraso da amostra, o círculo marca o primeiro valor mínimo da curva de informação mutua por atrasos de amostras, neste caso a escolha de 13 amostras.

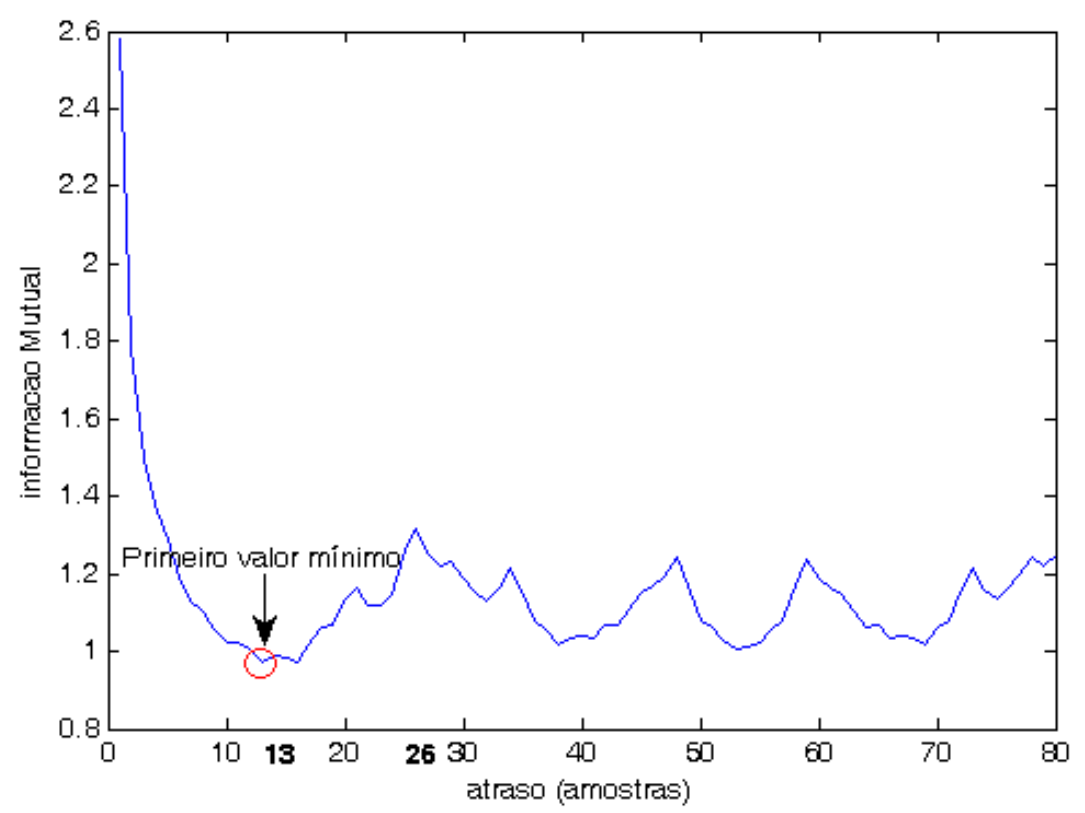

Figura 3.8: Curva de informação mútua por atraso de amostras para o sinal apresentado na figura 3.7C (10 ciclos).

Uma vez realizada a seleção do tempo de atraso, podem-se obter três projeções dos padrões visuais da dinâmica vocal; uma projeção do trecho de sinal bidimensional $(x, y)$, exemplificado na figura 3.9; uma tri-dimensional $(x, y$, $z$ ) na figura 3.10; e uma projeção em função do tempo $(x, y, t)$ apresentada na figura 3.11. Estes gráficos são uma representação da dinâmica do sistema vocal (sinal de voz) e foram denominadas Padrões Visuais de Dinâmica Vocal (PVDV). Embora seja possível obter 3 projeções diferentes dos PVDV, para este trabalho somente a projeção bidimensional (eixos x e y) será analisada. 


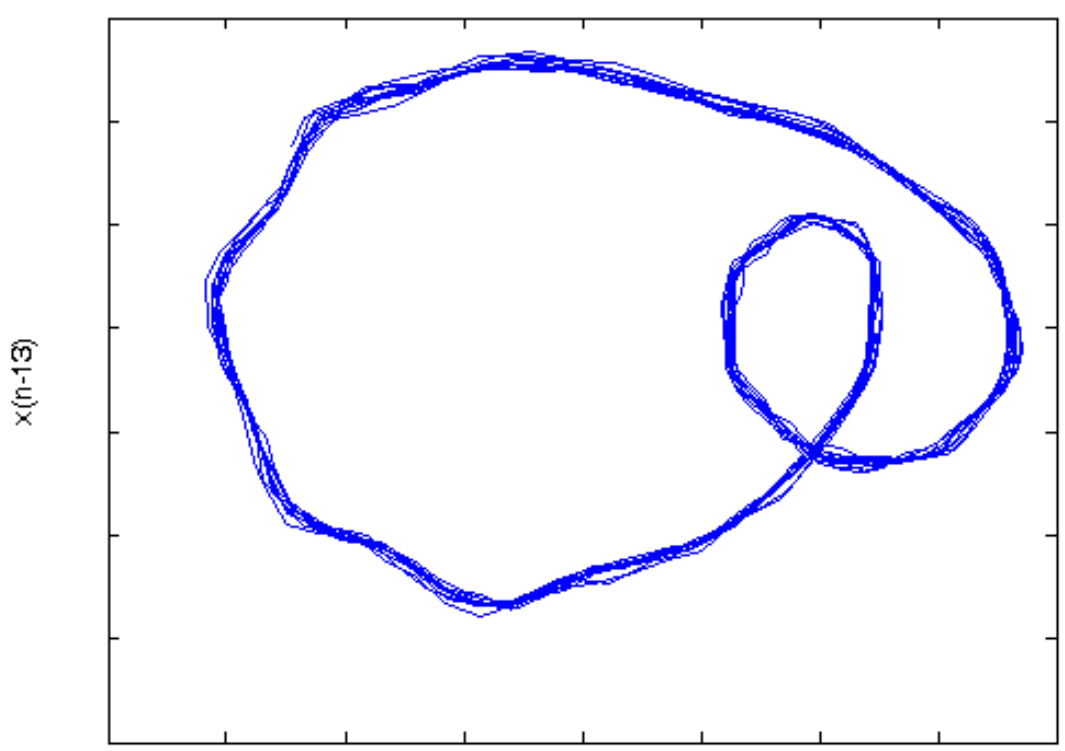

$\times(n)$

Figura 3.9: Exemplo de um PVDV bidimensional de uma vogal sustentada le/ do sinal apresentado na figura 3.7C (10 ciclos) com atraso de 13 amostras.

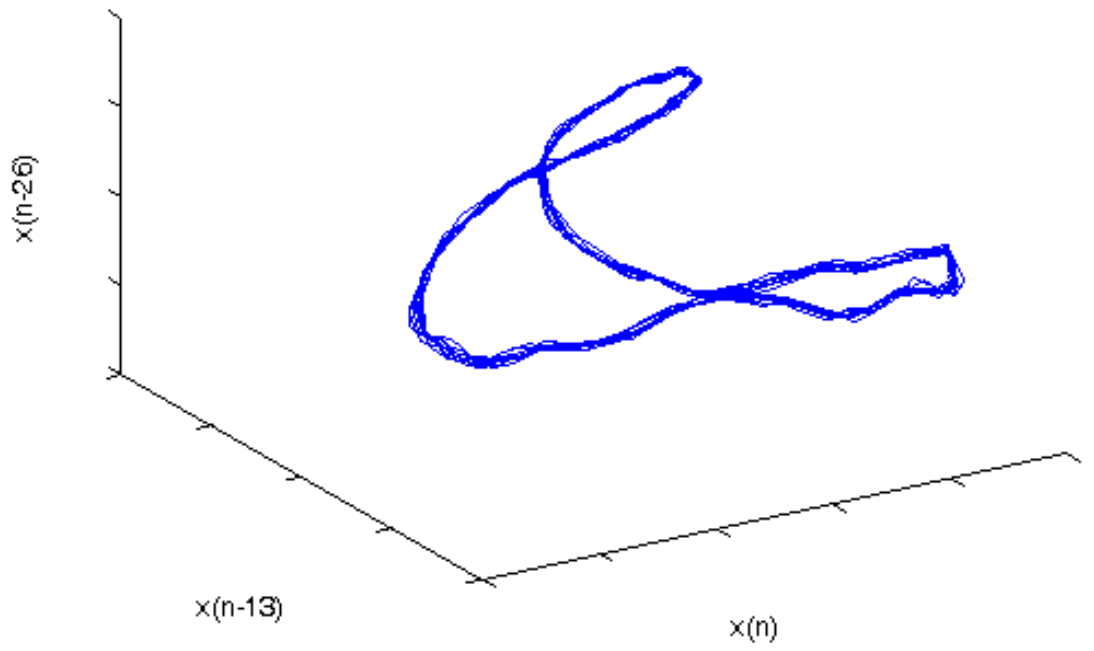

Figura 3.10: Exemplo do PVDV tridimensional (eixos $x, y, z$ ) do sinal de 10 ciclos apresentado na figura $3.7 \mathrm{C} \mathrm{com}$ atraso de 13 amostras. 


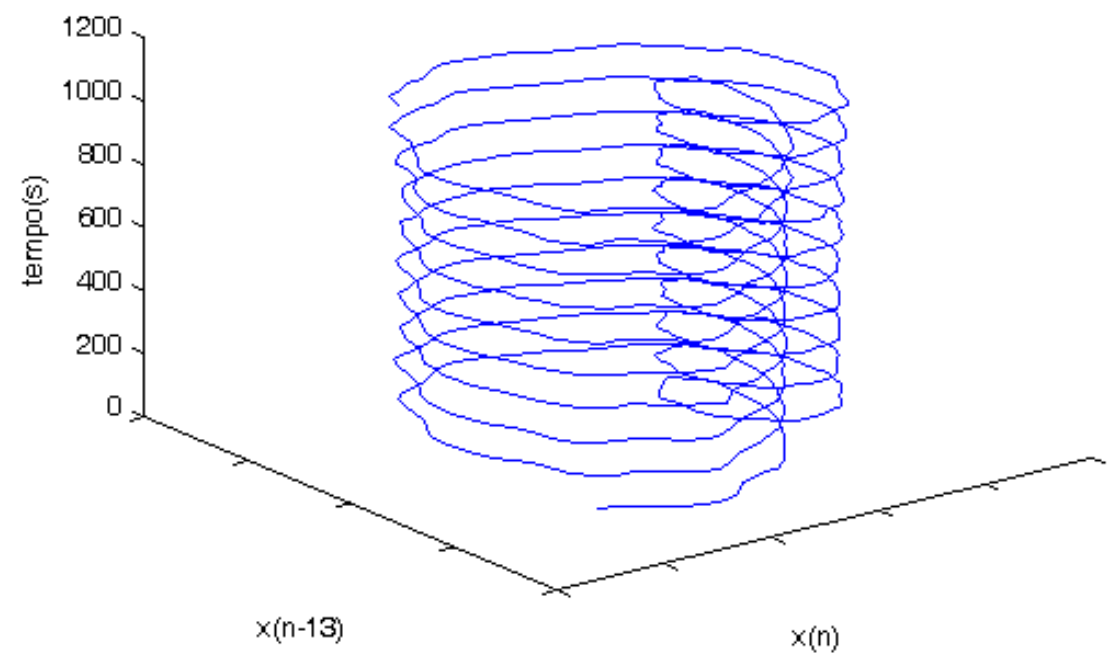

Figura 3.11: Exemplo do PVDV em função do tempo do sinal de 10 ciclos apresentado na figura 3.7C com atraso de 13 amostras.

Em outras palavras, a análise dos PVDV é usada para mapear os traços instantâneos de um sinal de voz com evolução no tempo. Esta ferramenta permite observar a periodicidade, a mudança na forma da onda glótica, a variação ciclo a ciclo e a presença de ruído de um sinal de voz. Para ilustrar melhor esta ferramenta serão apresentados três sinais com seus respectivos PVDV, os dois primeiros são sinais simulados (sem e com adição de perturbação em freqüência e amplitude), e por último um sinal de voz humano.

No caso dos sinais simulados é possível observar as mudanças nos PVDV de um sinal simulado de uma única freqüência (formato senoidal) quando é adicionada uma porcentagem de perturbação da freqüência (jitter) e/ou da amplitude (shimmer) como mostram as respectivas figuras 3.12 e 3.13 . Nestas figuras o mesmo sinal artificial de $170 \mathrm{~Hz}$ é apresentado na figura 3.12 sem nenhuma porcentagem de perturbação e na figura 3.13 com adição de $0,1 \%$ de jitter e $1 \%$ de shimmer. 
No exemplo do sinal sem perturbação, e independente do comprimento do trecho escolhido para análise, as trajetórias passam ciclo a ciclo pelos mesmos pontos formando um PVDV com uma figura circular única. O sinal com acréscimo de jitter e shimmer embora apresente um formato circular semelhante muda respeito à comportamento de convergência da trajetórias, ciclo a ciclo o mesmo ponto passa próximo mas não exatamente no mesmo lugar.
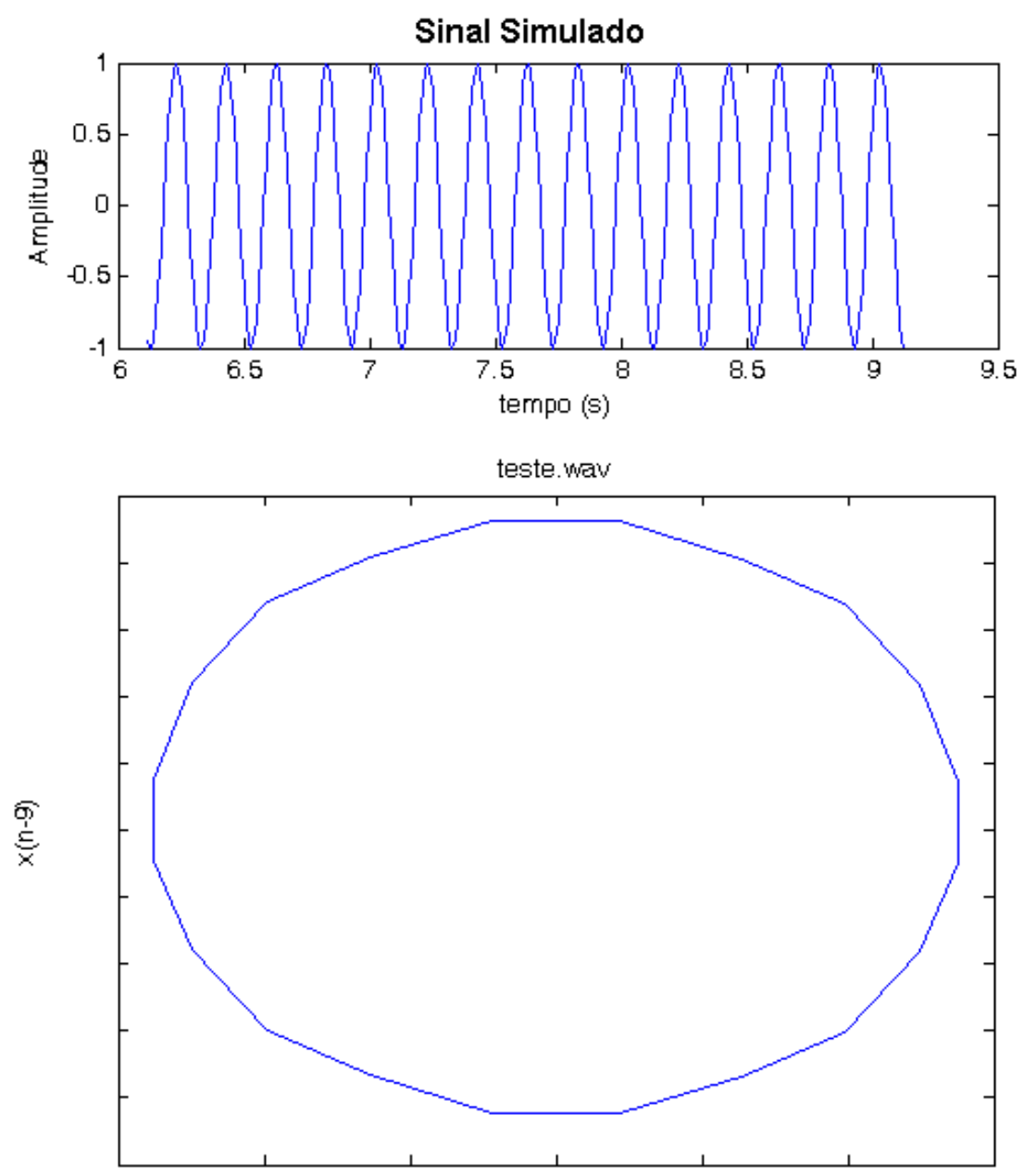

$x(n)$

Figura 3.12: Exemplo do PVDV de um sinal simulado de uma única freqüência. 

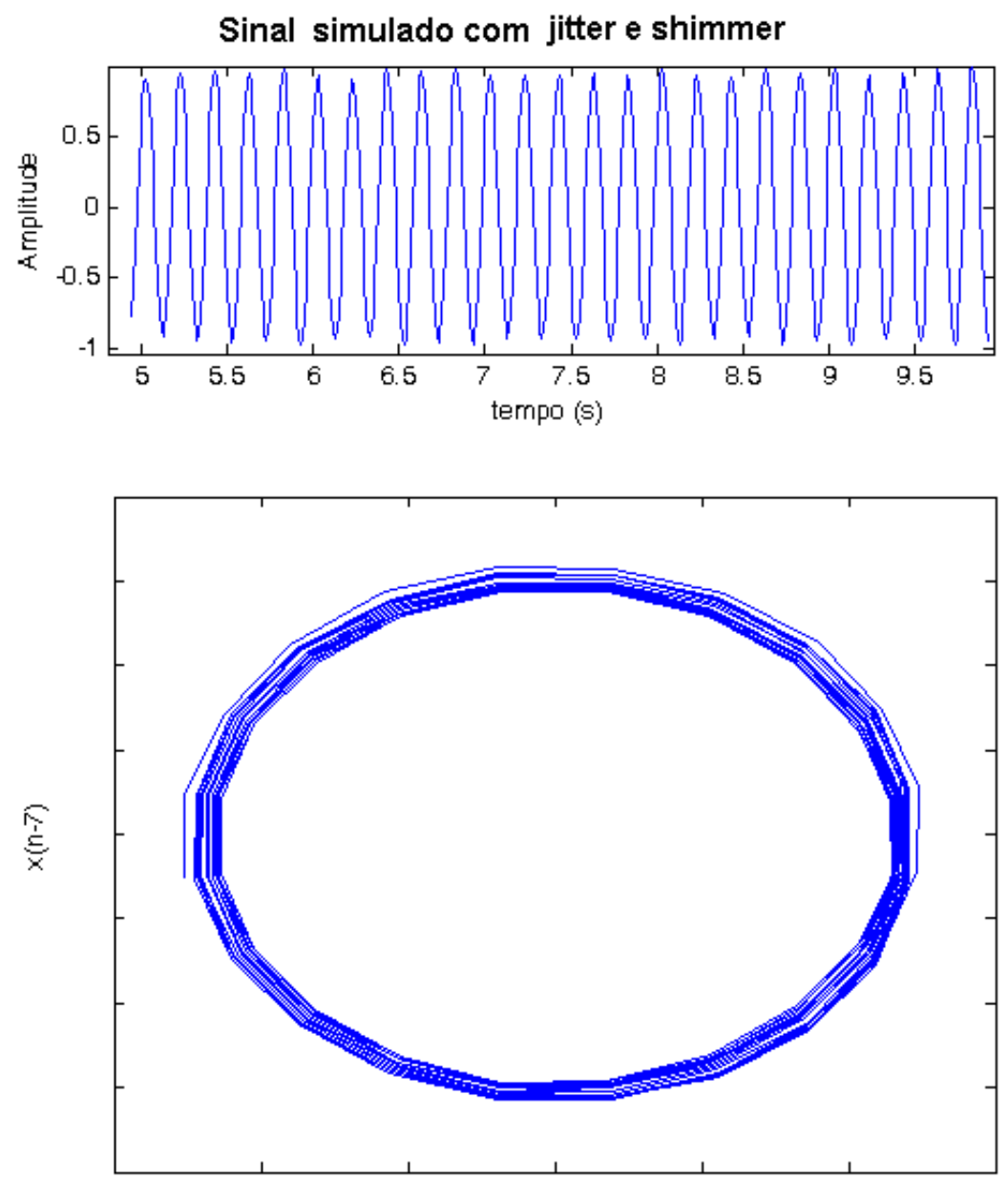

$x(n)$

Figura 3.13: Exemplo do PVDV de um sinal simulado de uma única freqüência e com acréscimo de $0,1 \%$ de jitter e $1 \%$ de shimmer.

Quando analisado um sinal de voz com predomínio de uma única freqüência e com as variações mínimas de jitter e shimmer esperadas para uma voz saudável, o PVDV obtido reflete uma dinâmica semelhante à obtida no sinal simulado com adição de perturbações. Na figura 3.14 é possível observar como um sinal de voz humano quase-periódico com vários ciclos é representado por um formato semi-arredondado de único laço (loop) e com traçados próximos um dos outros, mas que não convergem ponto a ponto. 
Portanto, num sinal de voz real qualquer variação - própria da voz humana - será projetada como uma discreta irregularidade nos traçados e/ou dispersão das trajetórias, como mostra o exemplo da figura 3.14 .
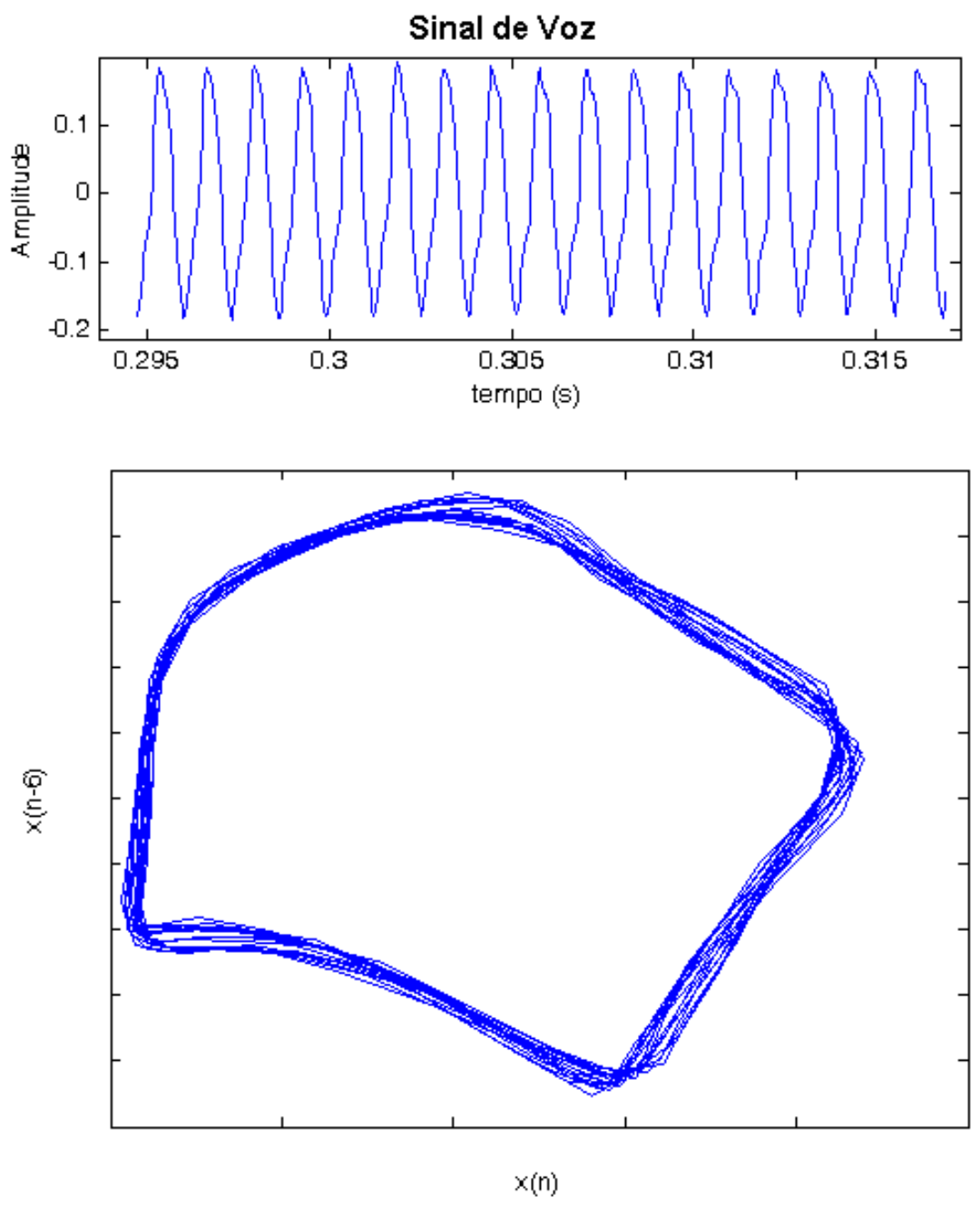

Figura 3.14: Exemplo do PVDV de um sinal de voz saudável, de uma vogal lil sustentada.

A figura 3.14 apresenta um trecho de sinal de voz (real) com 17 ciclos vocais de uma vogal sustentada /i/ de um sujeito sem queixa ou alteração vocal. Pode-se observar que no sinal no tempo é difícil enxergar a variação normal ciclo a ciclo; mas no Padrão Visual de Dinâmica Vocal (PVDV) as mínimas variações de cada período são evidenciadas claramente, fornecendo 
parâmetros dinâmicos para a avaliação de voz em vez de parâmetros médios como fazem outras ferramentas.

\section{Avaliação qualitativa dos PVDV}

Para avaliação qualitativa dos padrões visuais da dinâmica vocal foram considerados 3 aspectos da configuração: a) Número de laços (loops); b) Regularidade dos traçados e c) Convergência doa traçados,

a) Número de laços (loops):

Foi empregada uma escala gradativa descendente de 4 a 0 para avaliar o aspecto concernente aos loops da vogal /a/. É necessário mencionar que para avaliar o comportamento da vogal /a/ esta escala considera os PVDV com laços (loops) graus 4 e 3 como normais, devido a configuração do trato vocal da vogal /a/ do português brasileiro - por ser central e aberta - evidencia diferentes amplitudes em seus formantes (BEHLAU, 2001). Esta observação é fundamental, porque a configuração do PVDV estará fortemente relacionada com o formato de onda do sinal, e conseqüentemente com a conformação do trato vocal para produzir o som vocálico - neste caso da vogal /a/.

O exemplo da figura 3.15 mostra como os cinco picos da onda de um sinal de voz da vogal /a/ - relacionados com os formantes do sinal - estão representados na projeção bidimensional do PVDV mantendo a sua proporcionalidade. 

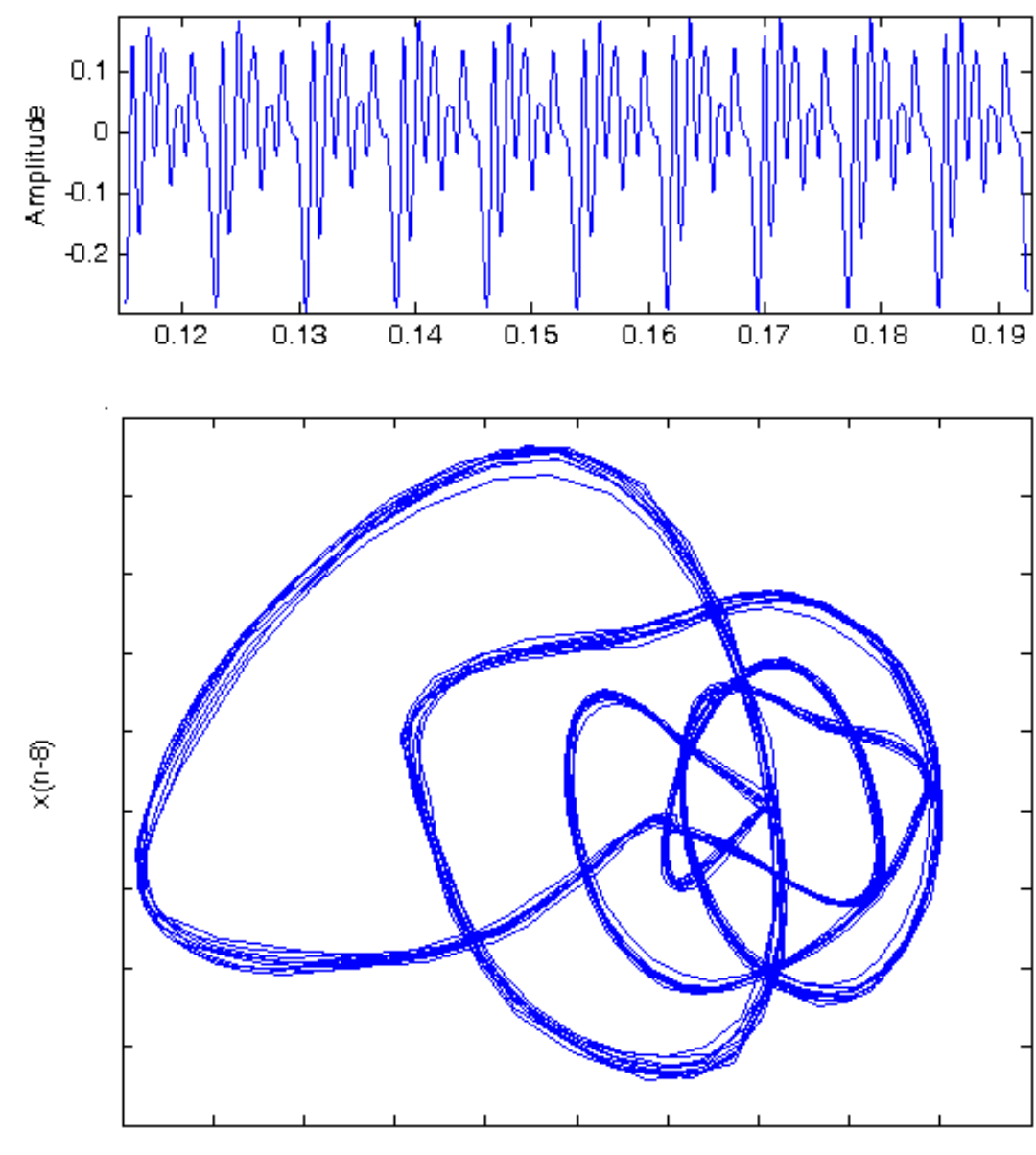

$x(n)$

Figura 3.15: Exemplo de uma vogal /a/ no tempo com seu respectivo PVDV de um sujeito sem queixa ou alteração vocal.

Ë importante mencionar que a escala proposta é uma subcategorização de uma determinada característica dinâmica observada, e não deve ser considerada uma escala gradativa linear. $\mathrm{Na}$ escala proposta o grau 4 corresponde a configurações que apresentem um número maior que 3 laços; grau 3 para 3 laços; grau 2 para configurações com 2 laços, o grau 1 refere-se a PVDV com 1 laços, e grau 0 corresponde à configurações onde não é possível avaliar a quantidade de laços. A figura 3.16 apresenta exemplos de PVDV de cada um dos graus contemplados pela escala para avaliar configuração de laços (loops). 


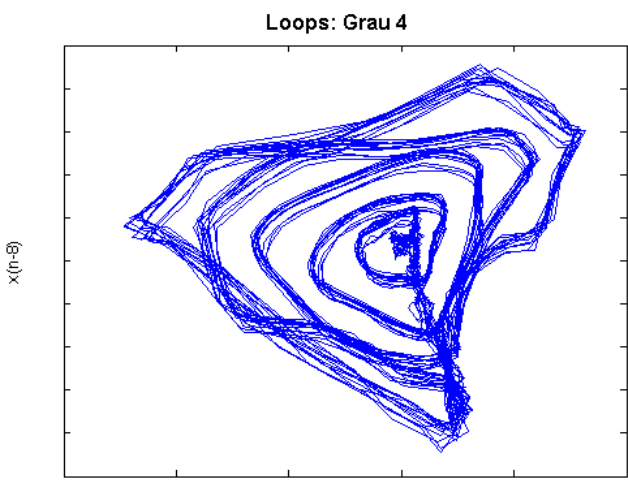

$x(n)$

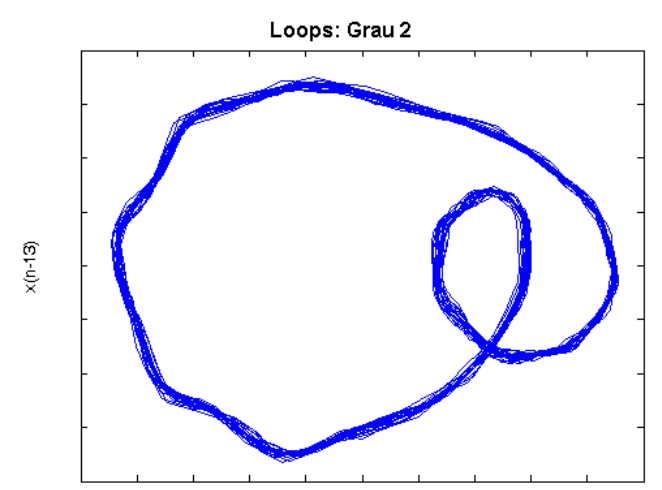

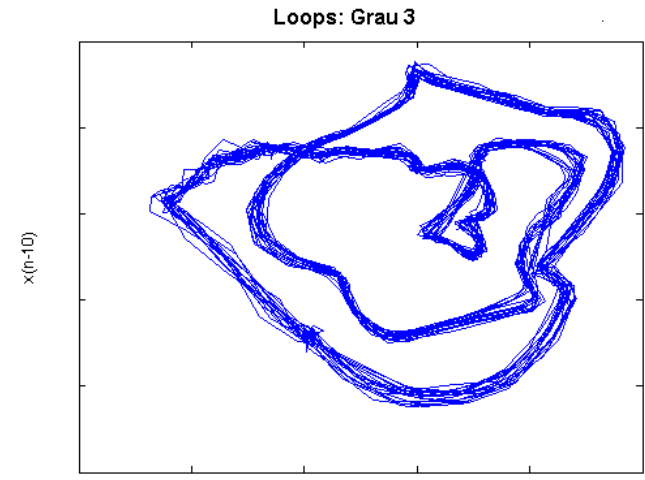

$x(n)$

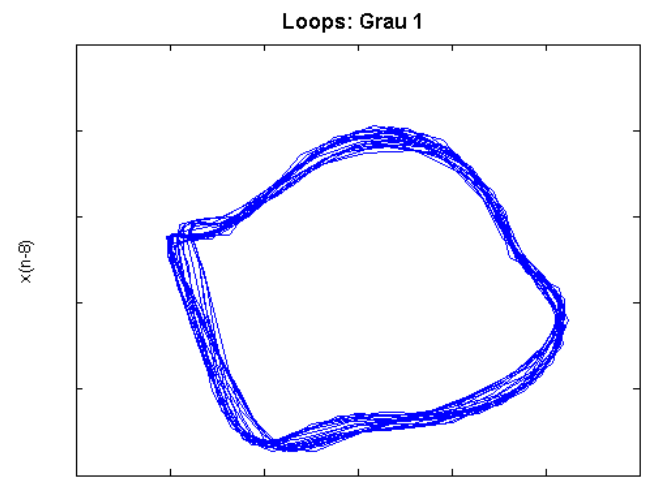

$x(n)$

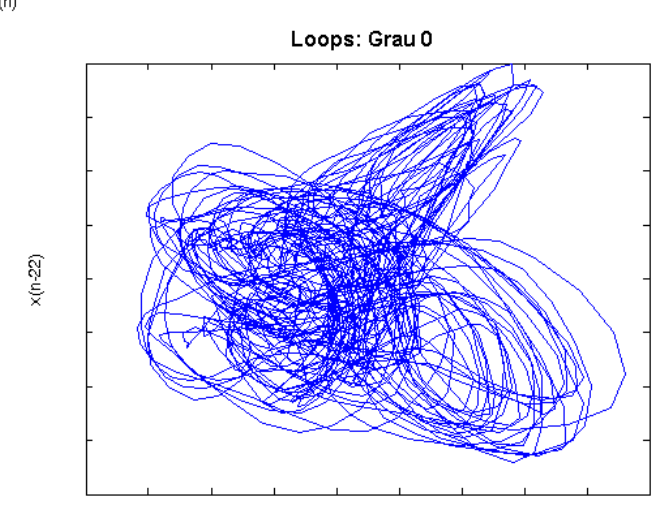

$x(n)$

Figura 3.16: Exemplos de graus de laçs dos PVDV. Grau 4- para configurações com mais de 3 laços; grau 3- para três laços ; grau 2- para dois laços; grau 1- para um laço e grau 0 - para número indefinido.

b) Regularidade dos traçados:

A diferença da classificação do número de laços - ligada à configuração do trato vocal para cada um dos sons vocálicos - a avaliação da regularidade dos traçados está ligada à presença de ruído no sinal de voz (SCALASSARA ET AL, 2009) e (DAJER, SOBRINHO, PEREIRA, 2010). Conseqüentemente, a 
escala proposta pode ser aplicada a qualquer uma das vogais. A transformação do sinal no tempo para o PVDV permite que seja possível observar ciclo a ciclo o comportamento do sinal respeito a mínimas perturbações de freqüência, amplitude e ruído.

Para classificar a regularidade dos traçados foi proposta uma escala gradativa descendente de 5 a 0 , onde grau 5 indica o máximo grau de regularidade, esperado para vozes sem alterações, e grau 0 indica o mínimo de regularidade ou completamente irregular, esperado em vozes com intensas alterações vocais. Para esta classificação é observada a dinâmica individual e geral dos traçados, com o objetivo de visualizar se estes são regulares e retilíneos ou apresentam algum grau de irregularidade ou desvios no percurso.

A figura 3.17 mostra um exemplo de um sinal de voz no tempo com presença de ruído e o correspondente PVDV. Nesta figura estão marcados os pontos $A$ e $B$ tanto no sinal no tempo como no PVDV. As diferenças são dificilmente detectáveis no sinal no tempo, mas no PVDV são evidenciadas pelo tipo de projeção. 

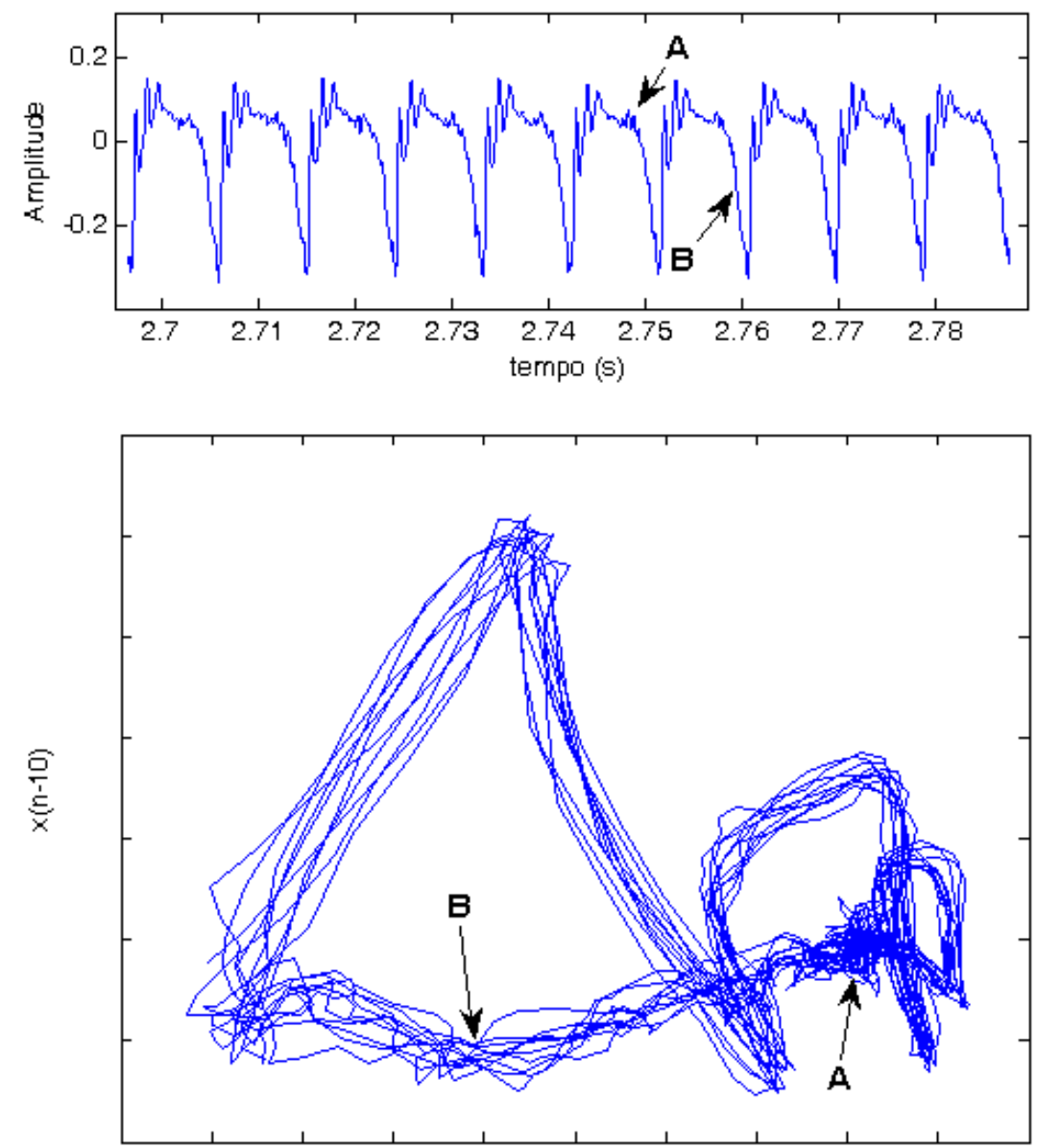

$x(n)$

Figura 3.17: Exemplo de um sinal de vogal /a/ no tempo (superior) e o respectivo PVDV de um sujeito com alteração vocal (inferior).

Nesta escala o grau 5 corresponde a traçados regulares ao longo de todo o percurso; o grau 4 corresponde a traçados regulares que apresentam comportamento irregular numa porção restrita do percurso; grau 3 indica uma regularidade intermitente dos traçados; o grau 2 é destinado para traçados com irregularidade leve global; ; o grau 1 corresponde a traçados com irregularidade leve e com um ou mais focos de irregularidade ao longo de todo o percurso e finalmente o grau 0 corresponde para configurações com irregularidade global nos traçados, isto é trajetórias rugosas ao longo de todo o percurso. A figura 3.18 mostra exemplos dos 6 graus de regularidade de traçados na avaliação 
qualitativa de padrões visuais de trechos de sinais de voz de 200 milissegundos da vogal sustentada /a/.
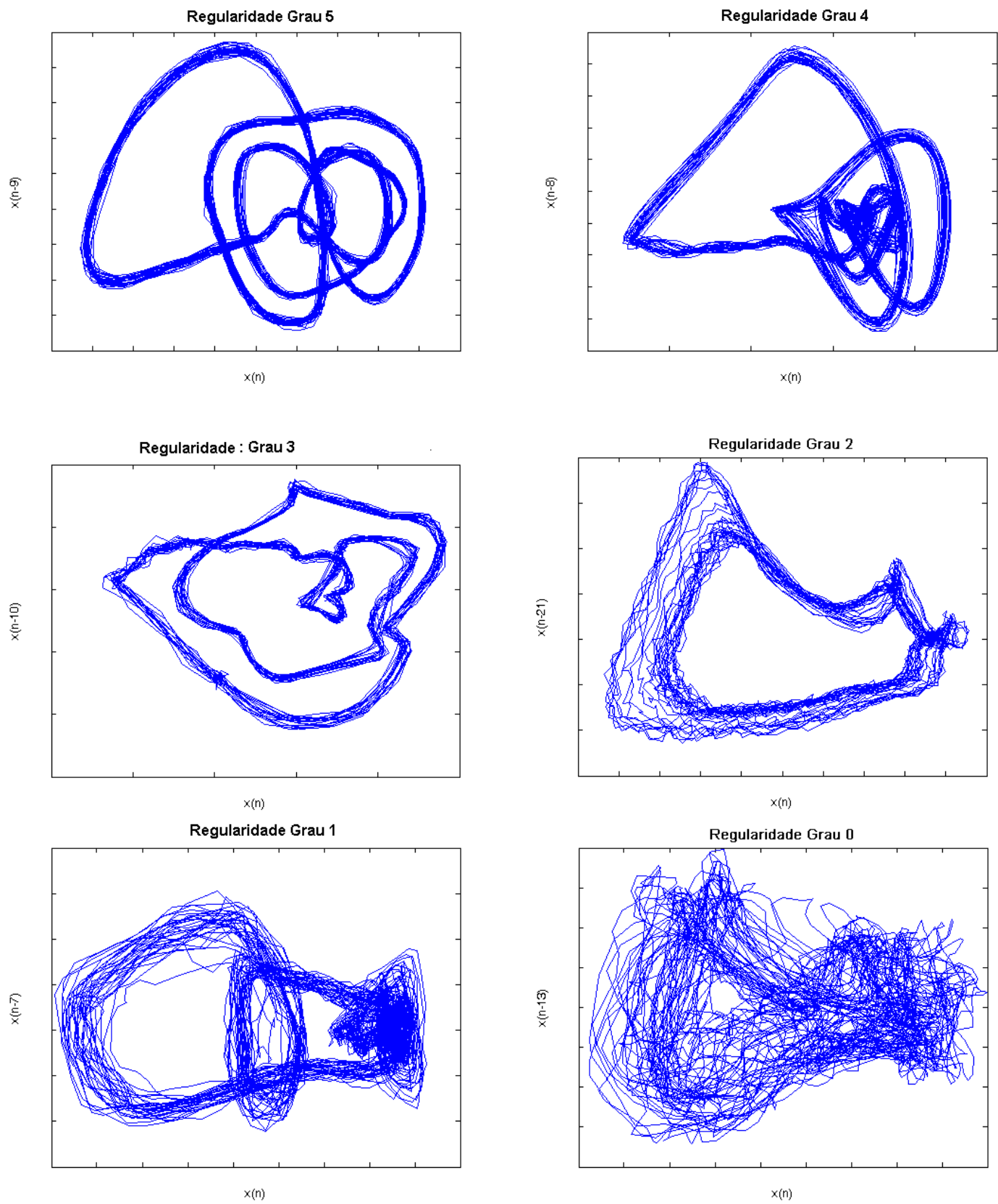

Figura 3.18: Exemplos dos graus de regularidade de traçados. Grau 5- traçado regulares em todo o percurso; grau 4- traçados regulares com uma porção de irregularidade; grau 3- regularidade intermitente; grau 2 - traçados levemente irregulares; grau 1- traçados levemente irregulares com região de irregularidade, e grau 0- para traçados irregulares em todo o percurso. 
c) Convergência dos traçados:

A convergência das traçados foi classificada com uma escala de 4 a 0 . 0 comportamento convergente das trajetórias está diretamente relacionado com a periodicidade do sinal de voz, e conseqüentemente os desvios observados na convergência estarão relacionados com perturbações de freqüência e amplitude do sinal de voz no tempo, como ilustra a figura 3.19. Nesta figura na parte superior encontra-se um trecho de um sinal de voz com variações mínimas no período e na amplitude do sinal; estas variações ficam mais evidentes quando projetada no PVDV, como mostra a parte inferior da figura. De modo geral, PVDV com configurações similares as da figura 3.19 correspondem a vozes com valores de jitter e shimmer alterados (JIANG ET AL, 2009), (SCALASSARA ET AL, 2009) e (DAJER, SOBRINHO, PEREIRA, 2010).

Para avaliar qualitativamente a convergência de um PVDV a escala propõe o grau 4 como maior grau de convergência e corresponde a trajetórias com forte convergência global, que tendem a passar repetidamente pelo mesmo ponto ou muito próximas dele. No outro extremo, o grau 0 (menor grau de convergência) corresponde para trajetórias com fraca convergência global, ou seja, ciclo a ciclo as trajetórias passam afastadas do mesmo ponto e é impossível distinguir os diferentes loops da configuração. Os graus 1, 2 e 3 representam trajetórias de convergência mista, onde a dinâmica dos traçados possuem características de forte e fraca convergência respectivamente, mas com diferentes combinações. 

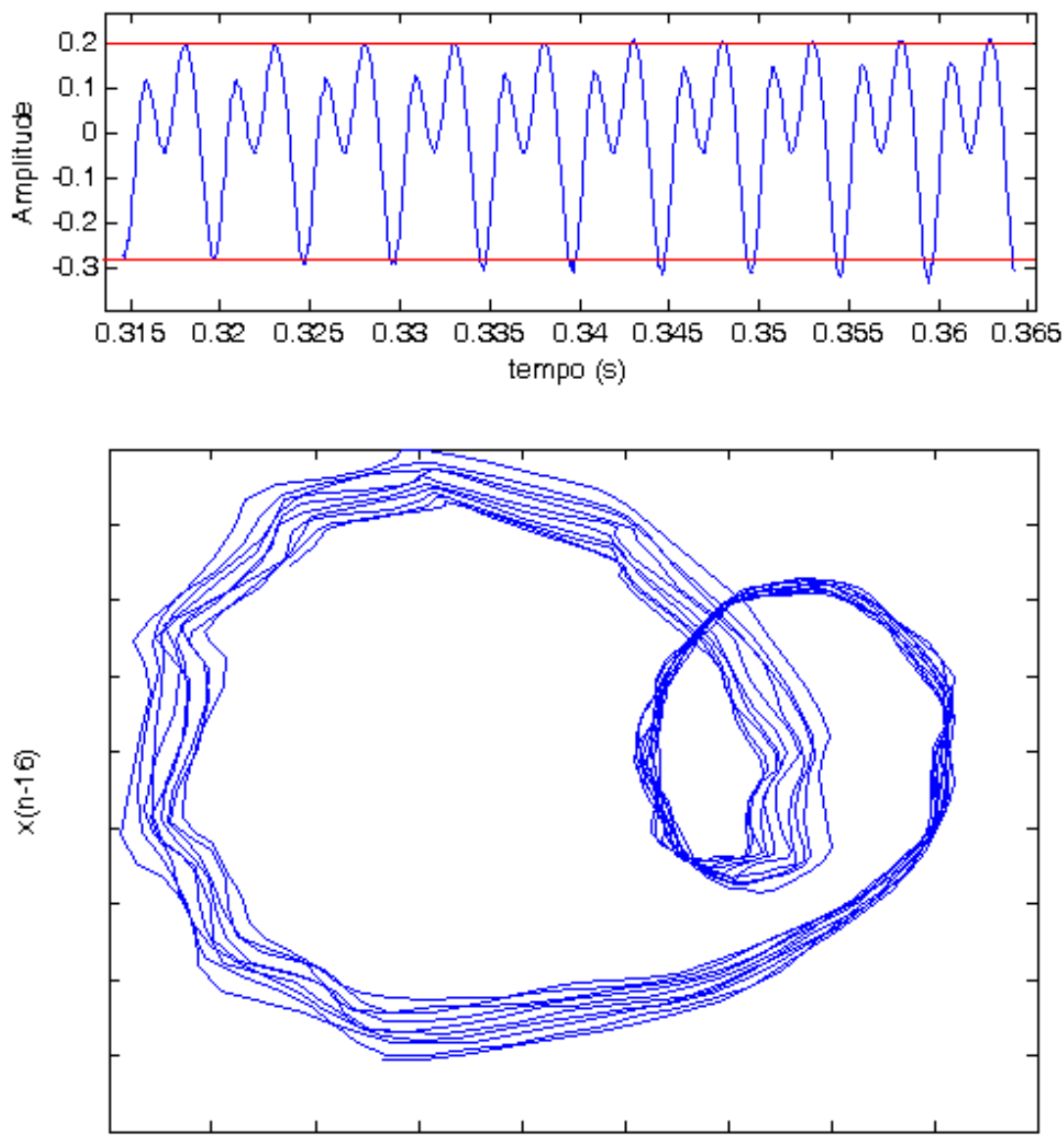

$x(n)$

Figura 3.19: Exemplo de uma vogal lel no tempo com seu respectivo Padrão Visual da Dinâmica Vocal de um sujeito com alteração vocal.

De forma detalhada, o grau 3 classifica os traçados com convergência de alta a media; ou seja, a maior parte do percurso com comportamento convergente mas com uma pequena porção de traçados espalhados entre si. 0 grau 2 refere-se a convergência media, onde o espalhamento dos traçados é evidente, apresenta algumas partes do percurso com maior convergência e é possível diferenciar a que laço (loop) pertencem os traçados. O grau 1 corresponde a traçados com convergência de media a fraca, são claramente mais dispersas, e é difícil identificar a qual laço (loop) corresponde cada traçado. A figura 3.20 apresenta exemplos dos 5 graus de convergência dos 
traçados para os PVDV da vogal sustentada la/ (trechos de 200 milissegundos).

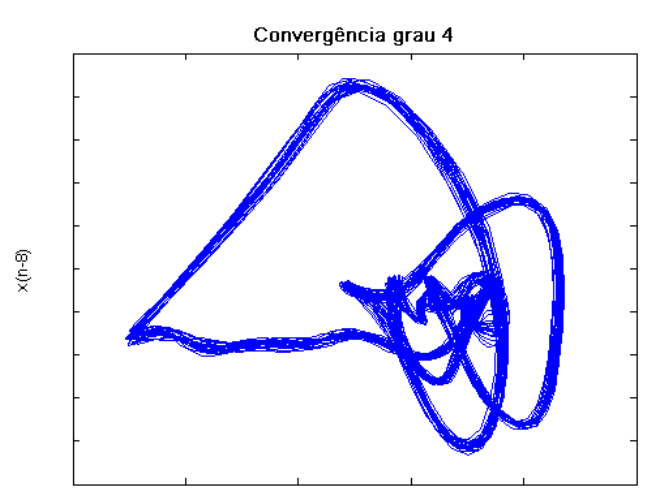

$x(n)$

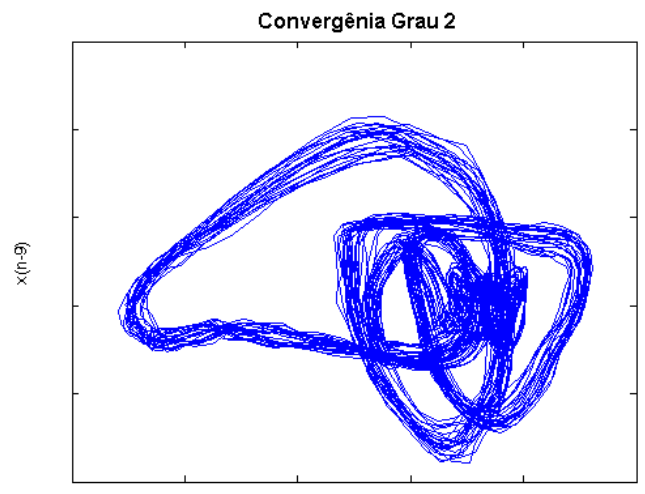

$x(n)$

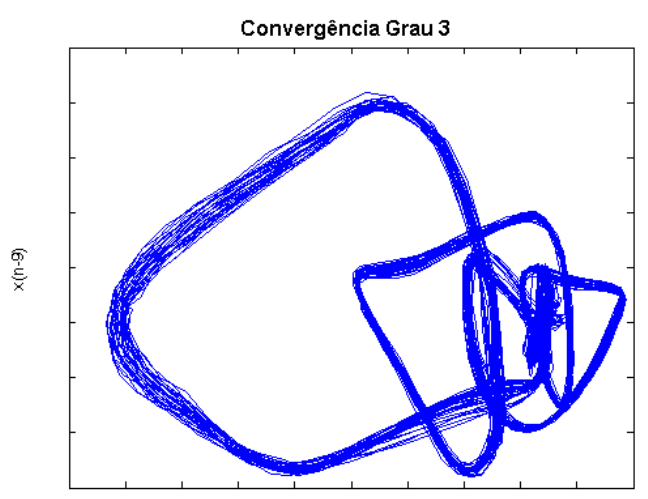

$x(n)$

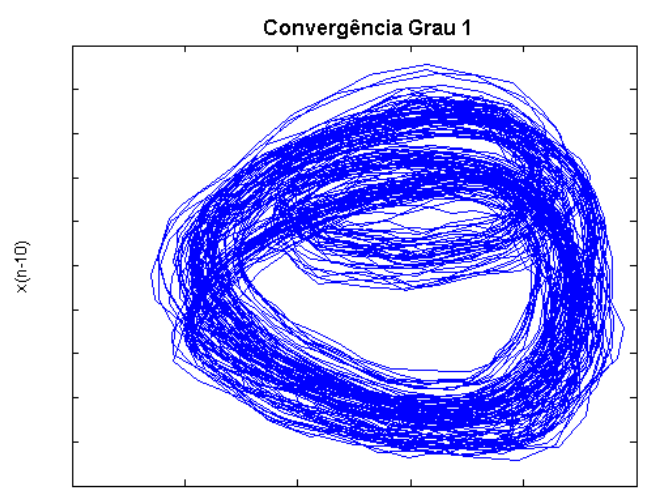

$x(n)$

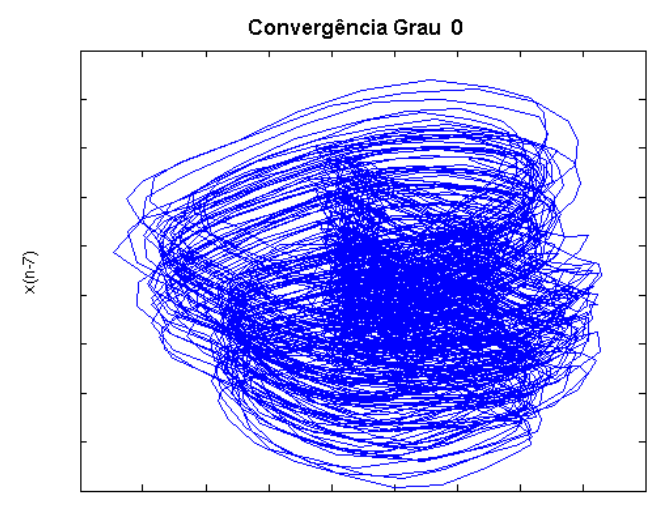

$x(n)$

Figura 3.20: Exemplos de PVDV com os 5 graus de convergência de traçados para sinais de voz da vogal sustentada la/. Onde o grau 4- apresenta uma forte convergência dos traçados e o grau 0- uma convergência fraca. Os graus 1, 2 e 3 são intermediários e mostram uma dinâmica de convergência mista.

Resumindo, a transformação de um sinal de voz no tempo para um PVDV permite ter acesso ponto a ponto à dinâmica intrínseca do sinal e avaliar qualitativamente o formato de onda, a perturbação de freqüência e amplitude, a 
presença de ruído e considerar também a fase do sinal. Esta dinâmica é caracterizada de acordo com os diferentes graus outorgados aos três aspectos observados no PVDV:

- Laços ou loops: este aspecto é avaliado como um todo, tendo em conta o número de "anéis" presente na configuração.

- Regularidade dos traçados das trajetórias: os traçados são avaliados individualmente ao longo de todo o percurso e de cada um dos ciclos plotados no PVDV, observando se são contínuos, homogêneos e retilíneos ou se apresentam uma dinâmica variável e heterogênea ao longo do tempo.

- Convergência dos traçados: os traçados são avaliados em conjunto, uns em relação aos outros e independentemente da regularidade. Deve-se observar se a partir do primeiro ciclo completo os traçados restantes repetem o percurso passando pelos mesmos pontos ou distantes deles.

A figura 3.21 exemplifica como é realizada a avaliação qualitativa de um PVDV considerando os diferentes graus de laços, regularidade e convergência dos traçados. O PVDV apresentado corresponde a um sinal de voz de um voluntário masculino sem patologia ou queixa vocal avaliado com grau 4 para laços, regularidade grau 4 e convergência grau 3. 


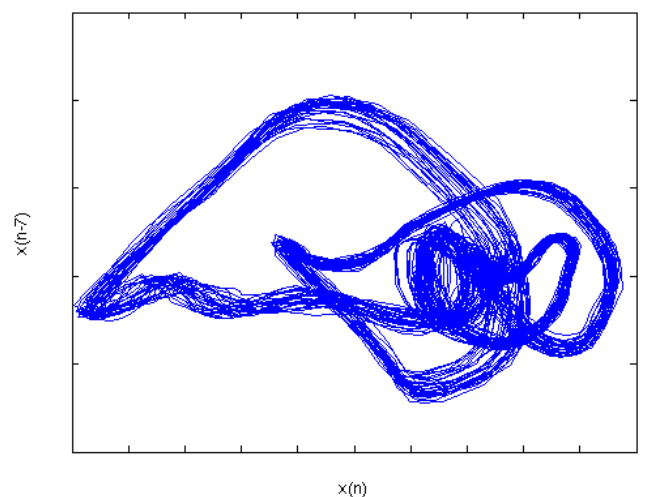

$x(n)$

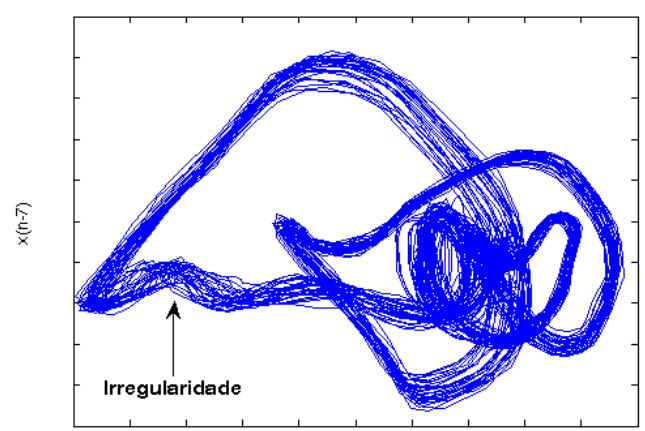

$x(n)$
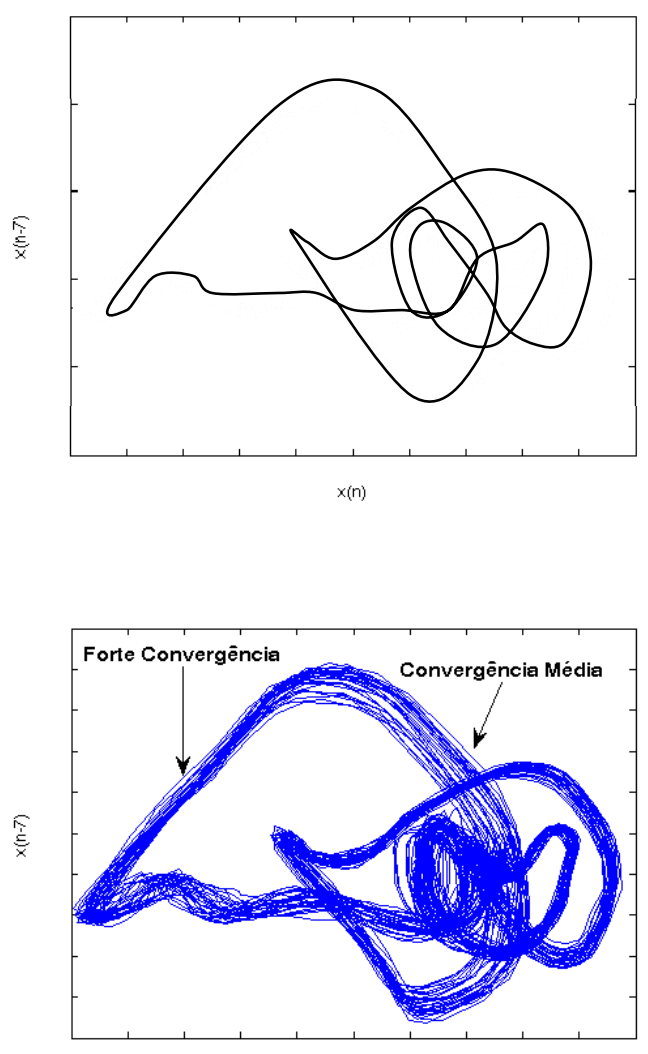

$x(n)$

\begin{tabular}{cc|cc|cc}
\hline Grau & LOOPS & Grau & TRAÇADO & Grau & CONVERGENCIA \\
\hline 0 & Indefinido & 0 & Irregular global & 0 & Fraca global \\
1 & 1 loop & 1 & Irregular leve c/ focos irregulares & 1 & Fraca a média \\
2 & 2 loops & 2 & Irregular leve global & 2 & Média \\
3 & 3 loops & 3 & Regular intermitente & $\mathbf{3}$ & Média a forte \\
$\mathbf{4}$ & + de 3 loops & $\mathbf{4}$ & Regular cl foco de irregularidade leve & 4 & Forte global \\
& 5 & Regularidade global & & \\
\hline \hline
\end{tabular}

Figura 3.21: Exemplo de avaliação qualitativa de um Padrão Visual da Dinâmica Vocal de um trecho de voz de $\mathbf{2 0 0}$ milissegundos de um voluntário sem patologia ou queixa vocal. 
4 RESULTADOS

\subsection{Análise perceptivo-auditiva}

Para avaliação perceptivo-auditiva de cada parâmetro foi empregada uma escala de graus que varia de 0 à 3 . Sendo que o grau 0 é empregado quando nenhuma alteração vocal é percebida pelo ouvinte e pode ser considerado normal; o grau 1 é reservado para alterações vocais discretas; o grau 2 para alterações moderadas e o grau 3 para alterações vocais intensas. Os resultados foram analisados com o teste não-paramétrico de Kruskal-Wallis e o teste de comparação múltipla, ou teste de Dunn, ambos com 0,05 de significância.

\subsubsection{Vozes saudáveis}

Os dezesseis sinais de voz saudáveis apresentaram grau 0 ou 1 para os 4 parâmetros avaliados. Para rugosidade doze amostras (75\%) foram avaliadas com grau 1 e quatro amostras (25\%) com grau 0 . Para soprosidade nove sinais de voz $(56,25 \%)$ foram avaliadas com grau 1 e sete sinais $(43,75 \%)$ com grau 0. Treze sinais $(81,25 \%)$ foram avaliadas com tensão grau 0 e três sinais $(18,75 \%)$ com tensão grau 1 . Somente duas amostras (12,5\%) foram avaliadas com grau 0 de instabilidade e as restantes, 14 vozes $(87,5 \%)$, com instabilidade grau 1. A tabela 4-1 mostra os resultados da avaliação perceptivo-auditiva para 
os parâmetros de rugosidade (R), soprosidade (S), tensão (T) e Instabilidade (I) para cada amostra do grupo de vozes saudáveis.

Tabela 4-1: Resultados da avaliação perceptivo-auditiva dos sinais saudáveis.

\begin{tabular}{ccccc}
\hline Sinal de Voz & $\mathbf{R}$ & $\mathbf{S}$ & $\mathbf{T}$ & $\mathbf{I}$ \\
\hline Sinal 01 & 1 & 1 & 0 & 0 \\
Sinal 02 & 0 & 1 & 0 & 1 \\
Sinal 03 & 0 & 1 & 0 & 1 \\
Sinal 04 & 1 & 0 & 0 & 0 \\
Sinal 05 & 1 & 0 & 1 & 1 \\
Sinal 06 & 1 & 1 & 1 & 1 \\
Sinal 07 & 1 & 1 & 0 & 1 \\
Sinal 08 & 1 & 0 & 1 & 1 \\
Sinal 09 & 1 & 1 & 0 & 1 \\
Sinal 10 & 1 & 1 & 0 & 1 \\
Sinal 11 & 0 & 1 & 0 & 1 \\
Sinal 12 & 1 & 0 & 0 & 1 \\
Sinal 13 & 1 & 1 & 0 & 1 \\
Sinal 14 & 1 & 0 & 0 & 1 \\
Sinal 15 & 0 & 0 & 0 & 1 \\
Sinal 16 & 1 & 0 & 0 & 1 \\
\hline \hline
\end{tabular}

Legenda: R (rugosidade); S (soprosidade); T (tensão) e I (instabilidade)

\subsubsection{Voz normal com mudanças posturais}

Foram analisados 30 trechos de sinais de voz de um mesmo sujeito, na emissão confortável da vogal sustentada /a/ em três posturas: 1) 10 sinais na postura neutra, 2) 10 sinais com anteriorização de cabeça com extensão do pescoço e 3) 10 sinais com aumento da cifose toráxica com anteriorização de cabeça. 
$\mathrm{Na}$ análise perceptivo-auditiva as 10 vozes das três posturas apresentaram grau 0 ou 1 para os 4 parâmetros avaliados. Sendo que nove (90\%) das amostras da postura 1 (postura neutra) foram avaliadas com todos os parâmetros em 0 e um sinal com T grau 1. Na postura 2, cinco sinais $(50 \%)$ foram avaliados com todos os parâmetros em 0 ; três sinais $(30 \%)$ com tensão grau 1 e duas vozes (20\%) com R grau 1. Na postura 3, duas amostras $(20 \%)$ foram classificadas com $\mathrm{R}$ grau 1 e as amostras restantes (80\%) com todos os parâmetros em 0. A tabela 4-2 mostra a avaliação perceptivo-auditiva de cada amostra de voz nas três posturas.

Tabela 4-2: Avaliação perceptivo-auditiva dos sinais de voz com três posturas nos 10 dias de coleta.

\begin{tabular}{c|cccc|cccc|cccc}
\hline & \multicolumn{4}{|c|}{ POSTURA 1 } & \multicolumn{3}{c|}{ POSTURA 2 } & \multicolumn{3}{c}{ POSTURA 3 } \\
\hline Dia & R & S & T & I & R & S & T & I & R & S & T & I \\
\hline 1 & 0 & 0 & 0 & 0 & 0 & 0 & 0 & 0 & 0 & 0 & 0 & 0 \\
2 & 0 & 0 & 0 & 0 & 0 & 0 & 0 & 0 & 0 & 0 & 0 & 0 \\
3 & 0 & 0 & 0 & 0 & 0 & 0 & 0 & 0 & 0 & 0 & 0 & 0 \\
4 & 0 & 0 & 0 & 0 & 0 & 0 & 0 & 0 & 0 & 0 & 0 & 0 \\
5 & 0 & 0 & 0 & 0 & $\mathbf{1}$ & 0 & 0 & 0 & $\mathbf{1}$ & 0 & 0 & 0 \\
6 & 0 & 0 & 0 & 0 & $\mathbf{1}$ & 0 & 0 & 0 & $\mathbf{1}$ & 0 & 0 & 0 \\
7 & 0 & 0 & 0 & 0 & 0 & 0 & $\mathbf{1}$ & 0 & 0 & 0 & 0 & 0 \\
8 & 0 & 0 & 0 & 0 & 0 & 0 & 0 & 0 & 0 & 0 & 0 & 0 \\
9 & 0 & 0 & 0 & 0 & 0 & 0 & $\mathbf{1}$ & 0 & 0 & 0 & 0 & 0 \\
10 & 0 & 0 & $\mathbf{1}$ & 0 & 0 & 0 & $\mathbf{1}$ & 0 & 0 & 0 & 0 & 0 \\
\hline \hline
\end{tabular}

Legenda: R (rugosidade); S (soprosidade); T (tensão) e I (instabilidade)

O teste não-paramétrico de Kruskal-Wallis mostrou que os valores de $\mathrm{H}_{\text {corrigido }}$ foram inferiores à $\mathrm{H}_{\text {crítico }}$ de 5,99 para 0,05 de significância; por tanto se aceita a hipótese nula e os três grupos podem ser considerados iguais. 


\subsubsection{Vozes patológicas}

Foi realizada a análise perceptivo-auditiva de 46 amostras de vozes com alterações patológicas. Destas amostras, 31 são sinais de voz com disfonia de origem organofuncional (16 sinais de edema de Reinke e 15 de nódulos vocais); e 14 amostras são vozes com disfonia de origem neurológica.

\subsubsection{Vozes com disfonia organofuncional}

\section{Edema}

Nove vozes $(56,25 \%)$ foram avaliadas com grau 2 para rugosidade, seis $(37,5 \%)$ com rugosidade grau 1 e um sinal $(6,25 \%)$ com rugosidade grau 0. Para soprosidade três vozes $(18,75 \%)$ apresentaram grau 2 , onze vozes $(68,75 \%)$ grau 1 e duas vozes (12,5\%) grau 0. Quinze amostras $(93,75 \%)$ foram classificadas com grau 0 de tensão e somente um sinal $(6,25 \%)$ apresentou tensão grau 2. Onze vozes (68,75\%) receberam grau 1 de instabilidade e cinco vozes $(31,25 \%)$ instabilidade grau 2 .

Na tabela 4-3 estão os resultados da avaliação perceptivo-auditiva das vozes com edema de Reinke. 
Tabela 4-3: Avaliação perceptivo-auditiva das vozes com edema de Reinke.

\begin{tabular}{ccccc}
\hline Sinal de Voz & $\mathbf{R}$ & $\mathbf{S}$ & $\mathbf{T}$ & $\mathbf{I}$ \\
\hline paciente 1 & 1 & 2 & 0 & 2 \\
paciente 2 & 1 & 0 & 0 & 1 \\
paciente 3 & 1 & 1 & 0 & 1 \\
paciente 4 & 2 & 1 & 0 & 2 \\
paciente 5 & 2 & 1 & 0 & 2 \\
paciente 6 & 1 & 2 & 0 & 1 \\
paciente 7 & 2 & 1 & 0 & 1 \\
paciente 8 & 2 & 1 & 2 & 2 \\
paciente 9 & 0 & 0 & 0 & 1 \\
paciente 10 & 2 & 1 & 0 & 1 \\
paciente 11 & 2 & 1 & 0 & 1 \\
paciente 12 & 1 & 1 & 0 & 1 \\
paciente 13 & 2 & 1 & 0 & 1 \\
paciente 14 & 2 & 1 & 0 & 2 \\
paciente 15 & 1 & 2 & 0 & 1 \\
paciente 16 & 2 & 1 & 0 & 1 \\
\hline \hline
\end{tabular}

Legenda: R (rugosidade); S (soprosidade); T (tensão) e I (instabilidade

\section{Nódulos vocais}

Neste grupo onze $(73,33 \%)$ apresentaram rugosidade grau 1 , duas vozes $(13,33 \%)$ grau 2 , um sinal $(6,66 \%)$ com grau 3 e um sinal $(6,66 \%)$ com grau 0. Para soprosidade nove vozes (60\%) foram classificadas com grau 2 e seis vozes $(40 \%)$ com soprosidade grau 1 . Nenhum sinal apresentou grau 0 ou grau 3. Onze sinais $(73,33 \%)$ foram classificados com grau 0 de tensão; três sinais $(20 \%)$ com grau 1 e uma voz $(6,66 \%)$ com grau 2 ; não teve amostras classificadas com tensão grau 3. Doze vozes (80\%) foram avaliadas com instabilidade grau 1 , dois sinais $(13,33 \%)$ com grau 2 e uma voz $(6,66 \%)$ com 
grau 0; nenhum amostra foi avaliadas com grau 3 de instabilidade. A avaliação para cada sinal de voz encontra-se na tabela 4-4.

Tabela 4-4: Resultados da avaliação perceptivo-auditiva dos sinais com nódulo vocal.

\begin{tabular}{ccccc}
\hline Sinal de Voz & R & S & T & I \\
\hline Paciente 1 & 1 & 2 & 0 & 1 \\
Paciente 2 & 1 & 2 & 0 & 1 \\
Paciente 3 & 1 & 2 & 0 & 1 \\
Paciente 4 & 1 & 2 & 0 & 1 \\
Paciente 5 & 1 & 1 & 0 & 1 \\
Paciente 6 & 1 & 1 & 0 & 0 \\
Paciente 7 & 2 & 2 & 2 & 2 \\
Paciente 8 & 1 & 2 & 1 & 1 \\
Paciente 9 & 1 & 1 & 0 & 1 \\
Paciente 10 & 2 & 2 & 1 & 1 \\
Paciente 11 & 1 & 1 & 0 & 1 \\
Paciente 12 & 1 & 1 & 0 & 1 \\
Paciente 13 & 3 & 2 & 1 & 2 \\
Paciente 14 & 0 & 1 & 0 & 1 \\
Paciente 15 & 1 & 2 & 0 & 1 \\
\hline \hline
\end{tabular}

Legenda: R (rugosidade); S (soprosidade); T (tensão) e I (instabilidade)

\subsubsection{Vozes com disfonia orgânica de origem neurológica}

Neste grupo, oito sinais $(57,14 \%)$ apresentaram grau 1 para rugosidade; cinco sinais $(35,71 \%)$ com grau 2 ; e uma voz $(7,15 \%)$ com grau 0 . Para soprosidade oito vozes $(57,14 \%)$ foram avaliadas com grau 1 , cinco $(35,71 \%)$ com grau 2 e um sinal $(7,15 \%)$ com grau 0 . Seis sinais $(42,85 \%)$ foram avaliadas com grau 0 de tensão, um sinal de voz $(7,15 \%)$ com grau 2 e sete vozes (50\%) com grau 1 de tensão. Para instabilidade nove vozes $(64,29 \%)$ 
apresentaram grau 1 e cinco sinais de voz $(35,71 \%)$ com grau 2 . Nenhuma voz foi avaliada com grau 3 para os quatro parâmetros analisados; e para instabilidade nenhuma voz foi avaliada com grau 0 . Os resultados desta avaliação encontram-se na tabela 4-5.

Tabela 4-5: Avaliação perceptivo-auditiva das vozes com disfonia neurológica.

\begin{tabular}{ccccc}
\hline Sinal de Voz & R & S & T & I \\
\hline Paciente 1 & 2 & 2 & 1 & 2 \\
Paciente 2 & 1 & 1 & 2 & 1 \\
Paciente 3 & 2 & 1 & 0 & 1 \\
Paciente 4 & 1 & 1 & 0 & 1 \\
Paciente 5 & 1 & 1 & 1 & 2 \\
Paciente 6 & 2 & 2 & 0 & 1 \\
Paciente 7 & 1 & 2 & 0 & 1 \\
Paciente 8 & 0 & 1 & 0 & 1 \\
Paciente 9 & 1 & 1 & 0 & 1 \\
Paciente 10 & 1 & 0 & 1 & 1 \\
Paciente 11 & 2 & 2 & 1 & 2 \\
Paciente 12 & 1 & 1 & 1 & 2 \\
Paciente 13 & 2 & 2 & 1 & 2 \\
Paciente 14 & 1 & 1 & 1 & 1 \\
\hline \hline
\end{tabular}

Legenda: R (rugosidade); S (soprosidade); T (tensão) e I (instabilidade)

Foi aplicado o teste de KrusKal-Wallis para comparação dos grupos: saudáveis, edema de Reinke, nódulos vocais e disfonia neurológica. O teste mostrou que os $\mathrm{H}_{\text {corrigido }}$ dos parâmetros de rugosidade, soprosidade, tensão e instabilidade foram maiores ao $\mathrm{H}_{\text {tabela }}$ de 7,81 para 0,05 de significância, rejeitando-se então, a hipótese nula. 
O procedimento de comparações múltiplas demonstrou que a diferença para a rugosidade ocorreu para o grupo de saudáveis vs. Edema de Reinke que obteve um $Q_{\text {calculado }}=2,7221$, maior que $Q(0,05 ; 4)=2,64$. Para soprosidade, a diferença foi encontrada entre os grupos de saudáveis vs. nódulo com $Q_{\text {calculado }}=4,3567$; e para saudáveis vs. disfonias neurológicas com $Q_{\text {calculado }}=$ 2,9457 , ambos valores superiores a $\mathrm{Q}(0,05 ; 4)=2,64$. Para tensão a diferença foi obtida para edema de Reinke vs. disfonia neurológica com $Q_{\text {calculado }}=3,1156$. Para Instabilidade os grupos que diferiram foram edema de Reinke vs. disfonia neurológica com $Q_{\text {calculado }}=4,9271$; e edema de Reinke vs. nódulos com $Q_{\text {calculado }}=3,7031$. As restantes combinações dos quatro parâmetros analisados obtiveram valores menores ao $Q_{\text {tabela }}$ de 2,64 , e por tanto, foram considerados sem diferença estatística.

\subsection{Análise Acústica}

A nova versão do programa Análise de voz (MONTAGNOLI, PEREIRA, 2009) considera que porcentagens iguais ou inferiores a $0,35 \%$ de jitter (perturbação da frequência) e iguais ou inferiores a 2,25\% de shimmer (perturbação da amplitude) são os valores aceitáveis para vozes sem patologia vocal. Os resultados dos parâmetros jitter e shimmer foram analisados com o teste estatístico da variância ANOVA unilateral com 0,05 de significância; os resultados da freqüência fundamental $\left(F_{0}\right)$ para os grupos de vozes normais, edema de Reinke, nódulos e disfonia de origem neurológica não receberam tratamento estatístico por serem grupos heterogêneos respeito ao gênero. 


\subsubsection{Vozes normais}

Os valores encontrados para jitter foram: mínimo de 0,1\%; máximo de 0,35\%, média de $0,18 \%$ com desvio padrão de 0,05 . Para shimmer os valores médios foram: mínimo de 0,53\%; máximo de 2,25\%; média de 1,12\% com desvio padrão de $0,39 \%$. O resultado da freqüência fundamental para as vozes femininas foi mínimo de 193,80 Hz, máximo de 260,90 Hz; média de 219,70 Hz com desvio padrão de $26,90 \mathrm{~Hz}$. Os valores médios das vozes masculinas foram: mínimo de $99 \mathrm{~Hz}$; máximo de 133,90 Hz; média de 117,63 Hz com desvio padrão de 10,49 Hz. Os valores médios para jitter, shimmer e freqüência fundamental deste grupo encontram-se na tabela 4-6.

Tabela 4-6: Resultados de jitter, shimmer e $F_{0}$ das 16 vozes saudáveis.

\begin{tabular}{cccc}
\hline Sinal de voz & Jitter $(\%)$ & Shimmer $(\%)$ & $\mathbf{F}_{\mathbf{0}}(\mathbf{H z})$ \\
\hline Sinal 01 & 0,35 & 1,25 & 118,45 \\
Sinal 02 & 0,10 & 0,53 & 116,30 \\
Sinal 03 & 0,17 & 0,96 & 226,40 \\
Sinal 04 & 0,20 & 1,12 & 197,70 \\
Sinal 05 & 0,11 & 0,83 & 115,90 \\
Sinal 06 & 0,19 & 0,93 & 99,00 \\
Sinal 07 & 0,22 & 2,25 & 117,90 \\
Sinal 08 & 0,24 & 1,08 & 107,40 \\
Sinal 09 & 0,18 & 1,33 & 108,45 \\
Sinal 10 & 0,14 & 0,91 & 122,90 \\
Sinal 11 & 0,18 & 0,68 & 193,80 \\
Sinal 12 & 0,15 & 0,94 & 219,70 \\
Sinal 13 & 0,18 & 1,44 & 133,85 \\
Sinal 14 & 0,18 & 1,43 & 133,90 \\
Sinal 15 & 0,20 & 1,12 & 260,90 \\
Sinal 16 & 0,15 & 1,23 & 119,90 \\
\hline \hline
\end{tabular}




\subsubsection{Normais com diferentes posturas}

Os valores médios de jitter foram para postura 1: máximo de 0,17\%; mínimo de 0,11\%; média de 0,126\% e desvio padrão de 0,02\%. Para postura 2, máximo de 0,16\%; mínimo de 0,11\%; média de $0,13 \%$ e desvio padrão de 0,01\%. Para a postura 3, os valores médios de jitter foram: máximo de $0,17 \%$; mínimo de $0,11 \%$; média de $0,12 \%$ e desvio padrão de $0,01 \%$. Os valores médios de cada amostra das 3 posturas encontram-se na tabela 4-7.

Tabela 4-7: Valores médios de jitter (\%) das amostras de voz nas três posturas.

\begin{tabular}{cccc}
\hline Dia & $\begin{array}{c}\text { Postura 1 } \\
\text { (Jitter \%) }\end{array}$ & $\begin{array}{c}\text { Postura 2 } \\
\text { (jitter \%) }\end{array}$ & $\begin{array}{c}\text { Postura 3 } \\
\text { (jitter\%) }\end{array}$ \\
\hline Dia 1 & 0,170 & 0,160 & 0,150 \\
Dia 2 & 0,160 & 0,130 & 0,110 \\
Dia 3 & 0,115 & 0,130 & 0,130 \\
Dia 4 & 0,120 & 0,125 & 0,120 \\
Dia 5 & 0,120 & 0,125 & 0,110 \\
Dia 6 & 0,125 & 0,150 & 0,110 \\
Dia 7 & 0,110 & 0,115 & 0,120 \\
Dia 8 & 0,120 & 0,140 & 0,170 \\
Dia 9 & 0,110 & 0,130 & 0,110 \\
Dia 10 & 0,110 & 0,120 & 0,110 \\
\hline \hline
\end{tabular}

O resultado do Teste Anova (unilateral), com significância de 0,05, para jitter mostrou que para $F=0,55$ o p-valor é 0,5816 , e por tanto, sem diferença estatística. A distribuição dos dados encontra-se na figura 4.1. 


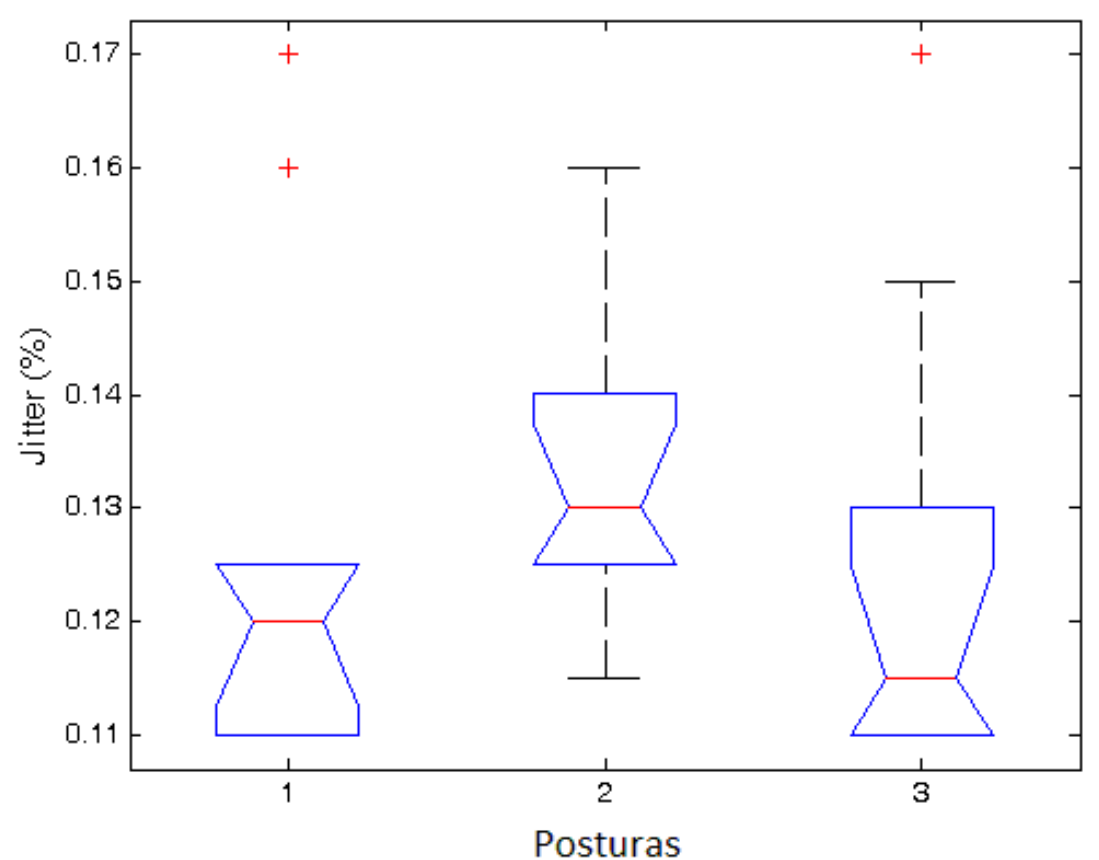

Figura 4.1: Gráfico de distribuição de valores de jitter para: 1- Postura neutra, 2- postura com anteriorização de cabeça com extensão do pescoço e 3 postura com aumento da cifose toráxica com anteriorização de cabeça.

Os valores médios para shimmer das três posturas foram: postura 1 máximo de 0,75\%; mínimo de 0,36\%; média de 0,58\% e desvio padrão de 0,12\%. Para a postura 2: máximo de $0,94 \%$, mínimo de $0,32 \%$, média de $0,55 \%$ e desvio padrão de $0,21 \%$. Por último, para a postura 3 , máximo de 0,87\%, mínimo de $0,31 \%$; média de $0,49 \%$ e desvio padrão $0,17 \%$.

A tabela 4-8 apresenta os valores médios de shimmer para cada voz nas três posturas avaliadas. 
Tabela 4-8: Valores médios de shimmer (\%) das amostras de voz nas três posturas.

\begin{tabular}{cccc}
\hline dia & $\begin{array}{c}\text { Postura 1 } \\
\text { (shimmer \%) }\end{array}$ & $\begin{array}{c}\text { Postura 2 } \\
\text { (shimmer \%) }\end{array}$ & $\begin{array}{c}\text { Postura 3 } \\
\text { (shimmer \%) }\end{array}$ \\
\hline dia 1 & 0,71 & 0,92 & 0,74 \\
dia 2 & 0,72 & 0,94 & 0,87 \\
dia 3 & 0,52 & 0,49 & 0,34 \\
dia 4 & 0,59 & 0,51 & 0,43 \\
dia 5 & 0,36 & 0,32 & 0,31 \\
dia 6 & 0,44 & 0,34 & 0,31 \\
dia 7 & 0,75 & 0,51 & 0,55 \\
dia 8 & 0,55 & 0,45 & 0,47 \\
dia 9 & 0,66 & 0,42 & 0,41 \\
dia 10 & 0,45 & 0,67 & 0,54 \\
\hline \hline
\end{tabular}

O Teste Anova com 0,05 de significância, mostrou que para $\mathrm{F}=0,5$ e o p-valor é 0,6119, ou seja sem diferencia estatística. A figura 4.2 apresenta a distribuição de valores encontrados para shimmer nas três posturas.

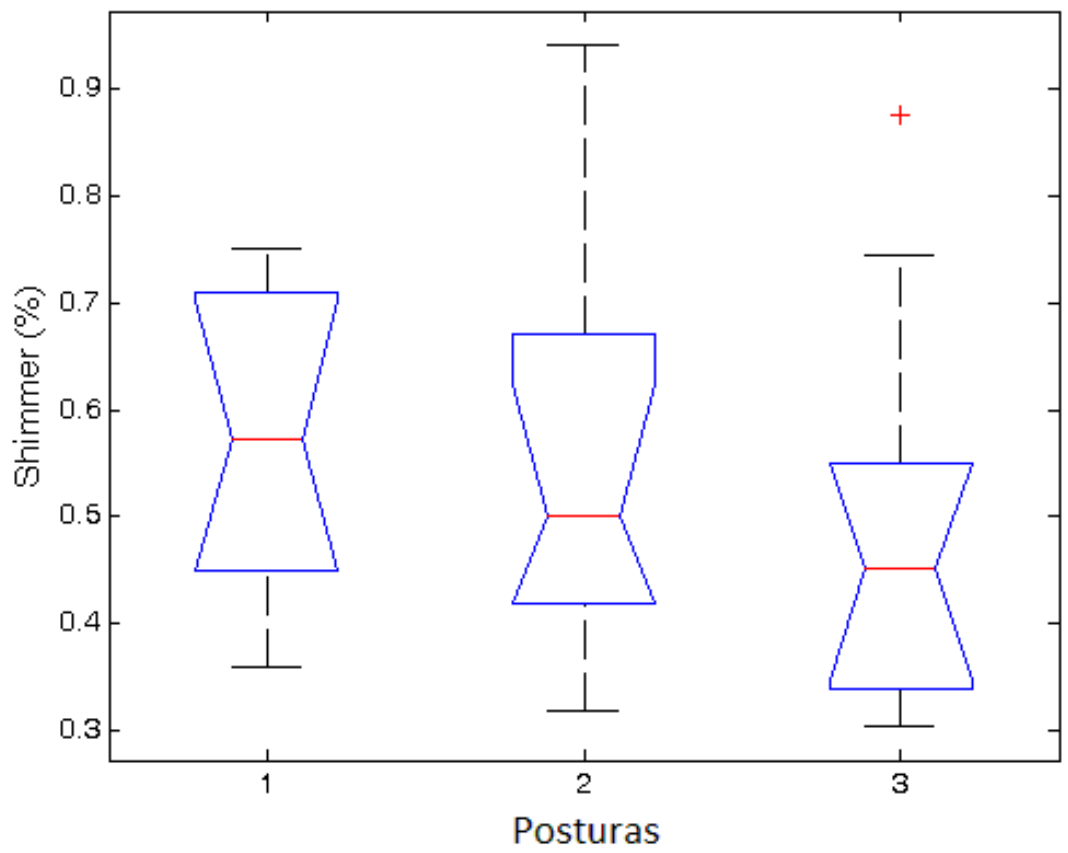

Figura 4.2: Gráfico de distribuição de valores de shimmer para: 1- Postura neutra, 2postura com anteriorização de cabeça com extensão do pescoço e 3 postura com aumento da cifose toráxica com anteriorização de cabeça. 
Para freqüência fundamental os valores médios foram para a postura 1: máximo de 139,20 Hz; mínimo de 105,25 Hz; média de 123,03 Hz e desvio padrão de $10,51 \mathrm{~Hz}$. Para a postura 2, o máximo foi de $139,40 \mathrm{~Hz}$; o mínimo de 111,40 Hz; a média de 125,88 Hz e desvio padrão de 9,85 Hz. Para postura 3, a máxima de 140,90 Hz, a mínima de $114,05 \mathrm{~Hz}$; a média de 127,95 Hz e desvio padrão de $8,67 \mathrm{~Hz}$. Na tabela 4-9 encontram-se os valores médios da freqüência fundamental $\left(F_{0}\right)$ de cada amostra de voz nas três posturas avaliadas.

Tabela 4-9: Valores da Freqüência fundamental F0 (Hz) das vozes nas três posturas.

\begin{tabular}{cccc}
\hline Dia & $\begin{array}{c}\text { Postura 1 } \\
\left(\mathbf{F}_{\mathbf{0}} \mathbf{H z}\right)\end{array}$ & $\begin{array}{c}\text { Postura 2 } \\
\left(\mathbf{F}_{\mathbf{0}} \mathbf{H z}\right)\end{array}$ & $\begin{array}{c}\text { Postura 3 } \\
\left(\mathbf{F}_{\mathbf{0}} \mathbf{H z}\right)\end{array}$ \\
\hline Dia 1 & 113,10 & 113 & 119,20 \\
Dia 2 & 105,25 & 111,40 & 114,05 \\
Dia 3 & 119,80 & 125,45 & 128,25 \\
Dia 4 & 114,10 & 113,15 & 115,80 \\
Dia 5 & 117,10 & 124,55 & 126,25 \\
Dia 6 & 125,40 & 127,60 & 133,40 \\
Dia 7 & 129,20 & 136,45 & 131 \\
Dia 8 & 139,20 & 139,40 & 138,25 \\
Dia 9 & 129,35 & 132,30 & 132,40 \\
Dia 10 & 137,85 & 135,50 & 140,90 \\
\hline \hline
\end{tabular}

O resultado do Teste Anova unilateral com 0,05 de significância, mostrou que para $F=0,58$ o p-valor é 0,566 ; por conseguinte, no há diferencia estatística significante entre os três grupos. Na figura 4.3 se observa a distribuição de valores médios para freqüência fundamental dos sinais de voz nas três posturas. 


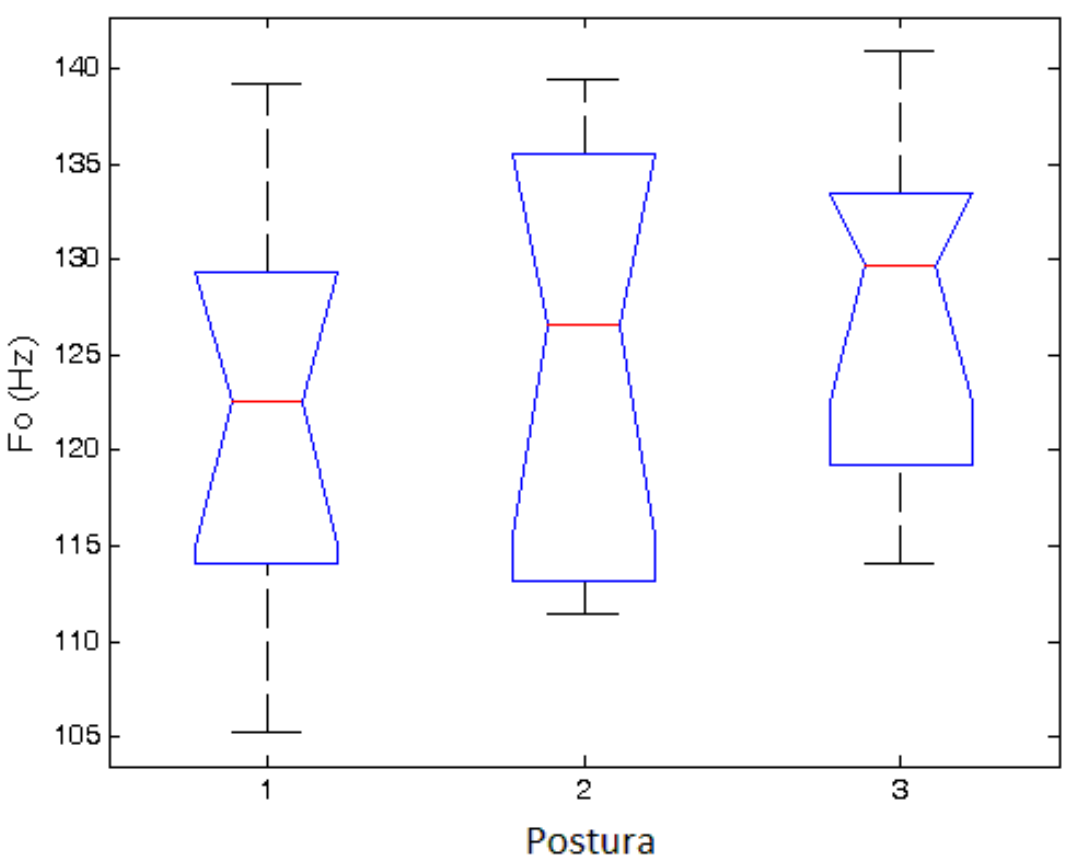

Figura 4.3: Gráfico de distribuição de valores de freqüência fundamenta F0 para: 1Postura neutra, 2- postura com anteriorização de cabeça com extensão do pescoço e 3 postura com aumento da cifose toráxica com anteriorização de cabeça.

Em sínteses, os testes estatísticos não apresentaram diferenças estatisticamente significantes para os parâmetros de jitter, shimmer e freqüência fundamental $\left(F_{0}\right)$ em diferentes posturas.

\subsubsection{Vozes patológicas}

\subsubsection{Vozes com disfonia organofuncional}

\section{Edema}

Para jitter os valores foram: máximo de 1,48\%; mínimo de 0,16\%; media de $0,35 \%$ e desvio padrão de $0,31 \%$. Para o parâmetro de shimmer o valor máximo foi de $11,05 \%$; mínimo de $0,43 \%$; valor médio de $1,80 \%$ e desvio padrão de $2,51 \%$. Os valores médios de jitter e shimmer não foram separados segundo gênero. 
Os valores médios de freqüência fundamental de todos os sinais de voz (masculinos e femininos) com edema de Reinke foram: máximo de 224,80 Hz; mínimo de 105,65 Hz; média 154,94 Hz e desvio padrão 42,32 Hz. Os valores por gênero foram: para as vozes femininas (14 sinais de voz) mínimo de 107,75 Hz; máximo de 224,80 Hz; média de $159,00 \mathrm{~Hz}$ e desvio padrão de 44,80 Hz. Para as vozes masculinas (2 sinais de voz) os valores foram: mínimo de 105,65 Hz; máximo de 161,30 Hz; média de 137,35 Hz e desvio padrão de 28,61 Hz. $\mathrm{Na}$ tabela 4-10 têm-se os valores médios das 16 amostras de vozes com edema de Reinke.

Tabela 4-10: Valores médios dos parâmetros acústicos jitter, shimmer, e $F_{0}$ para os 16 sinais de voz com edema de Reinke.

\begin{tabular}{cccc}
\hline Paciente & Jitter (\%) & Shimmer $(\%)$ & $\mathbf{F}_{\mathbf{0}}(\mathbf{H z})$ \\
\hline Paciente 1 & 0,17 & 0,70 & 208,00 \\
Paciente 2 & 0,30 & 1,78 & 155,40 \\
Paciente 3 & 0,30 & 0,71 & 145,80 \\
Paciente 4 & 0,16 & 1,54 & 109,90 \\
Paciente 5 & 0,29 & 1,25 & 110,95 \\
Paciente 6 & 0,17 & 0,43 & 134,00 \\
Paciente 7 & 0,24 & 1,09 & 145,05 \\
Paciente 8 & 0,34 & 1,71 & 105,65 \\
Paciente 9 & 0,25 & 1,77 & 135,90 \\
Paciente 10 & 0,23 & 0,54 & 221,05 \\
Paciente 11 & 0,30 & 1,91 & 224,80 \\
Paciente 12 & 0,22 & 1,05 & 224,00 \\
Paciente 13 & 0,47 & 1,27 & 135,00 \\
Paciente 14 & 1,48 & 11,05 & 161,30 \\
Paciente 15 & 0,34 & 1,19 & 107,75 \\
Paciente 16 & 0,33 & 0,76 & 154,50 \\
\hline \hline
\end{tabular}




\section{Nódulos}

Os valores médios para jitter foram: máximo de 1,94\%; mínimo de 0,16\%; média de 0,38 \% com desvio padrão de 0,45\%. Para shimmer o valor máximo foi de 6,75\%; mínimo de 0,62\%; média de 1,74\% e desvio padrão de $1,72 \%$. Os valores médios da freqüência fundamental $\left(F_{0}\right)$, sem divisão por gênero, foram: máximo de 277 Hz; mínimo de 109,2 Hz; média de 201,69 Hz e desvio padrão de 50,97 Hz. Quando divididos por gêneros, os valores das vozes femininas foram: máximo $277 \mathrm{~Hz}$; mínimo 109,20 Hz; média de 213,06 Hz com desvio padrão de 50,06 Hz. Para as vozes masculinas o valor máximo foi $200,80 \mathrm{~Hz}$, o mínimo $125,55 \mathrm{~Hz}$, média de $162,48 \mathrm{~Hz}$ com desvio padrão de 37,62 Hz. A tabela 4-11 apresenta os valores dos 15 sinais com nódulo.

Tabela 4-11: Valores médios de jitter, shimmer, e $\mathrm{F}_{0}$ dos 15 sinais com nódulos vocais.

\begin{tabular}{cccc}
\hline Sinal de Voz & Jitter (\%) & Shimmer $(\%)$ & $\mathbf{F}_{\mathbf{0}}(\mathrm{Hz})$ \\
\hline Paciente 1 & 0,29 & 0,95 & 239,80 \\
Paciente 2 & 0,35 & 0,87 & 232,55 \\
Paciente 3 & 0,39 & 0,745 & 236,70 \\
Paciente 4 & 0,28 & 1,83 & 204,40 \\
Paciente 5 & 0,17 & 1,35 & 109,20 \\
Paciente 6 & 0,16 & 0,99 & 164,10 \\
Paciente 7 & 0,17 & 0,72 & 178,80 \\
Paciente 8 & 0,17 & 0,78 & 139,10 \\
Paciente 9 & 1,94 & 4,78 & 244,65 \\
Paciente 10 & 0,25 & 6,75 & 125,55 \\
Paciente 11 & 0,17 & 0,62 & 200,80 \\
Paciente 12 & 0,66 & 1,99 & 270,70 \\
Paciente 13 & 0,21 & 1,38 & 189,80 \\
Paciente 14 & 0,20 & 1,04 & 212,20 \\
Paciente 15 & 0,32 & 1,33 & 277 \\
\hline \hline
\end{tabular}




\subsubsection{Vozes com disfonia orgânica de origem neurológica}

Os valores médios do jitter foram: máximo de 1,72\%; mínimo de 0,13\%; média de 0,39\% e desvio padrão de 0,401\%. Para shimmer, máximo de 13,18\%; mínimo de 1,17\%; média de 3,21\% e desvio padrão de 2,99\%. Para freqüência fundamental masculina (7 sujeitos) os valores médios foram: máximo de 250,30 Hz; mínimo de 105,80 Hz, media de 160,38 Hz e desvio padrão de 48,32 Hz. Para mulheres (7 sujeitos) os valores médios foram: máximo de 234,20 Hz; mínimo de 144,60 HZ; média de 190,98 Hz e desvio padrão de 34,45 Hz. A tabela 4-12 apresenta os valores médios de jitter, shimmer e $F_{0}$ de todos os sinais de voz de pacientes com alterações neurológicas.

Tabela 4-12: Valores médios de jitter, shimmer e freqüência fundamental de vozes de pacientes com disfonia neurológica.

\begin{tabular}{cccc}
\hline Sinal de voz & Jitter (\%) & Shimmer $(\%)$ & $\mathbf{F}_{\mathbf{0}}(\mathbf{H z})$ \\
\hline Paciente 1 & 0,300 & 2,41 & 200,7 \\
Paciente 2 & 0,170 & 1,85 & 174,2 \\
Paciente 3 & 0,560 & 3,07 & 105,8 \\
Paciente 4 & 0,270 & 2,14 & 129 \\
Paciente 5 & 1,720 & 13,18 & 234,2 \\
Paciente 6 & 0,185 & 1,17 & 187,75 \\
Paciente 7 & 0,270 & 2,37 & 208,2 \\
Paciente 8 & 0,160 & 1,88 & 139 \\
Paciente 9 & 0,180 & 2,70 & 223,7 \\
Paciente 10 & 0,130 & 1,36 & 136,65 \\
Paciente 11 & 0,200 & 4,02 & 250,3 \\
Paciente 12 & 0,470 & 1,78 & 144,6 \\
Paciente 13 & 0,515 & 3,59 & 167,7 \\
Paciente 14 & 0,450 & 3,50 & 157,8 \\
\hline \hline
\end{tabular}


Foi realizado o teste estatístico de variância ANOVA unilateral com 0,05 de significância, com objetivo de comparar os resultados de jitter e shimmer dos grupos de vozes saudáveis, edema de Reinke, nódulos e disfonias neurológicas. Para jitter o p-valor foi de 0,279; deste modo sem diferencia estatística entre grupos. A figura 4.4 mostra a distribuição dos valores médios de jitter para os quatro grupos.

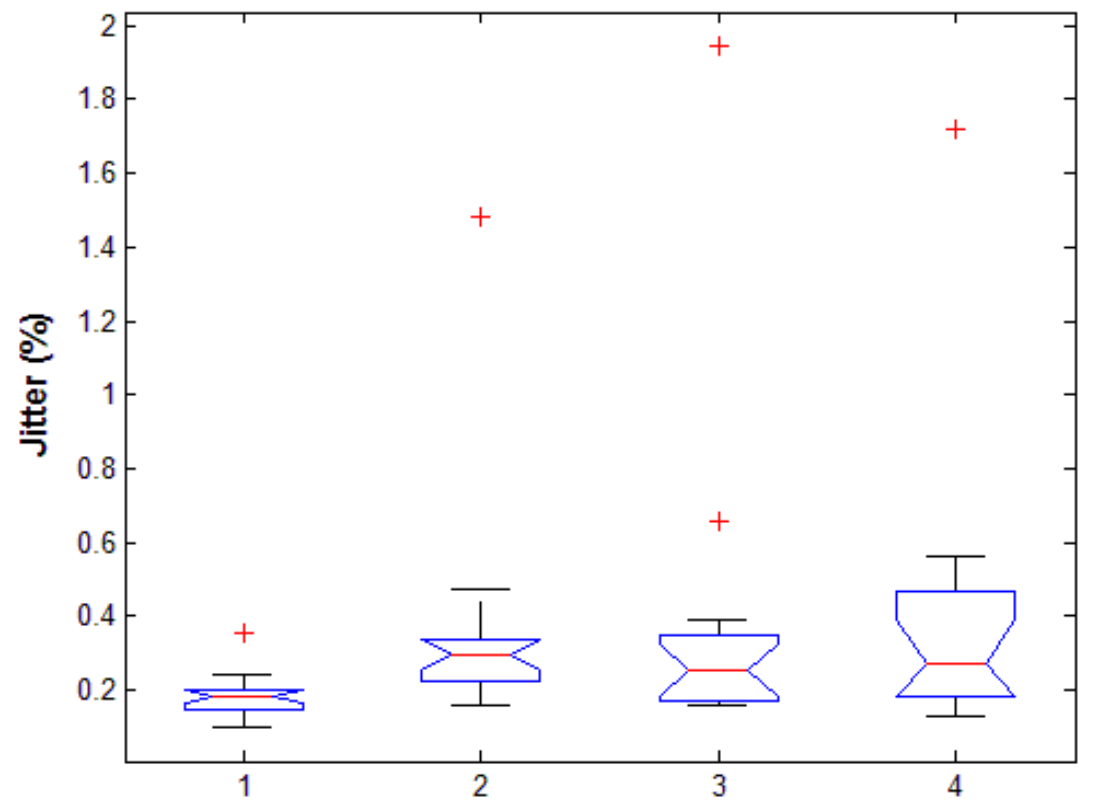

Figura 4.4: Gráfico de distribuição de valores de jitter para: grupo 1- vozes saudáveis, grupo 2- edema de Reinke; grupo 3- nódulos vocais e grupo 4- disfonia orgânica de origem neurológico.

Para shimmer a ANOVA calculou um p-valor de 0,0644 , isto indica uma tendência dos grupos serem diferentes, mas essa diferença não é estaticamente significativa. A figura 4.5 apresenta a distribuição dos valores médios dos quatro grupos. 
Para o parâmetro de freqüência fundamental $\left(F_{0}\right)$ não foi realizado o teste ANOVA, devido à diferença existente na quantidade de sujeitos quando divididos por gênero.

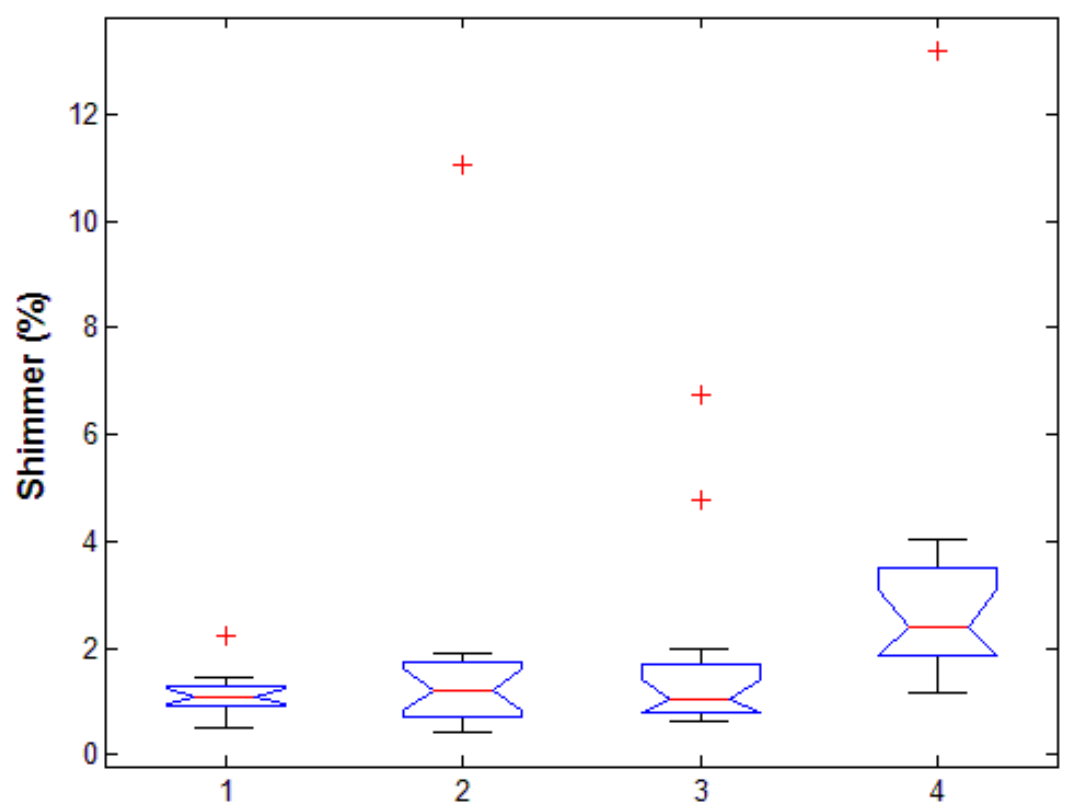

Figura 4.5: Gráfico de distribuição de valores de shimmer para: grupo 1- vozes saudáveis , grupo 2- edema de Reinke; grupo 3- nódulos vocais e grupo 4- disfonia orgânica de origem neurológico.

Em síntese, a análise acústica das medidas de perturbação de freqüência e amplitude - jitter e shimmer -não apresentou significância estatística para os quatro grupos comparados.

\subsection{Análise qualitativa dos Padrões Visuais da Dinâmica Vocal}

\subsubsection{Vozes normais}

A análise qualitativa descritiva da configuração dos PVDV foi realizada levando em conta: número de laços ou loops, regularidade e convergência dos 
traçádos. Os resultados receberam tratamento estatístico com os testes não paramétricos de Kruskal-Wallis e o teste de comparação múltipla, ou teste de Dunn, ambos com 0,05 de significância.

Com esta técnica, espera-se que dependendo da vogal sustentada analisada, os PVDV apresentem configurações de laços similares, refletindo uma dinâmica semelhante para um determinado gesto vocal, neste caso, a emissão da vocal /a/. Na tabela 4-13 encontram-se a avaliação qualitativa descritiva dos PVDV dos 16 sinais de voz saudáveis.

Tabela 4-13: Avaliação qualitativa dos PVDV das vozes saudáveis

\begin{tabular}{cccc}
\hline Sinal de Voz & LOOPS & REGULARIDADE & CONVERGÊNCIA \\
\hline Sinal 1 & 3 & 4 & 3 \\
Sinal 2 & 4 & 5 & 3 \\
Sinal 3 & 3 & 5 & 3 \\
Sinal 4 & 4 & 4 & 2 \\
Sinal 5 & 4 & 4 & 3 \\
Sinal 6 & 4 & 4 & 3 \\
Sinal 7 & 4 & 4 & 3 \\
Sinal 8 & 4 & 4 & 4 \\
Sinal 9 & 4 & 4 & 2 \\
Sinal 10 & 4 & 4 & 4 \\
Sinal 11 & 3 & 4 & 4 \\
Sinal 12 & 3 & 4 & 4 \\
Sinal 13 & 4 & 5 & 3 \\
Sinal 14 & 4 & 4 & 3 \\
Sinal 15 & 3 & 3 & 2 \\
Sinal 16 & 4 & 4 & 4 \\
\hline \hline
\end{tabular}

As 16 vozes saudáveis apresentaram configurações similares em relação ao formato e número de laços, sendo que todas as amostras foram 
avaliadas com grau 4 ou grau 3 . Onze sinais $(68,75 \%)$ apresentaram laços grau 4, ou seja mais de 3 loops; e 5 sinais $(31,25 \%)$ com laços grau 3 (configurações com três loops).

Doze (75\%) PVDV foram avaliados com regularidade de traçados grau 4 (traçados regulares com um foco de irregularidade); três (18,75\%) PVDV com grau 5 (traçados regulares globais) e somente um sinal (6,25\%) foi avaliado com grau 3 (regularidade intermitente).

$\mathrm{Na}$ avaliação qualitativa da convergência dos traçados, oito (50\%) PVDV foram avaliados com grau 3 (Convergência de forte a média); cinco (31,25\%) PVDV com grau 4 (forte convergência) e 3 PVDV (18,75\%) com grau 2 (convergência média).

A figura 4.6 apresenta seis exemplos de padrões visuais de dinâmica vocal de sinais de voz sem alteração ou queixa vocal. Nestes PVDV pode-se observar uma configuração similar de loops - vários laços concêntricos de diferentes tamanhos - o que indica que se trata de uma vogal /a/ com componentes harmônicas de diferente amplitude. 


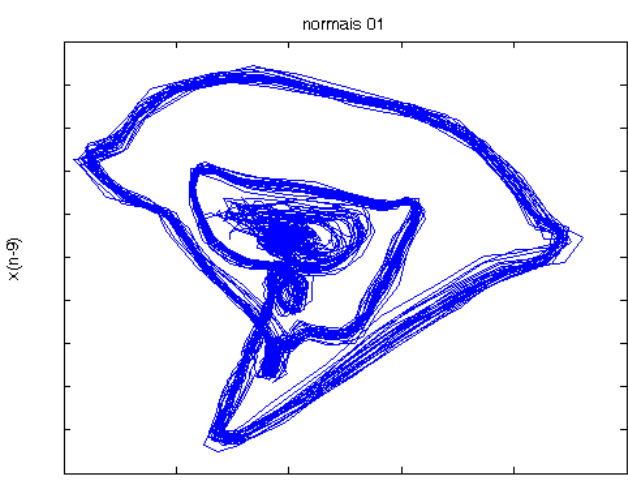

$x(n)$

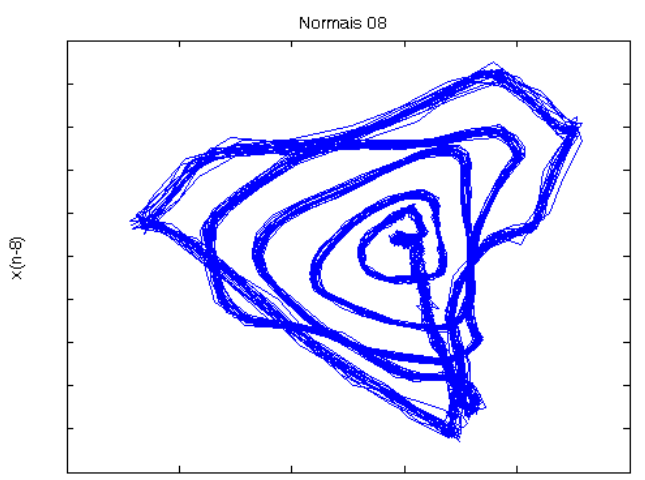

$x(n)$

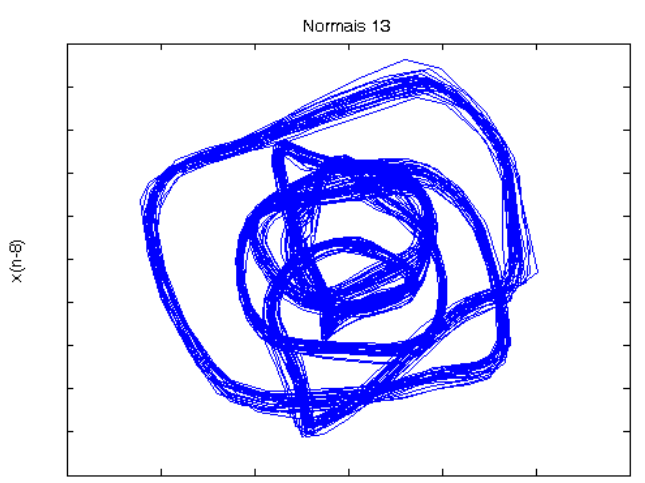

$x(n)$

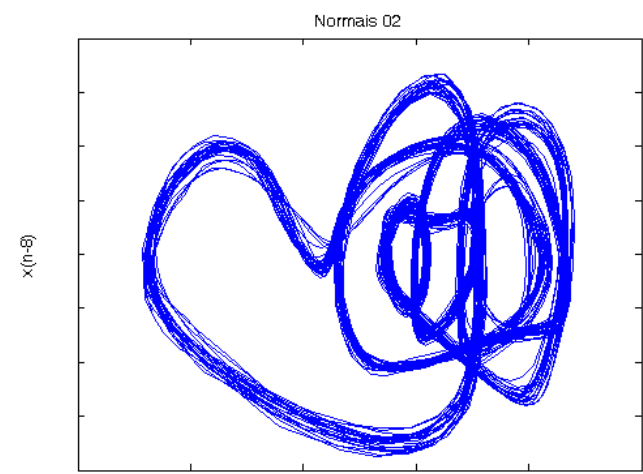

$x(n)$

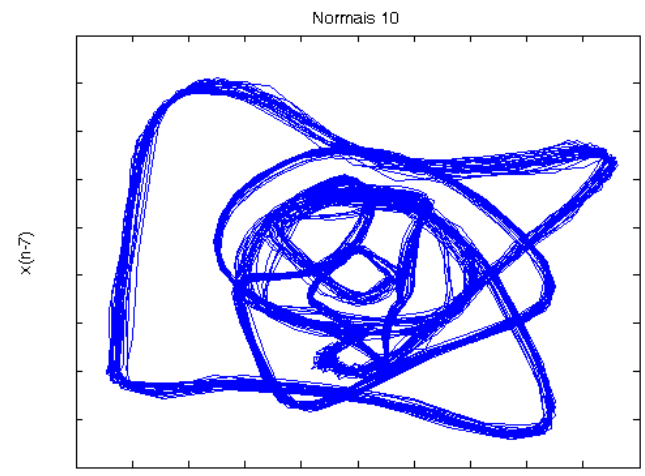

$x(n)$

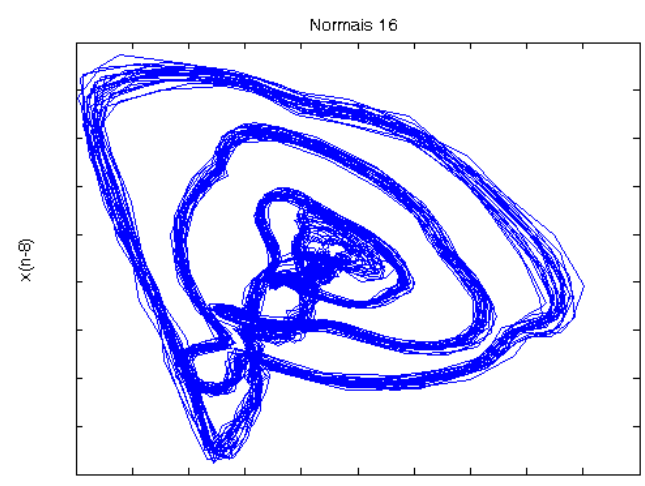

$x(n)$

Figura 4.6: Exemplos de PVDV de trechos de 200 milissegundos da vogal sustentada /a/ de vozes saudáveis.

Todas as amostras de voz deste grupo apresentaram características similares as dos exemplos ilustrados na figura 4.6, evidenciando a natureza de dinâmica não linear dos sinais de voz, que normalmente apresentam variações de ciclo a ciclo, mas com um padrão de comportamento semelhante. 


\subsubsection{Voz normal com mudanças posturais}

Neste grupo foram considerados os laços ou loops, a regularidade e a convergência dos traçados, assim como a estabilidade da configuração dos PVDV ao longo dos dias de avaliação. Foi aplicado o teste não paramétrico de Kruskal-Wallis e o teste de comparações múltiplas de Dunn com 0,05 de significância.

A fim de exemplificar esta avaliação qualitativa a figura 4.7 mostra os PVDV de trechos de voz de 200 milissegundos nas três posturas avaliadas; do lado direito se apresenta uma aproximação de um segmento do traçado. Nesta figura é possível visualizar o comportamento diferencial dos traçados e configurações para cada uma das posturas. Para este tipo de avaliação qualitativa é fundamental a observação detalhada de todo o percurso de traçados dos PVDV.

No exemplo da figura 4.7 o PVDV da postura 1 foi avaliado com laços grau 4 (mais que 3 loops) com traçados regulares (grau 5) e uma forte convergência de traçados (grau 4). Na postura 2, a configuração de número de laços se mantém estável em relação a postura 1, mas os traçados apresentam regularidade intermitente (grau 3), e a convergência foi classificada com grau 2 (convergência media), em outras palavras, trajetórias mais espalhadas uniformemente. Para a postura 3 a dinâmica de loops e de regularidade de traçado é similar à postura 1, mas a convergência muda para grau 3, de forte a média. 

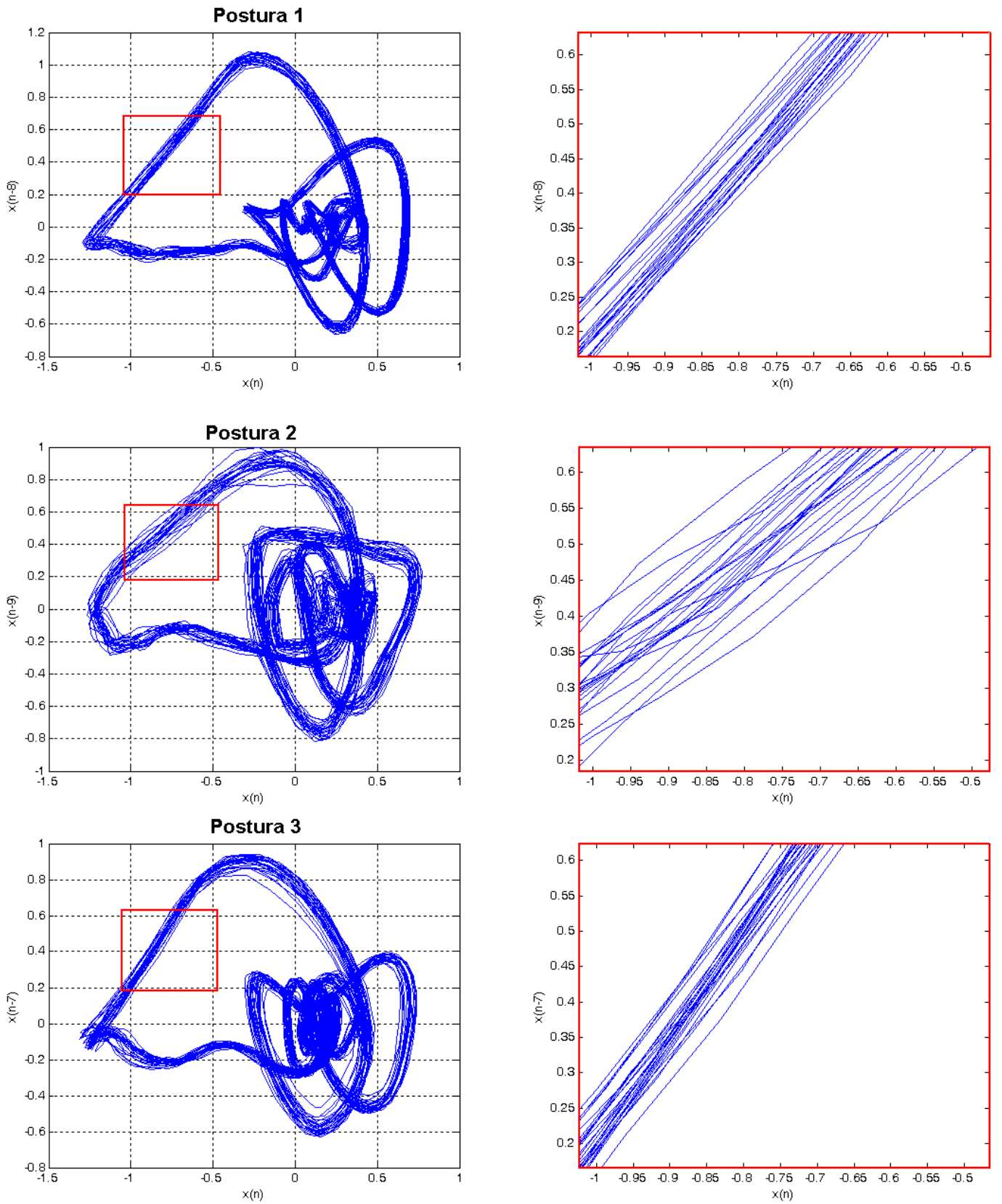

Figura 4.7: PVDV para as três posturas avaliadas. 1- Postura neutra, 2- postura com anteriorização de cabeça com extensão do pescoço e 3- postura com aumento da cifose toráxica com anteriorização de cabeça.

Os resultados para este grupo mostraram que para postura 1 (postura neutra) os dez sinais (100\%) foram avaliados com grau 4, ou seja, configurações com mais de 3 loops. Para regularidade dos traçados, quatro amostras de voz (40\%) foram classificadas com grau 4, três amostras (30\%) com grau 5 e as três amostras restantes (30\%) com grau 3; em outras 
palavras, o comportamento dos traçados foi de regular global a regular intermitente. $\mathrm{Na}$ avaliação de convergência de traçados seis sinais (60\%) apresentaram grau 4 (forte convergência) e quatro sinais (40\%) grau 3 (convergência de forte a média).

A Figura 4.8 ilustra quatro exemplos de PVDV para a postura neutra. Nos PVDV é possível perceber uma dinâmica similar para as três características avaliadas, mais de três laços, traçados retilíneos, regulares com convergência forte e homogênea em todo o percurso dos traçados.
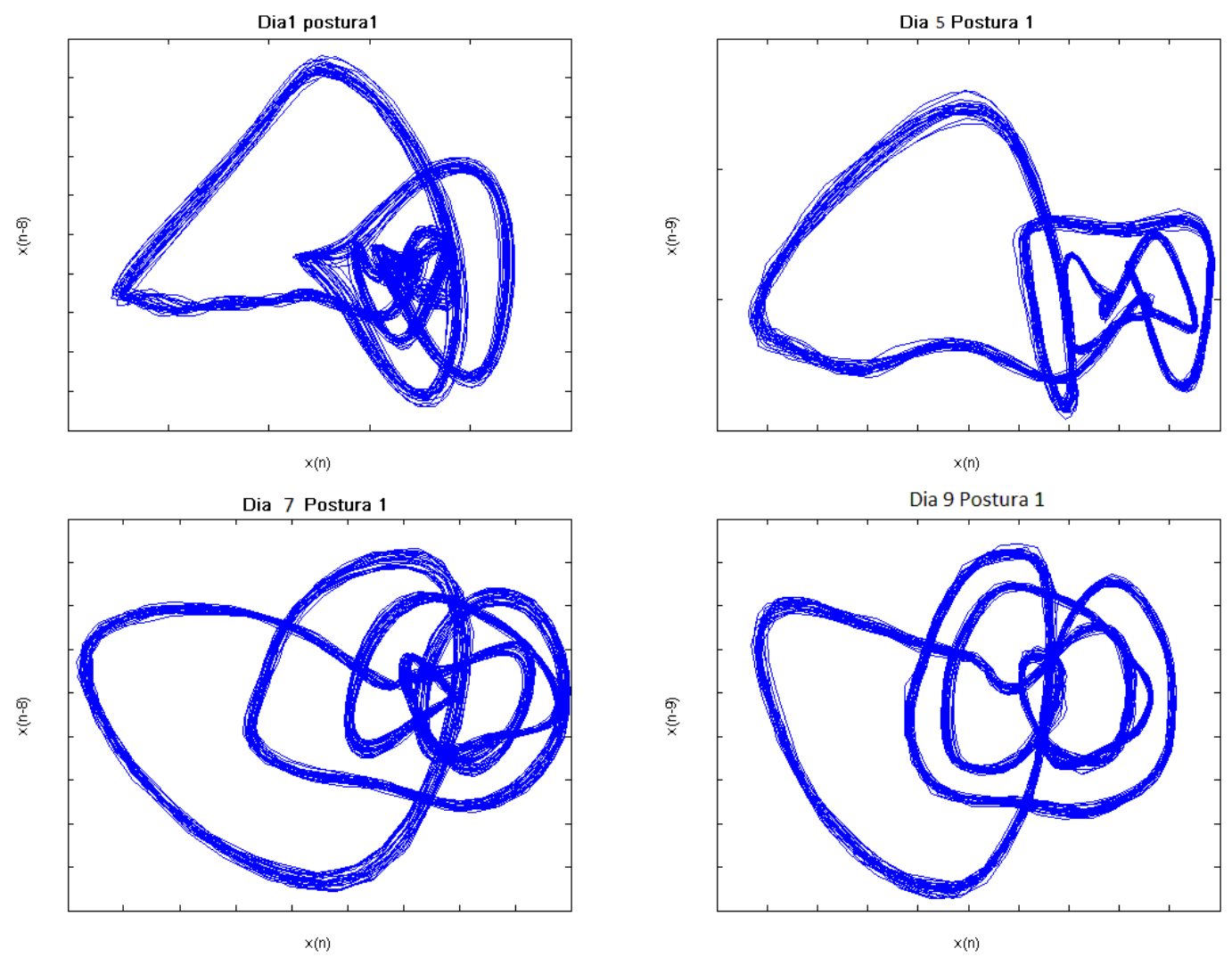

Figura 4.8: Exemplos de PVDV para a postura 1 ou Postura neutra correspondentes as amostras dos dias 1, 5, 7 e 9. 
Na avaliação dos PVDV da postura 2 , seis vozes $(60 \%)$ apresentaram configurações com mais de 3 laços (grau 4); três vozes (30\%) com loops grau 3 e uma voz com loops grau 2. Dois sinais $(20 \%)$ foram avaliadas com traçados grau 4 (regulares com uma porção de irregularidade); quatro sinais de voz $(40 \%)$ com traçados de regularidade intermitente ou grau 3 e quatro sinais (40\%) foram avaliadas como levemente irregulares ou grau 2 de regularidade. Na avaliação da convergência 3 PVDV (30\%) foram classificados com grau 4 (forte convergência); 6 PVDV (60\%) com grau 3 (convergência de forte a média) e 1 PVDV (10\%) com grau 2 (convergência média).

Os exemplos da Figura 4.9 correspondem a PVDV da postura 2 ou postura com anteriorização de cabeça e com extensão do pescoço. Os quatro exemplos apresentam uma dinâmica de configuração e de traçados claramente diferente em relação às amostras da postura neutra. 


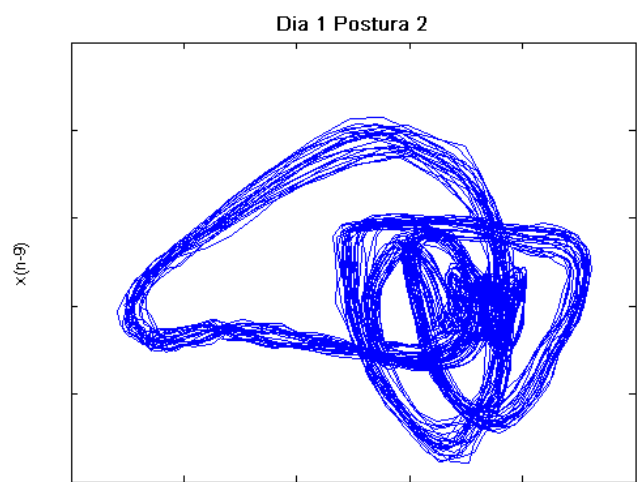

$x(n)$

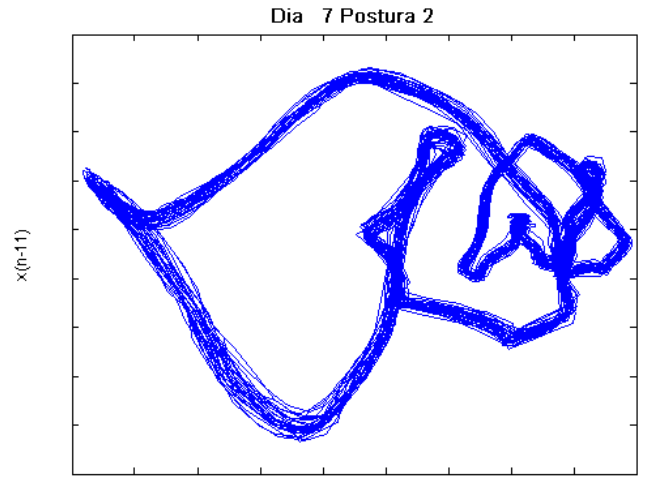

$x(n)$

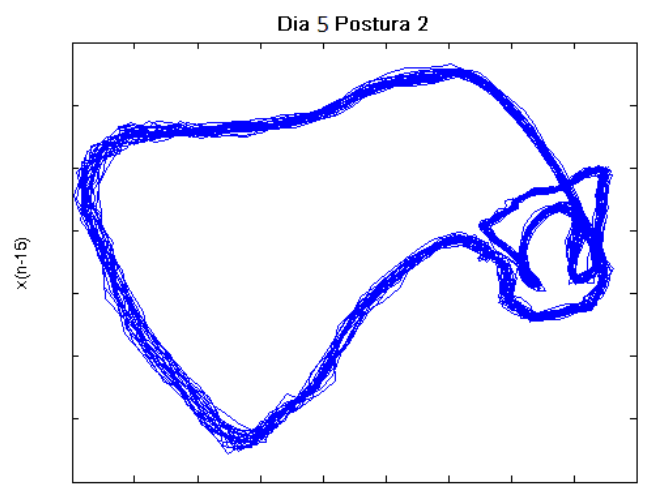

$x(n)$

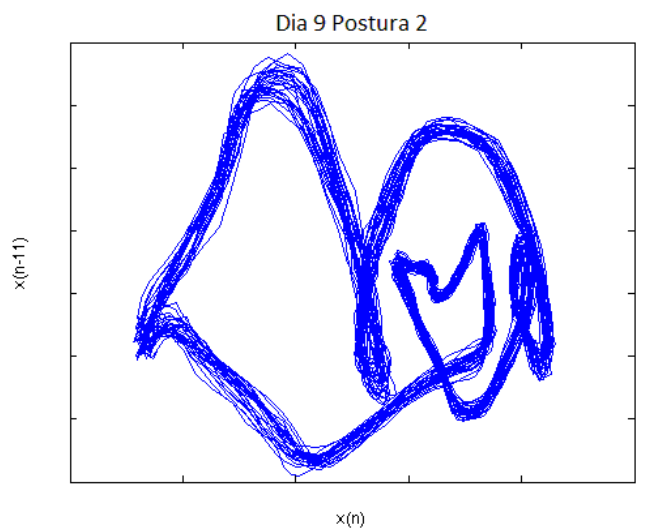

Figura 4.9: Exemplos de PVDV para a postura 2 ou postura com anteriorização de cabeça e com extensão do pescoço. Os quatro PVDV correspondem aos dias 1, 5, 7 e 9.

Para a postura 3, cinco vozes (50\%) foram classificadas com laços grau 4, dois sinais $(20 \%)$ com grau 3 e três sinais de voz (30\%) com loop grau 2. $\mathrm{Na}$ avaliação dos traçados: dois sinais $(20 \%)$ mostraram traçados completamente regulares ou grau 5; uma voz (10\%) apresentou traçados regulares com uma porção de irregularidade (grau 4) e sete (70\%) dos PDVD foram avaliados com grau 3 ou regularidade intermitente. Quatro PVDV (40\%) apresentaram convergência grau 4 (forte convergência) e seis sinais de voz (60\%) convergência grau 3 ( forte a média convergência).

Para ilustrar os resultados da postura 3 a Figura 4.10 apresenta quatro exemplos de PVDV. Nestes exemplos, observam-se algumas diferenças com 
respeito ao grupo de postura neutra, principalmente na dinâmica dos traçados e na configuração de laços.
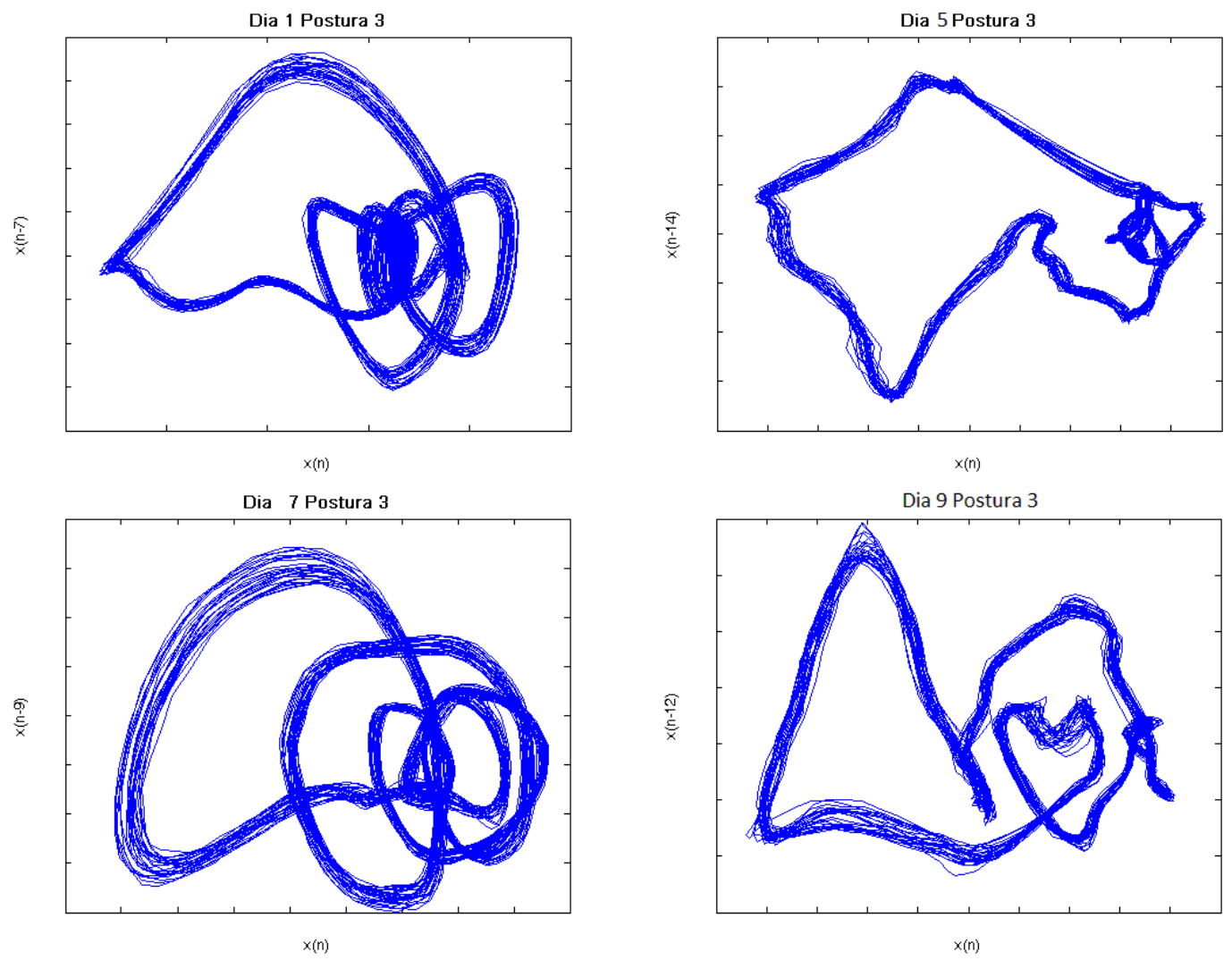

Figura 4.10: Exemplos de PVDV para a postura 3 ou postura com aumento da cifose toráxica. Os PVDV correspondem aos dias 1, 5, 7 e 9.

Tomando como padrão de referencia os PVDV da postura 1, pode-se observar diferenças em uma ou mais características dos PVDV das posturas 2 e 3. Sendo que o grau de laços e de traçados foram as características com dinâmica diferencial. Comparando a postura 1 e a postura 2, quatro PVDV $(40 \%)$ da postura 2 apresentaram uma configuração de laços com menor grau e os restantes seis mantiveram a mesma classificação. Nove PVDV (90\%) da postura 2 foram avaliados com menor grau de traçados e somente uma manteve o mesmo grau. Seis PVDV (60\%) apresentaram menor grau de 
convergência, dois PVDV aumentaram de grau 3 para grau 4 de convergência e dois PVDV mantiveram o mesmo grau de convergência.

A comparação dos resultados da postura neutra e da postura 3 evidenciou que cinco sinais de voz (50\%) não apresentaram diferença no grau de laços de uma postura para outra e os restantes, cinco sinais de voz $(50 \%)$, mostraram menor grau de laços. Na avaliação dos traçados, seis PVDV (60\%) mantiveram o mesmo grau em ambas as posturas, e quatro PVDV (40\%) diminuíram o grau de regularidade dos traçados. O grau de convergência permaneceu igual para quatro PVDV (40\%), diminuiu para dois sinais $(20 \%)$ e aumentou para dois PVDV (20\%). Os resultados comparativos dos PVDV das três posturas encontram-se detalhados para as três características avaliadas na tabela $4-14$.

Tabela 4-14: Avaliação em graus da configuração de laços, regularidade e convergência dos traçados dos PVDV nas diferentes posturas.

\begin{tabular}{|c|c|c|c|c|c|c|c|c|c|}
\hline & \multicolumn{3}{|c|}{ LAÇOS } & \multicolumn{3}{|c|}{ TRAÇADO } & \multicolumn{3}{|c|}{ CONVERGÊNCIA } \\
\hline Dia & P1 & P2 & P3 & P1 & P2 & P3 & P1 & P2 & P3 \\
\hline 1 & 4 & $4(=)$ & $4(=)$ & 4 & $4(=)$ & $4(=)$ & 4 & $3(-)$ & $3(-)$ \\
\hline 2 & 4 & $4(=)$ & $4(=)$ & 4 & $3(-)$ & $3(-)$ & 3 & $2(-)$ & $3(=)$ \\
\hline 3 & 4 & $4(=)$ & $2(-)$ & 3 & $2(-)$ & $3(=)$ & 3 & $4(+)$ & $4(+)$ \\
\hline 4 & 4 & $4(=)$ & $4(=)$ & 4 & $3(-)$ & $3(-)$ & 3 & $3(=)$ & $3(=)$ \\
\hline 5 & 4 & $2(-)$ & $2(-)$ & 3 & $2(-)$ & $3(=)$ & 3 & $4(+)$ & $4(+)$ \\
\hline 6 & 4 & $3(-)$ & $3(-)$ & 4 & $2(-)$ & $3(-)$ & 4 & $3(-)$ & $4(=)$ \\
\hline 7 & 4 & $3(-)$ & $4(=)$ & 5 & $3(-)$ & $5(=)$ & 4 & $3(-)$ & $3(-)$ \\
\hline 8 & 4 & $4(=)$ & $3(-)$ & 5 & $4(-)$ & $5(=)$ & 4 & $4(=)$ & $3(-)$ \\
\hline 9 & 4 & $3(-)$ & $2(-)$ & 5 & $3(-)$ & $3(-)$ & 4 & $3(-)$ & $3(-)$ \\
\hline 10 & 4 & $4(=)$ & $4(=)$ & 3 & $2(-)$ & $3(=)$ & 4 & $3(-)$ & $4(=)$ \\
\hline
\end{tabular}

Legenda: P1: postura 1; P2: postura 2 e P3: postura 3. (=) o grau se mantém igual; (-): menor grau e $(+)$ maior grau que a postura de referencia. 
Para o teste de Kruskal-Wallis os parâmetros de laços e regularidade de

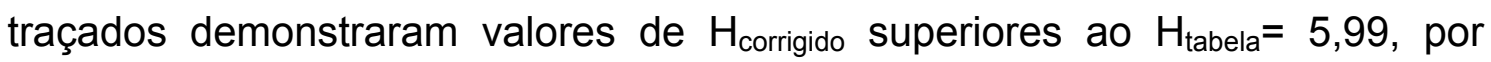
tanto se rejeita a hipótese nula, e os grupos são considerados diferentes. Com o teste de comparações múltiplas obteve-se que para o parâmetro de laços a diferença estatística se encontra nos grupos de postura 1 vs. postura 3 com $\mathrm{Q}_{\text {calculado }}=2,4516$. Para regularidade dos traçados a diferença foi obtida na postura 1 vs. postura 2 com $Q_{\text {calculado}}=2,8782$. Para convergência $\circ H_{\text {calculado }}$ de 2,82353, menor que $\mathrm{H}_{\text {tabela }}=5,99$. As restantes combinações de parâmetros apresentaram valores menores ao $Q_{\text {tabela }}$ de 2,394, por tanto sem significância estatística.

\subsubsection{Vozes patológicas}

São apresentados nesta subseção os resultados qualitativos dos três grupos de sinais de voz com disfonia - edema de Reinke, nódulos vocais e disfonia de origem neurológica. Os resultados destes três grupos foram comparados com os resultados do grupo vozes saudáveis e tratados estatisticamente com os testes não-paramétricos de Kruskal-Wallis e de comparações múltiplas ou teste de Dunn. 


\subsubsection{Vozes com disfonia organofuncional}

\section{Edema de Reinke}

$\mathrm{Na}$ análise qualitativa dos PVDV dois sinais (12,5\%) foram classificadas com laços grau 4 (mais de 3 loops); quatro vozes (25\%) com grau 3; cinco vozes $(31,25 \%)$ com grau 2 ; e os cinco sinais restantes $(31,25 \%)$ com 1 laço. Nenhum PVDV deste grupo foi avaliado com grau 0 de laços.

A regularidade dos traçados foi avaliada com três PVDV (18,75\%) com grau 4 (regular com um foco de irregularidade); seis PVDV (37,5\%) com grau 3 (regularidade intermitente); quatro (25\%) com regularidade de traçados grau 2 (irregularidade leve global); um sinal de voz $(6,25 \%)$ apresentou regularidade grau 1 e dois PVDV (12,5\%) com traçados irregulares globais (grau 0). Neste grupo, todos os PVDV apresentam traçados com irregularidades de diferentes graus.

Em relação ao grau de convergência, oito PVDV (50\%) foram avaliadas com grau 3 (convergência de forte a média); cinco PVDV $(31,25 \%)$ com grau 2 (convergência media) e três PVDV (18,75\%) com grau 1 (convergência de média a fraca). Nenhum PVDV deste grupo foi avaliado com grau 4 ou grau 0. Na tabela 4-15 são apresentados os resultados da avaliação qualitativa dos PVDV do grupo de edema de Reinke. 
Tabela 4-15: Resultados da avaliação dos PVDV das vozes com edema de Reinke.

\begin{tabular}{cccc}
\hline Paciente & Laços & Regularidade & Convergência \\
\hline Paciente 1 & 1 & 2 & 1 \\
Paciente 2 & 3 & 3 & 2 \\
Paciente 3 & 2 & 3 & 2 \\
Paciente 4 & 2 & 3 & 2 \\
Paciente 5 & 3 & 2 & 3 \\
Paciente 6 & 1 & 2 & 3 \\
Paciente 7 & 3 & 1 & 2 \\
Paciente 8 & 2 & 3 & 3 \\
Paciente 9 & 3 & 4 & 3 \\
Paciente 10 & 1 & 4 & 3 \\
Paciente 11 & 2 & 0 & 1 \\
Paciente 12 & 4 & 3 & 3 \\
Paciente 13 & 1 & 0 & 1 \\
Paciente 14 & 4 & 2 & 2 \\
Paciente 15 & 1 & 3 & 3 \\
Paciente 16 & 2 & 4 & 3 \\
\hline \hline
\end{tabular}

Como exemplo a figura 4.11 apresenta seis PVDV de sinais com edema de Reinke. 

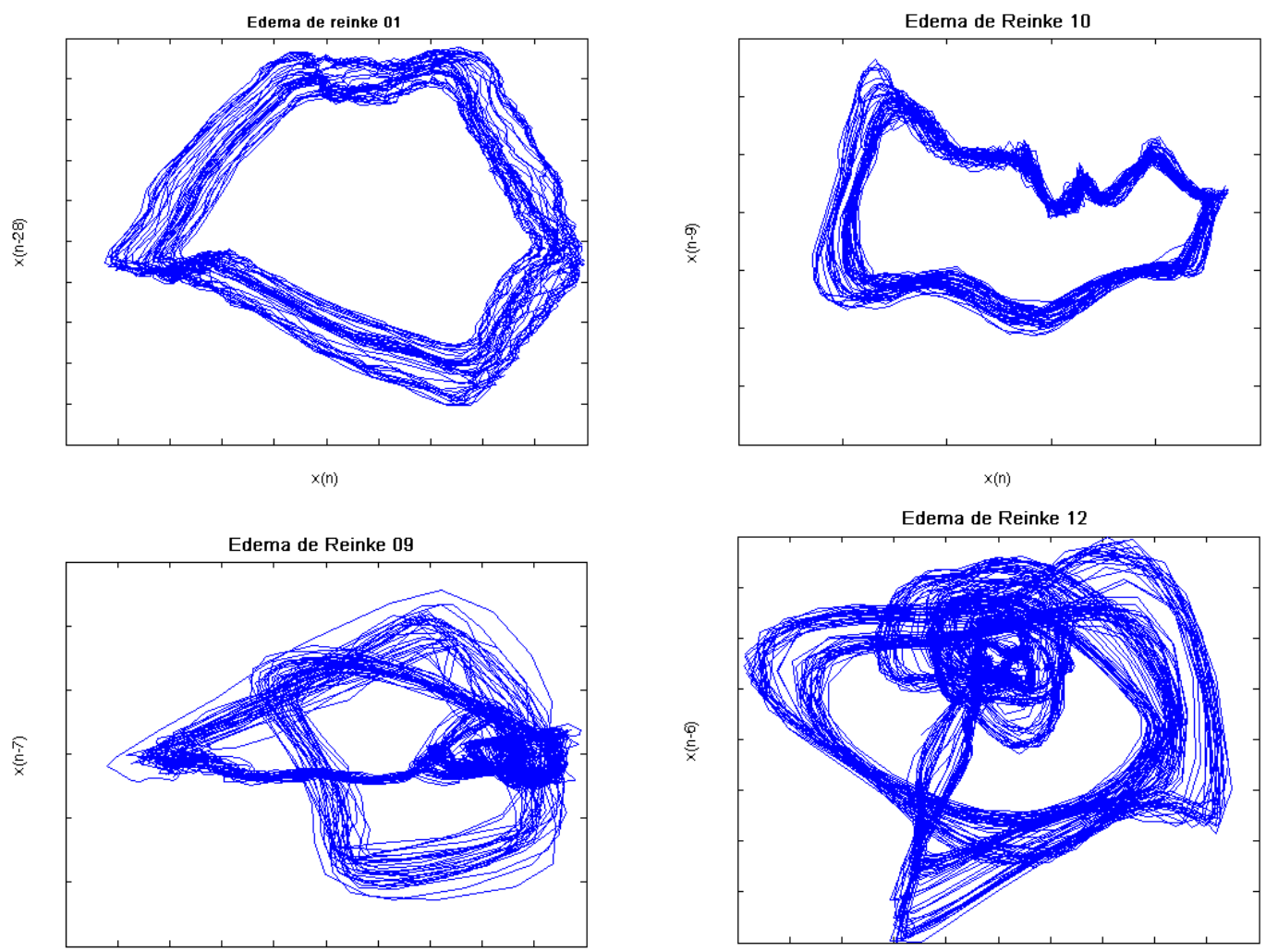

$x(n)$

$x(n)$
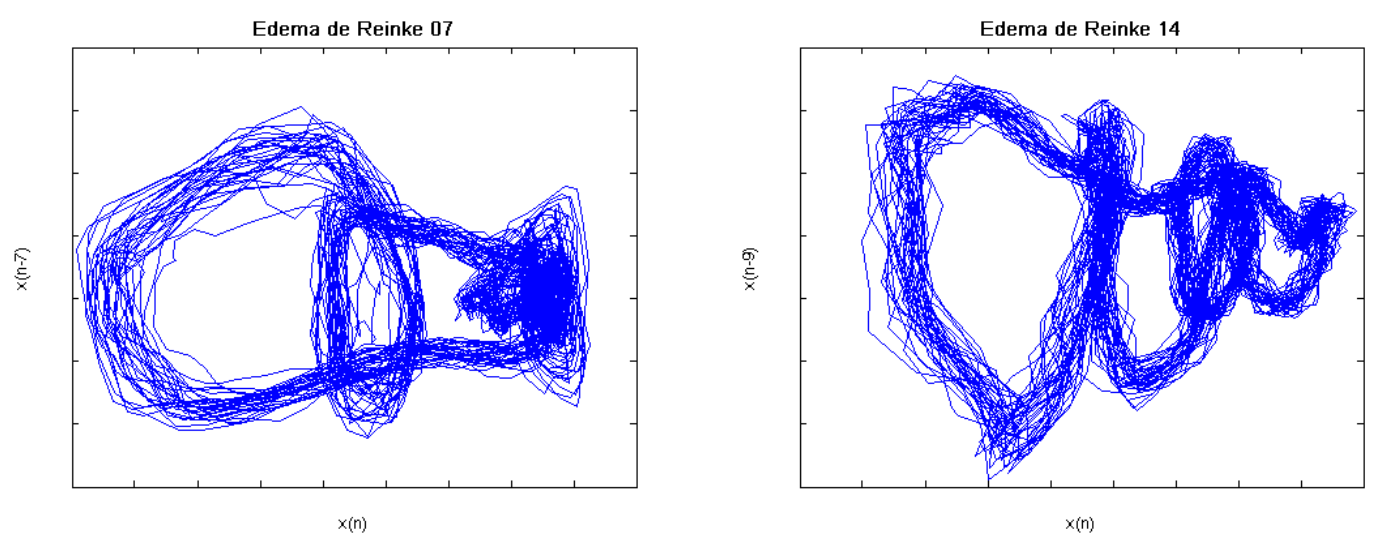

$x(n)$

Figura 4.11: Exemplos de PVDV de seis sinais de voz com edema de Reinke.

Do ponto de vista de uma avaliação comparativa com um grupo referencial - neste caso as vozes sem disfonia ou queixa vocal - a diferença do comportamento dinâmico entre os grupos fica evidente. Enquanto as vozes sem alteração apresentam PVDV com configurações complexas de 3 ou mais laços, com traçados retilíneos e tendência a forte convergência; os PVDV das 
vozes com edema de Reinke têm configurações menos complexas com menor regularidade e convergência dos traçados.

Nos exemplos 01 e 10 da Figura 4.11 os PVDV mostraram a perda de complexidade de laços - somente um - e também evidenciaram a presença de irregularidade (grau 2 e 4, respectivamente) e menor grau de convergência (grau 1 e 3, respectivamente), com traçados irregulares e espalhados.

Nos exemplos 09 e 12 os PVDV conservaram a complexidade de laços (grau 3 e grau 4), mas a dinâmica das trajetórias mostraram menor grau de convergência (grau 3 para ambos os casos) com traçados dispersos embora regulares (regularidade grau 4 e grau 3 respectivamente). A figura 4.12 mostra uma porção do PVDV onde é possível observar em detalhes a dinâmica da regularidade dos traçados e da convergência.
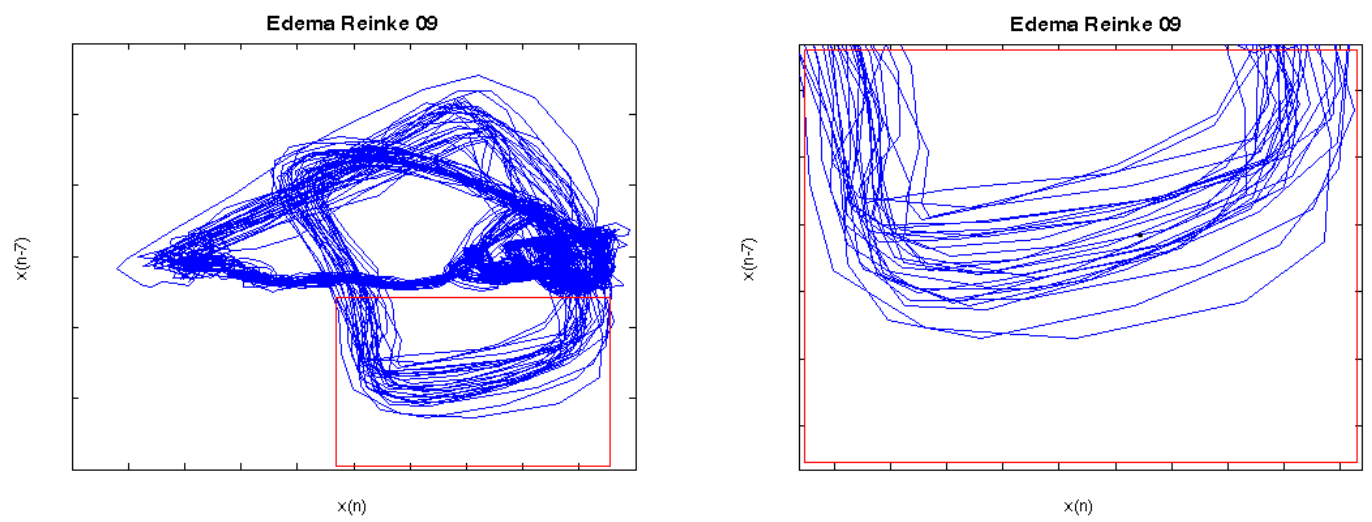

Figura 4.12: Exemplo 09 e uma aproximação de PVDV de uma voz com edema de Reinke.

Os PVDV dos sinais 07 e 14 foram classificados com grau de laços compatível com as vozes saudáveis (grau 3 e 4), mas a avaliação da regularidade dos traçados foi baixa (grau 1 e grau 2) com traçados irregulares 
ao longo de todo o percurso, ou levemente irregulares com focos de irregularidade. Estes PVDV também apresentaram menor grau de convergência (grau 2) ao longo de todo o percurso. A Figura 4.13 apresenta uma aproximação do PVDV do sinal 07 a fim de uma melhor visualização da dinâmica irregular dos traçados.

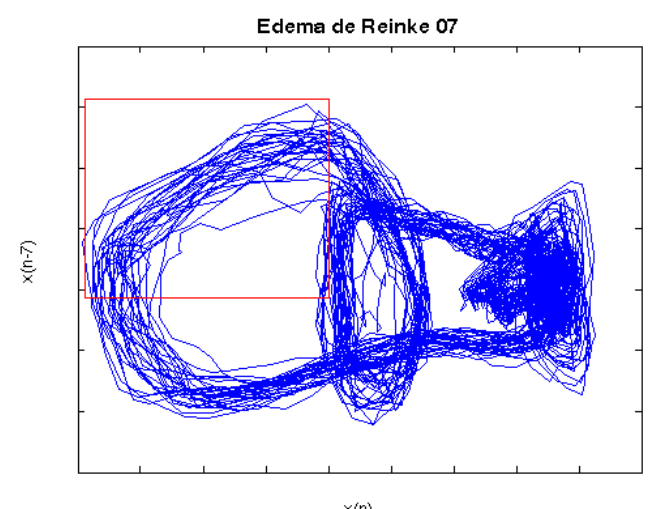

$x(n)$

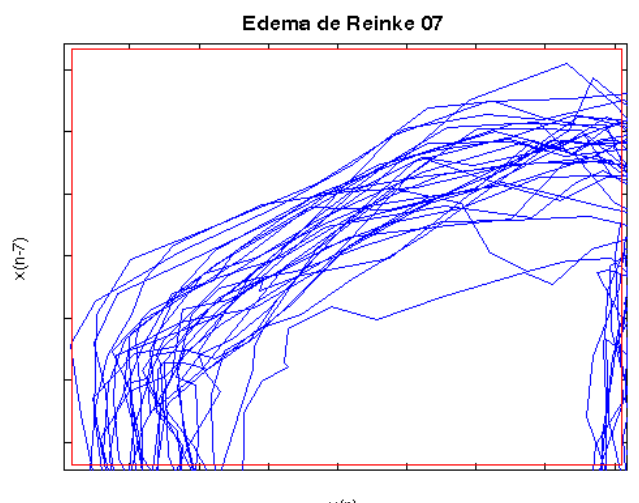

$x(n)$

Figura 4.13: Exemplo 07 e uma aproximação de PVDV de uma voz com edema de Reinke.

\section{Nódulos vocais}

Os resultados da análise qualitativa dos PVDV de sinais com nódulo foram: seis PVDV (40\%) com 1 laço; quatro PVDV (26,66\%) com 2 laços, dois PVDV (13,33\%) com 3 loops e dois PVDV (13,33\%) com 4 loops; somente um PVDV $(6,66 \%)$ foi avaliado com loop grau 0 . Referente à regularidade dos traçados, quatro PVDV $(26,66 \%)$ apresentaram traçados grau 3 (regularidade intermitente); quatro PVDV $(26,66 \%)$ com grau 2 (traçados irregulares leves global); quatro (26,66\%) com grau 1 (irregularidade leve com focos de irregularidade e três PVDV (20\%) com traçados grau 0 (irregularidade global). 
$\mathrm{Na}$ avaliação da convergência nove PVDV (60\%) apresentaram convergência de traçados de forte a média (Grau 3); dois PVDV (13,33\%) convergência média (grau 2); dois PVDV (13,33\%) com convergência de média a fraca, e dois PVDV (13,33\%) com convergência grau 0 (fraca convergência). A tabela 4-16 apresenta os resultados qualitativos da análise dos PVDV dos sinais de voz com nódulos vocais.

Tabela 4-16: Resultados qualitativos dos PVDV das vozes com nódulos vocais.

\begin{tabular}{cccc}
\hline Sinal de voz & Laços & Regularidade & Convergência \\
\hline Paciente 1 & 3 & 2 & 3 \\
Paciente 2 & 1 & 0 & 3 \\
Paciente 3 & 1 & 0 & 3 \\
Paciente 4 & 1 & 1 & 3 \\
Paciente 5 & 4 & 3 & 3 \\
Paciente 6 & 4 & 3 & 3 \\
Paciente 7 & 3 & 3 & 2 \\
Paciente 8 & 1 & 2 & 1 \\
Paciente 9 & 0 & 0 & 0 \\
Paciente 10 & 2 & 1 & 0 \\
Paciente 11 & 2 & 3 & 3 \\
Paciente 12 & 1 & 1 & 2 \\
Paciente 13 & 2 & 2 & 1 \\
Paciente 14 & 1 & 2 & 3 \\
Paciente 15 & 2 & 1 & 3 \\
\hline \hline
\end{tabular}

A figura 4.14 mostra 6 PVDV de sinais de voz com nódulo vocal, cada PVDV mostra a dinâmica diferenciada dos sinais de voz deste grupo. 


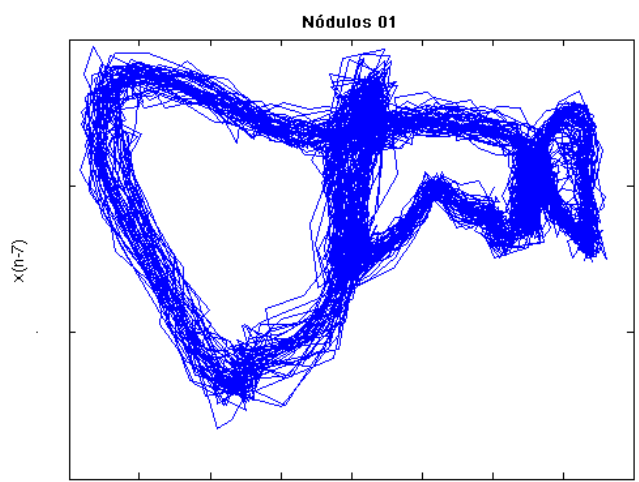

$x(n)$

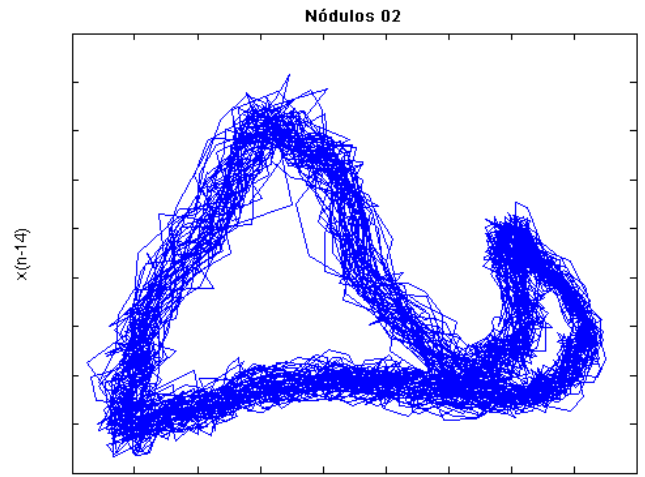

$x(n)$

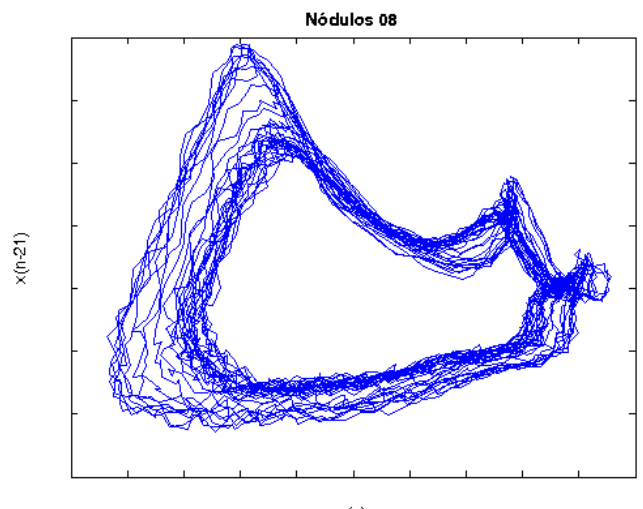

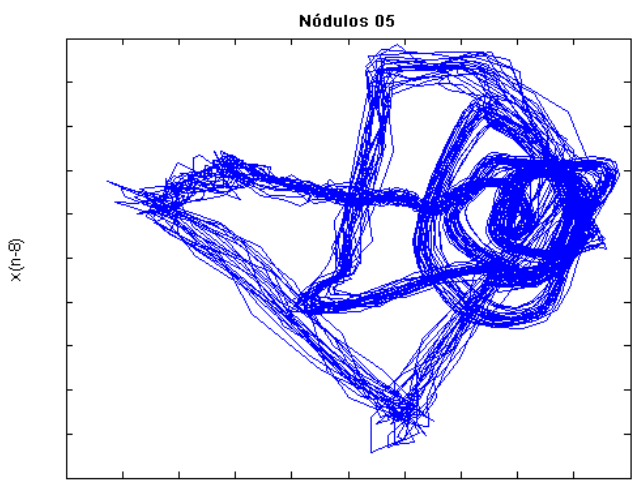

$x(n)$

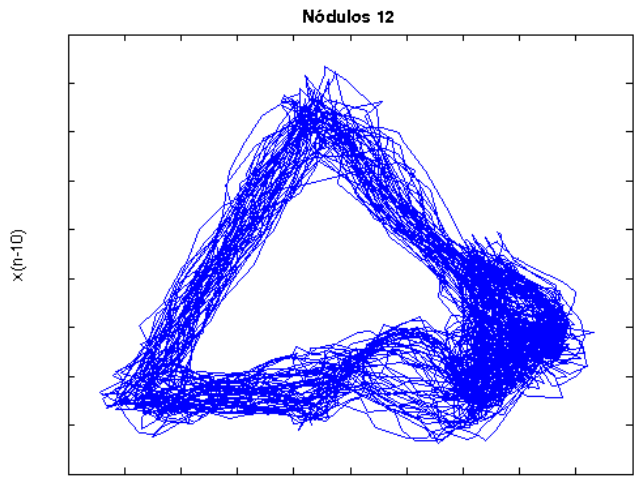

$x(n)$

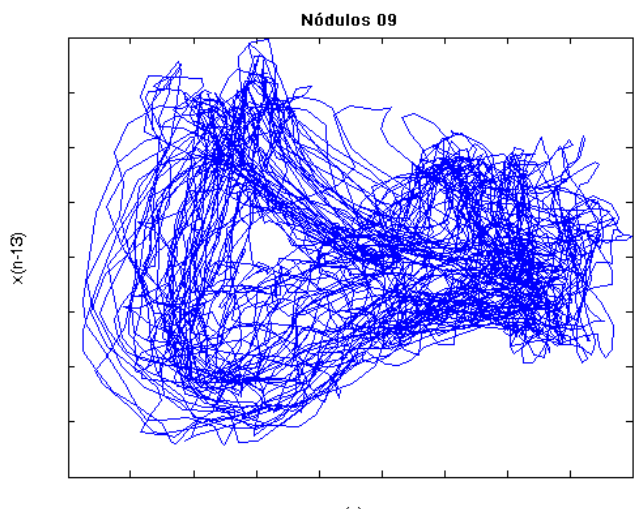

Figura 4.14: Exemplos de PVDV de seis vozes com nódulos vocais.

De modo particular, os PVDV 01 e 05 da figura 4.14 mostraram uma dinâmica similar à das vozes saudáveis com referência à configuração de laços (3 ou mais laços) mas em contrapartida apresentam menores graus de regularidade e a convergência, comparadas com as vozes saudáveis.

Nos exemplos 02 e 12 os PVDV mostraram um tipo de traçado com diferentes graus de irregularidade (grau 0 e grau 1, respectivamente) que 
evidência a proporção de ruído no sinal de voz. Nestes exemplos é possível ver a perda de laços na configuração - relacionada com menor quantidade de harmônicos do sinal de voz - e uma convergência média. A Figura 4.15 apresenta uma aproximação de uma porção do PVDV do sinal 12 , nesta imagem é possível apreciar as características de dinâmica irregular de sinais com nódulos vocais.

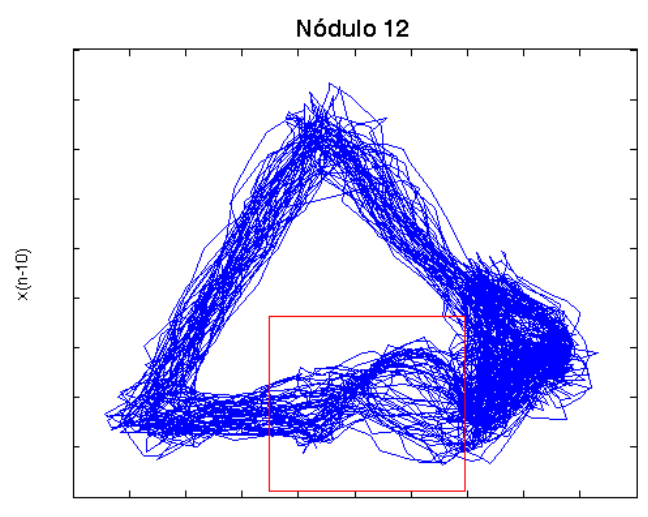

$x(n)$

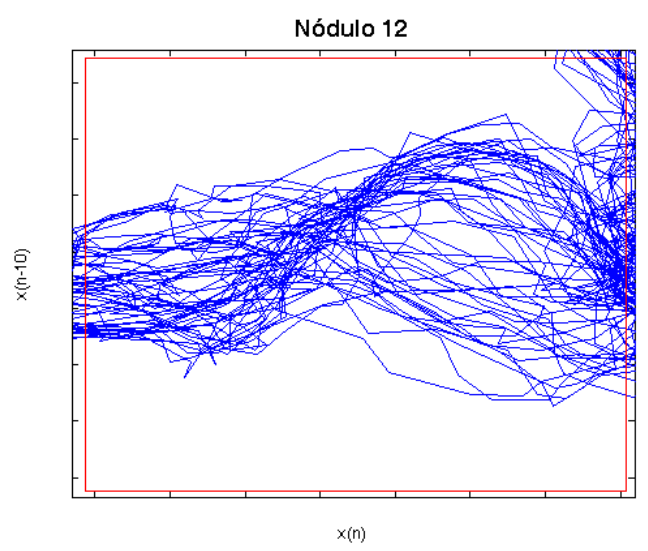

Figura 4.15: Exemplos de PVDV de seis vozes com nódulos vocais.

Os PVDV das vozes de nódulos 08 e 09 ilustram mais uma característica desviada, o grau de convergência. Nestas figuras é possível apreciar PVDV com configuração de loops grau 1, alta irregularidade dos traçados (Irregular leve global e Irregular global) e baixos graus de convergência (média a fraca, e fraca global). A figura 4.16 mostra em detalhe uma porção do PVDV da voz 08; nela é possível observar a irregularidade e a dispersão de traçados na dinâmica de uma voz com nódulos. 

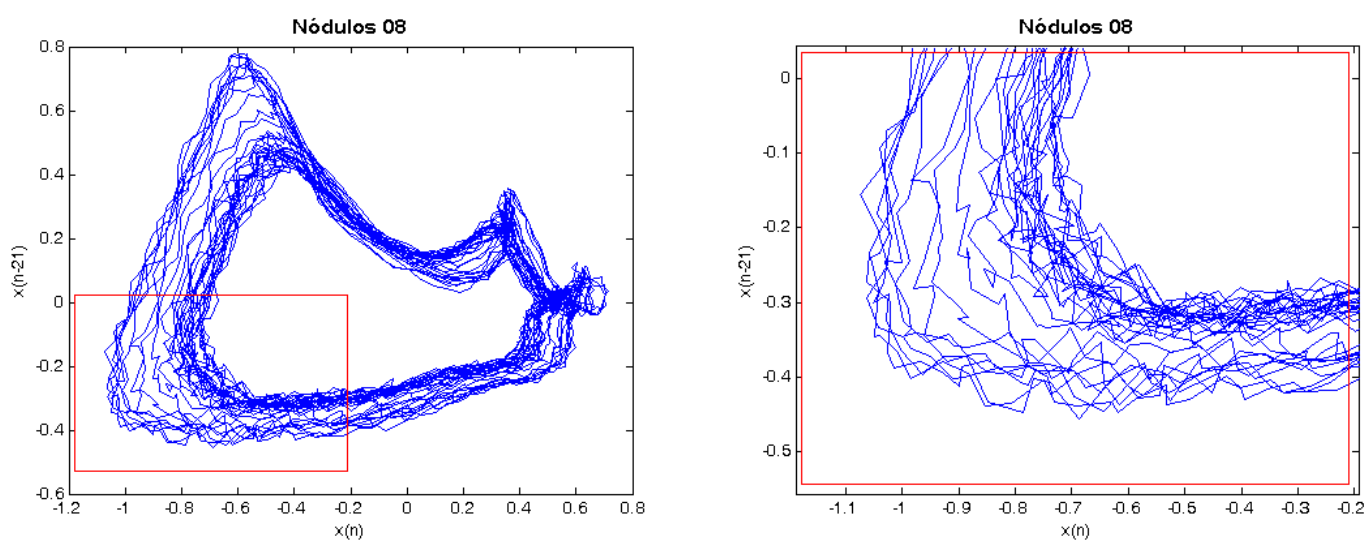

Figura 4.16: Exemplos de PVDV de seis vozes com nódulos vocais.

\subsubsection{Vozes com disfonia orgânica de origem neurológica}

A análise qualitativa dos padrões visuais de dinâmica vocal do grupo de vozes com alterações neurológicas resultou em: seis PVDV $(42,85 \%)$ com laços ou loops grau 0; um PVDV $(7,14 \%)$ com 1 laço; três PVDV $(21,42 \%)$ com 2 laços e três PVDV com três laços, e um PVDV $(7,14 \%)$ com mais de 3 laços (grau 4). Relativo ao traçado das órbitas, oito PVDV $(57,14 \%)$ apresentaram regularidade intermitente (grau 3); dois PVDV (14,28\%) com grau 2 e dois $(14,28 \%)$ PVDV com grau 0; um PVDV $(7,41 \%)$ com traçado (grau 1) e um PVDV $(7,41 \%)$ com traçado irregular (grau 4). A convergência foi avaliada com quatro PVDV (28,57\%) com grau 0 e quatro PVDV (28,57\%) com grau 1 de convergência; um PVDV ( 7,14\%) apresentou grau 3 e cinco PVDV $(35,71 \%)$ com grau 2. A tabela 4-17 apresenta os resultados completos da avaliação qualitativa deste grupo. 
Tabela 4-17: Avaliação qualitativa dos PVDV das vozes com disfonia neurológica.

\begin{tabular}{lccc}
\hline Pacientes & Laços & Regularidade & Convergência \\
\hline Paciente 1 & 0 & 3 & 0 \\
Paciente 2 & 2 & 3 & 1 \\
Paciente 3 & 0 & 0 & 0 \\
Paciente 4 & 0 & 3 & 2 \\
Paciente 5 & 0 & 3 & 0 \\
Paciente 6 & 4 & 3 & 3 \\
Paciente 7 & 3 & 2 & 2 \\
Paciente 8 & 3 & 3 & 2 \\
Paciente 9 & 0 & 2 & 1 \\
Paciente 10 & 3 & 3 & 2 \\
Paciente 11 & 0 & 4 & 0 \\
Paciente 12 & 1 & 0 & 2 \\
Paciente 13 & 2 & 3 & 1 \\
Paciente 14 & 2 & 1 & 1 \\
\hline \hline
\end{tabular}

A figura 4.17 mostra seis exemplos PVDV de vozes com alterações neurológicas. Nesta figura pode-se apreciar a dinâmica dos sinais com traçados de convergência média a fraca, nas quais é difícil avaliar a configuração geral e o número de laços ou loops. 


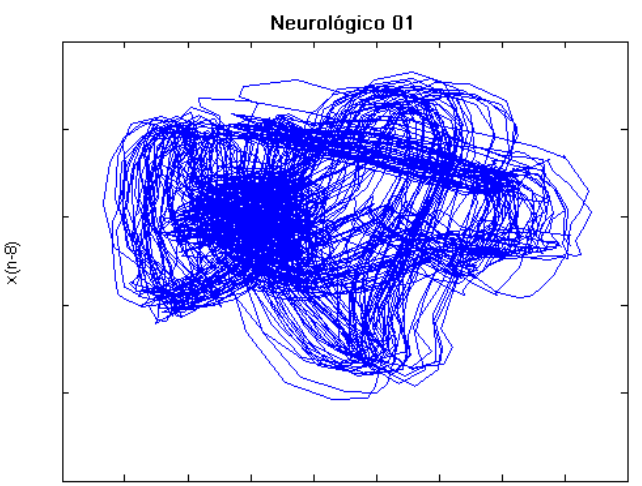

$x(n)$

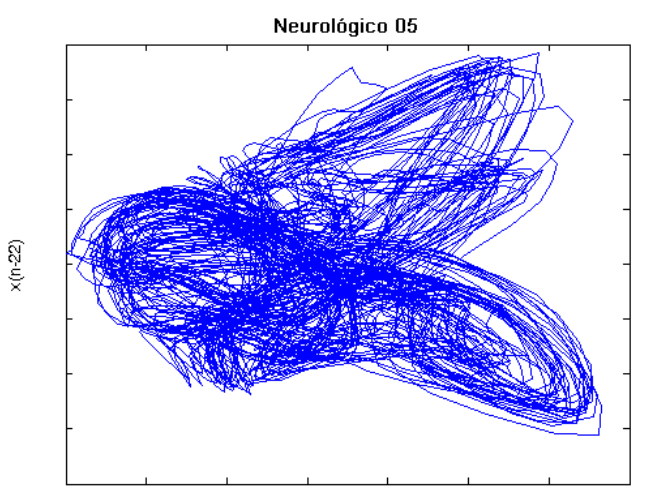

$x(n)$

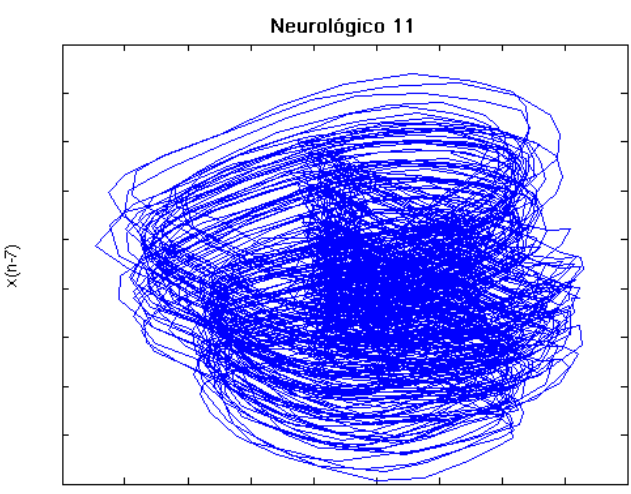

$x(n)$

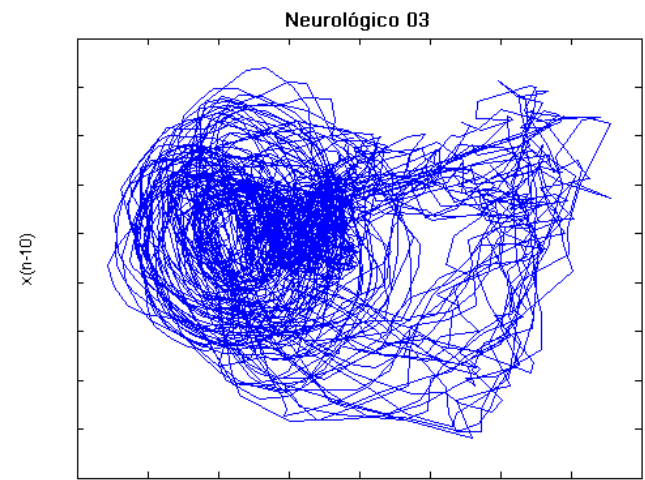

$x(n)$

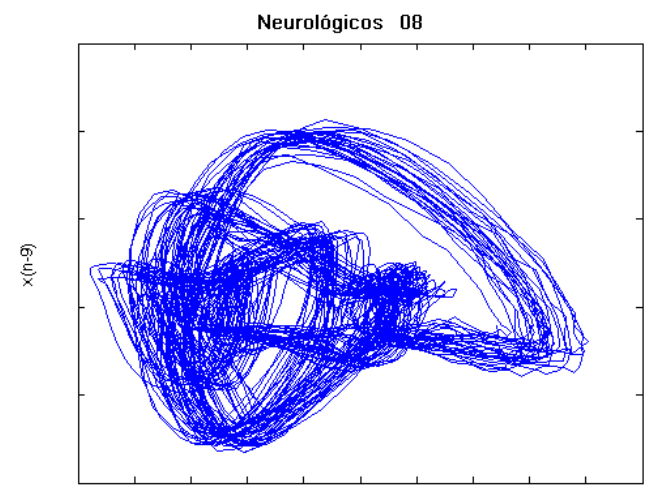

$x(n)$

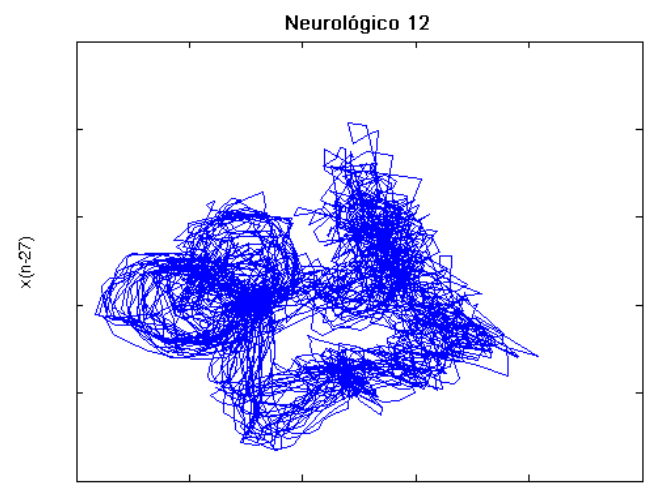

$x(n)$

Figura 4.17: Exemplos de PVDV de vozes de pacientes com alterações neurológicas.

Na maioria dos casos que a convergência é fraca o número de laços também se encontra classificado com grau 0 , já que formato e loops ficam prejudicados na projeção do PVDV, como mostram os exemplos 01, 05 e 11 da Figura 4.17. Estes PVDV embora com baixos graus de convergência e de laços apresentam trajetórias com grau de regularidade intermitente e regularidade com foco de irregularidade como mostra em detalhe da figura 4.18. 


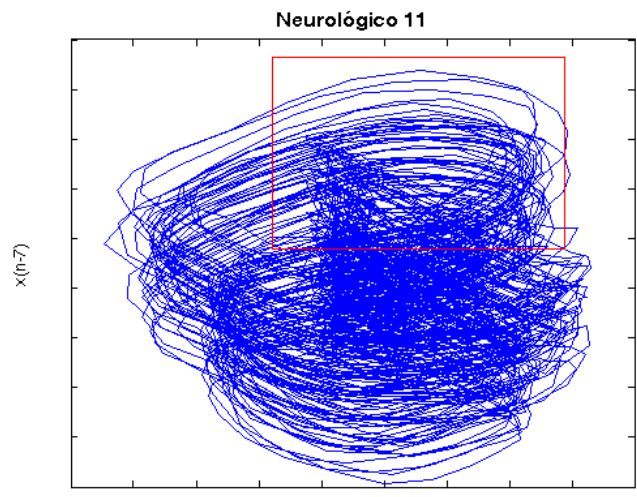

$x(n)$

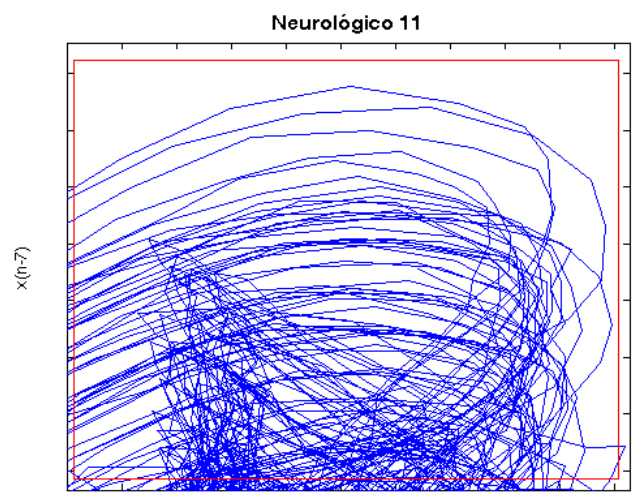

$x(n)$

Figura 4.18: Exemplo 11 e uma aproximação de PVDV de uma voz com disfonia de origem neurológica.

No caso dos exemplos 03 e 12, ambas foram avaliadas com traçados de irregularidade global (grau 0) mas diferentes graus de convergência e loops, a característica mais notória é a irregularidade como mostra a aproximação na figura 4.19.
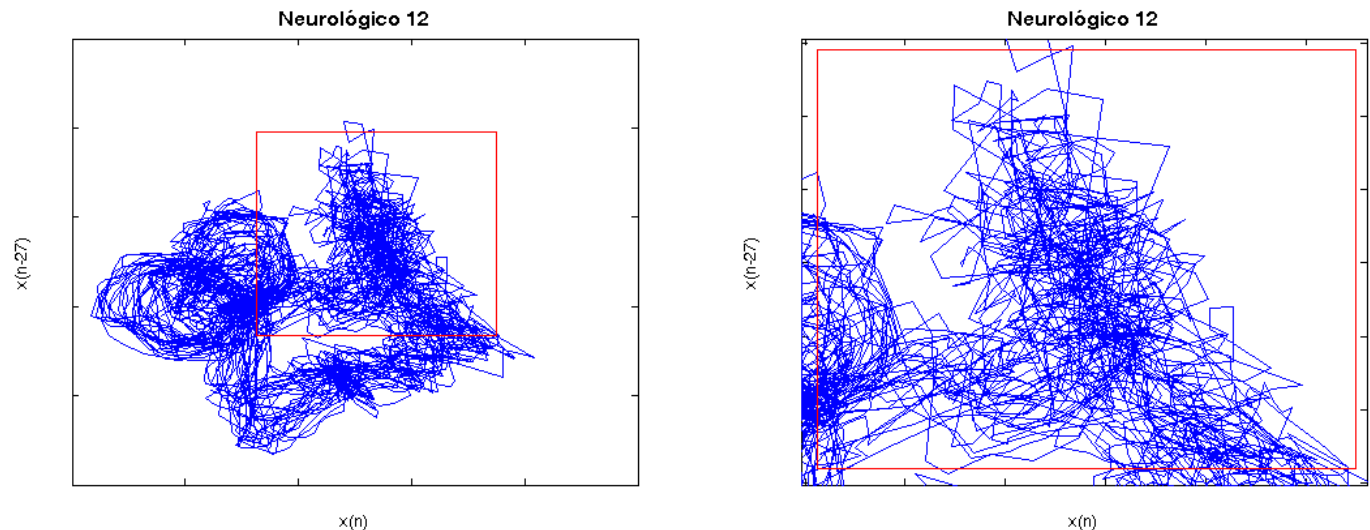

Figura 4.19: Exemplo 12 e uma aproximação de PVDV de uma voz com disfonia de origem neurológica.

$\mathrm{Na}$ avaliação geral dos sinais com disfonia neurológica foram observadas mudanças do formato e número de laços ou loops, da regularidade e da convergência dos traçados, se comparadas com as vozes saudáveis e também com os outros grupos de sinais com disfonia organofuncional. 
Conseqüentemente, as vozes com disfonia metrológica apresentam uma dinâmica característica que as diferencia dos outros grupos

\section{Avaliação comparativa dos 4 grupos de vozes.}

A tabela 4-18 apresenta comparativamente as porcentagens de ocorrência de grau de laços ou loops para cada grupo.

Tabela 4-18: Comparação de porcentagens de graus de laços dos 4 grupos de vozes

\begin{tabular}{ccc|cc|cc|cc}
\hline & \multicolumn{2}{c|}{ Saudáveis } & \multicolumn{2}{c|}{ Edema de Reinke } & \multicolumn{2}{c|}{ Nódulos } & \multicolumn{2}{c}{ D. Neurológica } \\
\hline Loops & $\%$ & $\mathrm{~N}$ & $\%$ & $\mathrm{~N}$ & $\%$ & $\mathrm{~N}$ & $\%$ & $\mathrm{~N}$ \\
Grau 4 & 68,75 & 11 & 12,5 & 2 & 13,34 & 2 & 7,14 & 1 \\
Grau 3 & 31,25 & 5 & 25 & 4 & 13,34 & 2 & 21,43 & 3 \\
Grau 2 & - & - & 31,25 & 5 & 26,66 & 4 & 21,43 & 3 \\
Grau 1 & - & - & 31,25 & 5 & 40 & 6 & 7,14 & 1 \\
Grau 0 & - & - & - & - & 6,66 & 1 & 42,86 & 6 \\
\hline \hline
\end{tabular}

Legenda: $\mathrm{N}=$ número de amostras

Quando realizado o tratamento estatístico do parâmetro de laços ou loops, encontrou-se que um $\mathrm{H}_{\text {corrigido }}=18,7512$ superior à o $H_{\text {tabela }}=7,81$ para 0,05 de significância, por tanto rejeita-se a hipótese nula e os quatro grupos podem ser considerados diferentes. O teste de Dunn evidencio que existe diferença entre os grupos de: saudáveis vs. edema de Reinke com um $Q_{\text {calculado }}=3,6393$; saudáveis vs. nódulos com $Q_{\text {calculado }}=3,8636$ e saudáveis vs. disfonia neurológica com $Q_{\text {calculado }}=4,50649$, todos valores superiores ao $Q(0,05 ; 4)=2,64$. As combinações entre patologias mostraram valores de

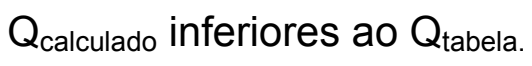

Tomando como referência o grupo de vozes saudáveis, na avaliação da regularidade dos traçados, também foi observada uma dinâmica diferencial 
entre os grupos. O parâmetro de regularidade dos traçados teve um comportamento similar ao de loops. Mostrando semelhanças entre os grupos de edema de Reinke e nódulos, que apresentaram PVDV sem graus 5 e 4; com uma distribuição mais uniforme de graus e com maior concentração nos grau 3 e 2. Nenhuma das vozes com disfonia neurológica apresentou traçados regulares; este grupo teve maior concentração de casos para o grau 3 (regularidade intermitente). A tabela 4-19 apresenta as porcentagens e número de casos para o grupo.

Tabela 4-19: Comparação de porcentagens de graus de regularidade de traçados dos 4 grupos de vozes

\begin{tabular}{ccc|cc|cc|cc}
\hline & \multicolumn{2}{c|}{ Saudáveis } & \multicolumn{2}{c|}{ Edema de Reinke } & \multicolumn{2}{c|}{ Nódulos } & \multicolumn{2}{c}{ D. Neurológica } \\
Regularidade & $\%$ & $\mathrm{~N}$ & $\%$ & $\mathrm{~N}$ & $\%$ & $\mathrm{~N}$ & $\%$ & $\mathrm{~N}$ \\
\hline Grau 5 & 18,75 & 3 & - & - & - & - & - & - \\
Grau 4 & 75 & 12 & 18,75 & 3 & - & - & 7,15 & 1 \\
Grau 3 & 6,25 & 1 & 37,50 & 6 & 26,66 & 4 & 57,14 & 8 \\
Grau 2 & - & - & 25 & 4 & 26,66 & 4 & 14,28 & 2 \\
Grau 1 & - & - & 6,25 & 1 & 26,66 & 4 & 7,15 & 1 \\
Grau 0 & - & - & 12,5 & 2 & 20 & 3 & 14,28 & 2 \\
\hline \hline
\end{tabular}

No teste estatístico, a regularidade dos traçados dos quatro grupos apresentou um $\mathrm{H}_{\text {calculado }}=32,89441$ superior ao $\mathrm{H}_{\text {tabela }}=7,81$; então é rejeitada a hipótese nula e os grupos são considerados estatisticamente diferentes. $O$ teste de Dunn mostrou que os grupos com diferença foram: saudáveis vs. Edema de Reinke com $Q_{\text {calculado }}=3,860021$; saudáveis vs. nódulos com $Q_{\text {calculado }}=5,455822$ e saudáveis vs. disfonia neurológica com $Q_{\text {calculado }}=$ 3,918488 As combinações entre patologias apresentaram valores inferiores ao $Q_{\text {tabela }}=2,64$. 
Para o parâmetro de convergência de traçados, os sinais saudáveis foram avaliados em sua maioria com grau 4 e 3 , enquanto os sinais de vozes patológicas tiveram maior ocorrência de dispersão, principalmente nos pacientes com disfonia neurológica. Vozes saudáveis, de edema e de nódulos apresentaram maior número de casos para o grau 3 , mas a distribuição dos restantes sinais foi diferente para nódulos e edema. A tabela 4-20 apresenta comparativamente as porcentagens de ocorrência de grau de convergência para cada grupo.

Tabela 4-20: Comparação de porcentagens de graus de convergência para os 4 grupos

\begin{tabular}{ccc|cc|cc|cc}
\hline & \multicolumn{2}{c|}{ Saudáveis } & \multicolumn{2}{c|}{ Edema de Reinke } & \multicolumn{2}{c|}{ Nódulos } & \multicolumn{2}{c}{ D. Neurológica } \\
\hline Convergência & $\%$ & $\mathrm{~N}$ & $\%$ & $\mathrm{~N}$ & $\%$ & $\mathrm{~N}$ & $\%$ & $\mathrm{~N}$ \\
G4 & 31,25 & 5 & - & - & 0 & 0 & - & - \\
G3 & 50 & 8 & 50 & 8 & 60 & 9 & 7,14 & 1 \\
G2 & 18,75 & 3 & 31,25 & 5 & 13,33 & 2 & 35,71 & 5 \\
G1 & - & - & 18,75 & 3 & 13,33 & 2 & 28,57 & 4 \\
G0 & - & - & - & - & 13,33 & 2 & 28,57 & 4 \\
\hline \hline
\end{tabular}

Para grau de convergência, o teste não paramétrico de Kruskal- Wallis, mostrou diferença estatística entre os grupos, com um $H_{\text {calculado }}=22,11417$, superior ao $\mathrm{H}$ crítico $=7,81$ para $\alpha=0,05$. O teste de Dunn evidenciou diferenças entre os grupos: saudáveis vs. disfonia neurológica com $Q_{\text {calculado }}=4,698701$; edema de Reinke vs. disfonia neurológica com $Q_{\text {calculado }}=2,714065$ e entre nódulos vs. disfonia neurológica com $Q_{\text {calculado }}=2,691783$, valores de $Q_{\text {calculado }}$ superiores ao $Q(0,05 ; 4)=2,64$. As comparações restantes foram inferiores ao $Q$ crítico e, portanto, sem diferença estatisticamente significante.

Para avaliar a associação de variáveis das três técnicas utilizadas avaliação perceptivo-auditiva, acústica e de PVDV - foi aplicado o coeficiente 
de correlação (r), avaliado qualitativamente quanto à intensidade segundo os critérios propostos por CALLEGARI-JACQUES (2003). Para validar os coeficientes de correlação foi aplicado o teste $\mathrm{T}$, com um nível de significância de $\alpha=0,05$, o $t_{\text {tabela }}$ foi de 1,98 . Todos os coeficientes de correlação $(r)$ e os valores de $\mathrm{t}$ calculado encontram-se na tabela 4-21.

Tabela 4-21: Coeficiente de correlação ( $r$ ) para as três técnicas de análise de voz

\begin{tabular}{|c|c|c|c|}
\hline Acústica x Perceptiva & $r$ & Grau de correlação & T calculado \\
\hline Jitter x Rugosidade & 0,2912 & Fraca & $2,8716^{*}$ \\
\hline Jitter $\times$ Soprosidade & 0,243 & Fraca & $2,3633^{*}$ \\
\hline Jitter x Tensão & 0,0603 & Fraca & 0,5699 \\
\hline Jitter $x$ Irregularidade & 0,3952 & Regular & $4,0581^{*}$ \\
\hline Shimmer $\times$ Rugosidade & 0,3471 & Regular & $3,4916^{*}$ \\
\hline shimmer $\times$ Soprosidade & 0,2791 & Fraca & $2,742^{*}$ \\
\hline Shimmer x Tensão & 0,2093 & Fraca & $2,0193^{*}$ \\
\hline Shimmer $\mathrm{x}$ Irregularidade & 0,4756 & Regular & $5,1006^{*}$ \\
\hline Acústica x PVDV & $r$ & Grau de correlação & T calculado \\
\hline jitter x Loop (laço) & $-0,4089$ & Regular & $4,2271^{*}$ \\
\hline Jltter x Regularidade & $-0,3812$ & Regular & $3,89^{*}$ \\
\hline Jitter x Convergência & $-0,484$ & Regular & $5,2179^{*}$ \\
\hline Shimmer x Loop (laço) & $-0,322$ & Regular & $3,2086^{*}$ \\
\hline Shimmer $\times$ Regularidade & $-0,2278$ & Fraca & $2,2071^{*}$ \\
\hline Shimmer $\times$ Convergência & $-0,5729$ & Regular & $6,5941^{*}$ \\
\hline Perceptiva x PVDV & $r$ & Grau de correlação & T calculado \\
\hline Rugosidade x Loop (laço) & $-0,4589$ & Regular & $4,8726^{*}$ \\
\hline Rugosidade $x$ Regularidade & $-0,3987$ & Regular & $4,1014^{*}$ \\
\hline Rugosidade x Convergência & $-0,5281$ & Regular & $5,8669^{*}$ \\
\hline Soprosidade x Loop (laço) & $-0,5684$ & Regular & $6,5175^{*}$ \\
\hline Soprosidade $\mathrm{x}$ Regularidade & $-0,4377$ & Regular & $4,5925^{\star}$ \\
\hline Soprosidade x Convergência & $-0,5113$ & Regular & $5,6127^{*}$ \\
\hline Tensão x Loop (laço) & $-0,1643$ & Fraca & 1,5714 \\
\hline Tensão x Regularidade & $-0,0663$ & Fraca & 0,6269 \\
\hline Tensão x Convergência & $-0,3427$ & Regular & $3,4414^{*}$ \\
\hline Irregularidade x Loop (laço) & $-0,5095$ & Regular & $5,5860^{*}$ \\
\hline Irregularidade $x$ Regularidade & $-0,2893$ & Fraca & $2,8512^{*}$ \\
\hline Irregularidade $\mathrm{x}$ Convergência & $-0,5661$ & regular & $6,4786^{*}$ \\
\hline
\end{tabular}




\section{DISCUSSÃO}

Neste trabalho foram processados 91 sinais de voz, separados em 4 grupos: vozes saudáveis, vozes com edema de Reinke, vozes com nódulos e vozes com disfonia neurológica. Também foi incluído um subgrupo para as vozes saudáveis: vozes saudáveis com alteração postural, este grupo foi incluído com o objetivo de avaliar mais profundamente as possibilidades das técnicas. Foram empregadas duas ferramentas tradicionais da clínica fonoaudiológica (avaliação perceptivo-auditiva e análise acústica) em conjunto com a nova técnica de análise dos padrões visuais de dinâmica vocal (PVDV). Por aplicar um conjunto de ferramentas, esta pesquisa proporcionou um panorama geral da abrangência da análise qualitativa dos PVDV, evidenciando seus alcances e limites; ademais de estabelecer associações e interferências entre parâmetros e técnicas.

Avaliação perceptivo-auditiva

Para o grupo de vozes sem alteração vocal, a análise perceptivo-auditiva apresentou resultados esperados e compatíveis com os encontrados na literatura. Embora alguns problemas com a terminologia comprometem o consenso e a comparação de resultados (KURDUK, 2009), as vozes saudáveis produzem ciclos glóticos quase-periódicos, porque a integridade da margem 
vibratória das pregas vocais produz uma boa qualidade vocal (SATALOFF, 1997).

Embora alguns autores (SCHNEIDER, DENNEHY, SAXON, 1997) e (KYRILLOS, CORTES, FEIJÓ, 2003) enfatizam que uma postura correta pode fazer grande diferença no resultado da produção vocal, o subgrupo de vozes saudáveis alteração postural, não apresentou diferença estatística na avaliação perceptivo-auditiva entre os três grupos avaliados, resultados semelhantes aos achados por CARNEIRO ET AL (2008) e CARNEIRO (2009). O trabalho de ARBOLEDA e FREDERICK (2008) afirma que a postura da coluna cervical esta diretamente relacionada à ressonância. Este aspecto não foi contemplado neste trabalho, portanto é sugerido que seja considerado em trabalhos futuros.

Os grupos de vozes com disfonias organofuncionais e orgânicas mostraram que o parâmetro de rugosidade foi um diferencial quando comparadas vozes saudáveis com vozes com edema de Reinke. Esta rugosidade percebida nas vozes com edema de Reinke pode ser ocasionada nos movimentos assimétricos das pregas vocais com sucessivas vibrações aperiódicas (HIRANO \& BLESS, 1997).

A soprosidade mostrou ser uma característica distintiva quando comparadas vozes saudáveis e vozes de nódulos, assim como para, vozes saudáveis e vozes com disfonia neurológica. De acordo com KARKOS; MCCORMICK (2009) os nódulos são lesões que interferem no fechamento glótico causando principalmente rugosidade e ocasionalmente soprosidade; no 
caso das disfonias de origem neurológicas a soprosidade pode ser uma das principais características em diversas patologias neurológicas (COLTON, CASPER, LEONARD, 2010).

A tensão e a irregularidade foram aspectos diferenciais na comparação de sinais de edema de Reinke e disfonias neurológicas. Nas vozes com edema de Reinke a massa da cobertura aumenta, enquanto sua rigidez diminui, e tal redução da rigidez permite maiores amplitudes de vibração com pouca ou mínima tensão vocal. De modo contrario, algumas das patologias neurológicas produzem disfonias espásticas, com maior tono muscular e reflexos hiperativos, assim como disfonias hipercinéticas, que produzem movimentos acelerados e descontrolados (BEHLAU, 2005). A irregularidade foi distintiva, entre os grupos de edema de Reinke e nódulos vocais, estas últimas lesões, se caracterizam por um fechamento glótico incompleto e dependendo do tamanho podem produzir maior irregularidade dos ciclos glóticos (KARKOS; McCORMICK, 2009).

A avaliação perceptivo-auditiva com uma escala de graus não apresentou diferenças estatisticamente significantes. Resulta importante mencionar que avaliações perceptivo-auditivas que empregam escalas analógicas, como por exemplo, a escala CAPE-V (ASHA, 2002), podem fornecer resultados diferentes aos encontrados neste estudo. 
Avaliação Acústica

$\mathrm{Na}$ avaliação acústica do grupo de vozes saudáveis encontrou-se porcentagens menores a $2,25 \%$ de shimmer e $0,3 \%$ de jitter. De acordo com (BEHLAU, 2001) vozes saudáveis apresentam simetria de amplitude e fase, periodicidade, e uma boa coaptacão glótica, que favorecem um sinal de voz estável com qualidade vocal e baixa porcentagem de perturbação de amplitude e freqüência. O mesmo aconteceu com as vozes com alterações posturais, que não apresentaram diferença estatística para a avaliação acústica, resultados similares aos de CARNEIRO ET AL (2008).

Em contrapartida, as vozes com disfonia tanto organofuncional quanto orgânica apresentaram valores maiores de jitter e shimmer, mas estas diferenças não foram estatisticamente significantes. Este resultado é similar ao encontrado no trabalho de DOUGLAS EL AT (2005), que analisou vozes sem alteração e vozes com doença de Parkinson. Algumas vozes com edema de Reinke e com nódulos apresentaram parâmetros acústicos compatíveis com os valores de vozes consideradas como saudáveis. Isto pode ser devido ao fato de as vozes com edema de Reinke e nódulos vocais pertencerem a diferentes estágios evolutivos. Para o grupo das disfonias neurológicas, é possível que a variedade de doenças consideradas neste grupo, seja um fator de interferência aumentando a heterogeneidade dos valores de jitter e shimmer. É sugerido que em próximos trabalhos sejam avaliadas vozes com um tipo de doença neurológica. 
Avaliação qualitativa dos PVDV

As vozes saudáveis, que foram avaliadas sem desvio da qualidade e com baixas porcentagens de perturbação de freqüência e amplitude, apresentaram PVDV com graus 4 e 3 para laços ou loops e convergência, e graus 5 e 4 para regularidade de traçados. De igual modo que em trabalhos anteriores, estas configurações foram tomadas como referenciais (SCALASSARA ET AL, 2009) e (DAJER, SOBRINHO, PEREIRA, 2010). As características da configuração de loops encontram-se relacionadas com a quantidade de formantes e suas respectivas amplitudes. Na vogal /a/ o gesto vocal proporciona a ressonância de várias freqüências harmônicas devido à cavidade bucal expandida (MAGRI, 2007).

Os resultados do parâmetro de regularidade das vozes saudáveis são similares aos achados por MAC CALLUM (2009), e sugerem que os sinais são altamente estacionários e com baixos índices de perturbações e ruído. 0 comportamento convergente das trajetórias é mais característico em sinais estacionários, onde as órbitas tendem a passar repetidamente pelo mesmo ponto ou muito próximo dele (KANTZ E SCHREIBER, 2003). Os traçados regulares, ou com uma pequena porção de irregularidade, indicam uma baixa proporção de ruído no sinal. A característica de forte convergência de traçádos, quando as trajetórias passam a cada ciclo pelo mesmo ponto ou muito próximo dele, refere-se à estacionaridade do sinal, e apresenta baixos índices de perturbação em freqüência e amplitude. Achados similares foram mencionados nos trabalhos com vozes saudáveis e patológicas de MAC CALLUM (2009), 
JIANG ET AL (2009), SCALASSARA ET AL (2009), DAJER, SOBRINHO, PEREIRA (2010) e MARRARA (2010).

A análise qualitativa dos PVDV do subgrupo de alterações posturais mostrou diferenças na dinâmica de loops, regularidade e convergência de traçados, se comparados os três grupos de posturas. A configuração de loops e a convergência foram diferentes para os grupos de postura 1 e postura 3; a regularidade apresentou diferenças para os grupos de postura1 e postura 2. Os efeitos destas mudanças encontram-se justificadas nos trabalhos de ARBOLEDA, (2008) e CARNEIRO (2009).

Nos sinais com edema de Reinke foi observada maior divergência nas configurações. Ainda que, todos os sinais pertençam ao mesmo grupo (mesma classificação por patologia), cada um deles tem uma dinâmica particular, e conseqüentemente, um PVDV único. Isto pode ser devido a: 1) cada voz é única e possui características próprias, que podem ser semelhantes a outras, mas nunca idênticas; e 2) os sinais de voz pertencem à pacientes em diferentes etapas evolutivas da patologia. MARTINS ET AL (2009) observaram que diversas lesões que aparecem nas pregas vocais com edema de Reinke também podem ser vistas em outras patologias como nódulos e pólipos. Estes motivos podem justificar que vozes com a mesma patologia apresentem um comportamento dinâmico semelhante, mas com diferenças de grau.

O grupo de nódulos foi avaliado com configurações menos complexas e menor quantidade de laços, o que está relacionado com a perda de freqüências 
harmônicas das vozes com lesões de massa. Também apresentou menor grau de regularidade e convergência de traçados, o que está relacionado com a quantidade de ruído no sinal e perturbação da freqüência e amplitude. Num estudo com técnicas não lineares aplicadas na análise de vozes saudáveis, nódulos e pólipos, JIANG ET AL (2009) acharam que as vozes saudáveis apresentaram espaços de fase com trajetórias regulares e próximas enquanto vozes patológicas mostraram espaços de fase irregulares.

Nas vozes com disfonia neurológica as configurações de PVDV refletiram a presença de ruído e instabilidade do sinal de voz deste tipo de patologia. Este grupo se caracterizou pela perda de loops, devido à perda de freqüências harmônicas do sinal, e flutuação de traçados que provocam desorganização na configuração e está relacionada com a instabilidade característica deste tipo de disfonia (BEHLAU, 2005). No estudo de MARRARA (2010) foi encontrado um comportamento dinâmico semelhante em pacientes com patologia neurológica, cabe mencionar que neste trabalho também foram consideradas diversas patologias de origem neurológica. É sugerido realizar trabalhos futuros com uma patologia especifica para evitar a interferência da diversidade de comportamentos.

Em síntese, a dinâmica dos PVDV das vozes de pacientes com disfonia organofuncional - como as de edema de Reinke e nódulos vocais, apresentadas neste trabalho - podem estar correlacionadas com as características anatomo-fisiológicas deste tipo de lesões. Nestas patologias a presença de uma massa interfere no fechamento da borda livre das pregas 
vocais; produzem escape de ar devido à presença da lesão (BEHLAU, 2001), e diminui a onda mucosa por alterações histológicas nas camadas das pregas vocais (MADRUGA ET AL, 2003). Os fatores mencionados produzem uma coaptação glótica insuficiente aumentando o ruído na fonte glótica e perturbação de freqüência e amplitude; o que no PVDV é representado pela irregularidade dos traçados, baixa convergência e perda de complexidade na configuração de laços ou loops.

Quando comparados os grupos de vozes normais, vozes com edema de Reinke, vozes com nódulos e vozes com disfonia neurológica, a análise qualitativa dos PVDV mostrou diferenças de dinâmica de loops, regularidade e convergência de traçados. Para os parâmetros de loops e de regularidade as vozes saudáveis comparadas com as de edema de Reinke, com as de nódulos e com as de disfonia neurológica apresentaram diferenças estatísticas, deixando evidente o comportamento característico de cada grupo. Mas comparando as vozes de edema de Reinke com as vozes de nódulos o comportamento foi semelhante entre si. Isto pode ser em decorrência de ambas serem lesões de massa com algumas características em comum, como por exemplo, perda de freqüências harmônicas, o que é refletido em PVDV com menor quantidade de loops.

O comportamento convergente foi diferencial para as vozes saudáveis e com disfonia neurológica, para as vozes de edema de Reinke e disfonia neurológica e para as vozes de nódulos e disfonia neurológica. Este parâmetro, 
diferente dos outros, foi capaz de distinguir o comportamento entre vozes com alterações patológicas, portanto deve ser mais explorado em trabalhos futuros.

Correlação de parâmetros perceptivos, acústicos e dinâmicos

$\mathrm{Na}$ associação dos parâmetros acústicos e perceptivos, encontramos uma correlação positiva de grau regular ou moderado, entre jitter e irregularidade, a medida que aumenta a porcentagem de jitter, as vozes são percebidas como mais irregulares. O mesmo tipo de correlação foi encontrado entre shimmer e rugosidade, e entre shimmer e irregularidade, ou seja, quanto maior a porcentagem de shimmer as vozes foram percebidas como mais rugosas e irregulares. Embora medidas acústicas e perceptivas sejam comumente usadas na clínica vocal, de acordo com o trabalho de meta-análise de MARYN ET AL (2009), as correlações entre parâmetros ainda são questionáveis.

Para os parâmetros acústicos e dinâmicos de PVDV, foi observada uma correlação negativa de grau moderado entre jitter e convergência, jitter e loops e entre jitter e regularidade, ou seja, o aumento de jitter está relacionado à perda de laços ou loops, menor grau de convergência e regularidade de traçados. O parâmetro de shimmer também apresentou correlação negativa de grau regular quando associado à convergência e loop, desta forma, na medida em que aumenta a porcentagem de shimmer diminui o grau de convergência e de laços do PVDV. 
Quando associados os parâmetros perceptivo-auditivos com os dinâmicos de PVDV, encontramos que rugosidade e soprosidade apresentaram uma correlação negativa de grau moderado com os três parâmetros dinâmicos; tensão e convergência também apresentaram o mesmo tipo de correlação; e irregularidade mostrou correlação negativa de grau moderado com convergência e loops.

Embora existam métodos que permitam quantificações dos Padrões Visuais de Dinâmica Vocal (como seção de Poincaré, Máximo Expoente de Lyapunov), a análise qualitativa descritiva dos PVDV tem um valor clínico que pode ser comparável com outras técnicas diagnósticas na área da saúde, como o ECG (eletrocardiograma), raios X, ou espectrograma. Este tipo de ferramenta evita valores médios - às vezes pouco representativos quando se fala em vozes patológicas - e permite ter uma visão geral dinâmica e descritiva de um sinal de voz, sem necessidade de uma prática invasiva.

Em contrapartida a outras ferramentas não invasivas de avaliação vocal, os PVDV permitem observar detalhadamente a dinâmica envolvida na produção de sinais de voz. Ademais fornecem, de forma rápida, econômica e não invasiva, informações complementares aos dados acústicos e perceptivos convencionais; o que possibilita caracterizar de forma mais acurada a dinâmica diferencial de cada sinal de voz, seja este considerando normal ou patológico.

$\mathrm{Na}$ avaliação e no tratamento de patologias vocais, este tipo de ferramenta fornece ao paciente outra via de informação - informação visual - 
que na maioria dos casos de pacientes com disfonia, causa maior impacto na conscientização da alteração vocal. Também podem ser úteis no processo terapêutico de disfonias, assim como, no treinamento vocal de profissionais da voz.

Com esta análise conjunta concluímos que embora as técnicas tradicionais de avaliação de voz proporcionem valores subjetivos e médios de grande valia e comparáveis com aqueles encontrados na bibliografia, a análise dos PVDV, por funcionar como parâmetro dinâmico e não depender da determinação da freqüência fundamental é uma ferramenta promissora para ser incorporada na clínica fonoaudiológica. 


\section{CONCLUSÕES}

A análise qualitativa descritiva dos PVDV mostrou resultados diferenciais para cada um dos grupos avaliados. Mostrando que configuração, regularidade e convergência dos traçados das vozes normais apresentam uma dinâmica diferencial em relação às vozes disfônicas. As características avaliadas nos traçados e na configuração dos Padrões Visuais de Dinâmica Vocal podem ser associadas e correlacionadas com aspectos da qualidade vocal e com as medidas de perturbação jitter e shimmer, oferecendo desta forma uma análise mais apurada e completa para o profissional e o paciente.

A associação entre técnicas mostra maiores índices para a correlação de parâmetros acústicos com PDVD, e para parâmetros perceptivos com PVDV. Entanto, a correspondência de variáveis acústicas e perceptivas obteve os menores índices. Mais especificamente, nas técnicas acústica e dinâmica, a maioria de sinais de voz com porcentagens elevadas de jitter são classificados com menor grau de convergência, assim como graus inferiores de regularidade de traçados e de loops. Sinais de voz com altas porcentagens de shimmer evidenciam PVDV com baixos graus de convergência e loops (laços).

A maioria das vozes avaliadas com grau elevado de rugosidade fornece

PVDV com menores graus de regularidade, convergência e loops. Sinais com 
grau mais elevado de soprosidade correspondem a configurações com graus inferiores para loops, regularidade e convergência. Elevados graus de tensão estão associados a configurações com menor grau de convergência. Vozes com maior grau de irregularidade as configurações de PVDV apresentam menor grau de loops (laços) e de convergência.

A análise dos PVDV ainda é uma ferramenta em desenvolvimento, portanto sugerimos trabalhos futuros com maior número de vozes, com diferentes patologias, com associação de outros métodos não lineares e inclusive, pesquisas que combinem análise do sinal de voz com imagem laríngea, a fim de correlacionar os mecanismos de produção vocal com os achados da análise dinâmica. Contudo, os resultados obtidos até o momento fazem pensar que a análise qualitativa descritiva dos Padrões Visuais da Dinâmica Vocal é uma importante ferramenta para triagens de voz, avaliação e acompanhamento de distúrbios da voz. 


\section{REFERÊNCIAS BIBLIOGRÁFICAS}

AMERICAN SPEECH-LANGUAGE-HEARING ASSOCIATION. Consensus Auditory-Perceptual Evaluation of Voice (CAPE-V). Rockville Pike, American Speech-Language-Hearing Association, 2002.

ARBOLEDA, BMW; FREDERICK, AL. Considerations for Maintenance of Postural Alignment for Voice Production. Journal of Voice, Vol. 22, Issue 1, pp. 90-99. 2008.

AWREJCEWICZ, J. Bifurcation Portrait of the Human Vocal Cord Oscillations. Journal of Sound and Vibration, 136 (1) pp. 151-156.1990.

BAKEN, RJ; ORLIKOFF, RF. Clinical Measurement of Speech and Voice. San Diego, CA: Singular Publishing Group, 2000.

BAKEN, RJ. Irregularity of vocal period and amplitude: A first approach to the fractal analysis of voice. Journal of Voice; Vol. 4: pp. 185-197; 1990.

BEHLAU, M. A Voz. O livro do especialista. Vol. I. Revinter, 2001.

BEHLAU, M. A Voz. O livro do especialista. Vol. II. Revinter, 2005.

BEHLAU, M. Oficina de técnicas de avaliação de voz. In: XV Congresso Brasileiro de Fonoaudiologia. Campos de Jordão, São Paulo, 2008.

BEHLAU, M; TOSI, O; PONTES, P. Determinação da freqüência fundamental e suas variações em altura (jitter), em intensidade (shimmer) para falantes do português brasileiro. Acta AWHO 4: pp. 5-9; 1985.

BEHRMAN, A. Common practices of voice therapists in the evaluation of patients. Journal of Voice. 19:pp. 454-469. 2005.

BERRY, D; HERZEL, H; TITZE, IR; Story BH. Bifurcations in excised larynx experiments. Journal of Voice. Vol. 10, pp. 129- 138. 1996. 
BHUTA, T; PATRICK, L; GARNETT, JD. Perceptual Evaluation of Voice Quality and its Correlation with Acoustic Measurements. Journal of Voice, Vol. 18, No. 3, pp. 299-304. 2004.

CALLEGARI-JACQUES, SM. Bioestatística: princípios e aplicações. Artemed Editora AS. São Paulo, 2003.

CARDING, P; CARLSON, E; EPSTEIN, R; MATHIESON, L; SHEWELL, C. Formal perceptual evaluation of voice quality in the United Kingdom. Logoped Phoniat Vocol.;25: pp. 133-138. 2000.

CARNEIRO, PR. Características acústicas da voz em diferentes posturas corporais. Dissertação (Mestrado) - Programa de Pós-Graduação Interunidades em Bioengenharia/ EESC/ FMRP/ IQSC. Universidade de São Paulo, São Carlos, 2009.

CARNEIRO, PR; DAJER, ME; MARRARA, JL; MARQUES, RM; TELES, LCS. Análise da qualidade vocal em profissionais da voz relacionada a diferentes posturas corporais. XV Congresso Brasileiro de Fonoaudiologia. Campos de Jordão, São Paulo, 2008.

CARSON, CP; INGRISANO, DRS; EGGLESTON, KD. The Effect of Noise on Computer-Aided Measures of Voice: A Comparison of CSpeechSP and the Multi-Dimensional Voice Program Software Using the CSL 4300B Module and Multi-Speech for Windows". Journal of Voice, Vol. 17, No. 1, pp. 12-20, 2003.

CHAN, KMK; YIU, EML. A Comparison of Two Perceptual Voice Evaluation Training Programs for Naive Listeners. Journal of Voice, Volume 20, Issue 2, pp. 229-241. 2006.

COLTON, RH; CASPER, JK; LEONARD, R. Compreendendo os problemas de voz: uma perspective fisiológica no diagnóstico e tratamento das disfonias. Ed. Revinter, 2010.

COMITÊ PARA TESTES DE FUNÇÃO FONATÓRIA DA SOCIEDADE JAPONESA DE LOGOPEDIA E FONIATRIA - Fita de Vídeo ilustrativo da "GRBAS", 1969.

DAJER, ME; MACIEL, CD; PEREIRA, JC. Chaos tool implementation for nonsinger and singer voice comparison (Preliminary study). Journal of Physics: Conference Series (JPCS). Vol.90, (012082). http://www.iop.org/EJ/toc/17426596/90/1. 2007

DAJER, ME; ANDRADE, FS; PEREIRA, JC. Qualitative and quantitative analysis of vocal dynamic visual patters. IALP congress, 2010.(NO PRELO) 
EADIE, TL; BAYLOR, CR. The Effect of Perceptual Training on Inexperienced Listeners' Judgments of Dysphonic Voice. Journal of Voice, Vol.20, Issue 4, pp. 527-544. 2006.

ESPANHOL, DR. Determinadores de Pitch. 2004. Dissertação (Mestrado em Engenharia Elétrica), Depto de Engenharia Elétrica, EESC - USP, 2004

FANT, G. Acoustic Theory of Speech Production. 2nd ed. The Hague: Mouton; 15-26.134-1140. 1970.

FLANAGAN, JL. Speech analysis, synthesis and perception. Springer-Verlag, New York, 2da Ed. 1972.

FRASER, AM; SWINNEY, HL. Independent coordinates for strange attractors from mutual information. Phys Rev Lett. ;33:1134-1140. 1986.

FUKUYAMA, EE. Análise acústica da voz captada na faringe próximo ä fonte glótica através de microfone acoplado ao fibrolaringoscópio. Rev Bras Otorrinolaringol, 67:776-86I, 2001.

GERRATT, BR; KREIMAN, J. Measuring vocal quality with speech synthesis. J Acoust Soc Am. 110:2560-2566. 2001.

GIOVANNI, A; OUAKNINE, M; TRIGLIA, JM. Determination of largest Lyapunov exponents of vocal signal: application to unilateral laryngeal paralysis. Journal of Voice, vol. 13, pp. 341-354. 1998.

GRAY, SD; HIRANO, M; SATO, K. Molecular and cellular structure of vocal fold tissue. In: TITZE, IR. Vocal Fold physiology: frontiers of basic science. San Diego: Singular Publishing Group, 1993.

GUARINELO, CS; BEHLAU, M. O impacto de uma eventual perda de voz na vida diária dos indivíduos normais. IN: BEHLAU. M. A voz do especialista II. Ed. Revinter Ltda. RJ. 2001

HAMMARBERG, B. Voice research and clinical needs. Folia Phoniat. Et Logop., 52: pp. 93-102. 2000.

HAMMARBERG, B; GAUFFIN, J. Perceptual and acoustics characteristics of quality differences in pathological voices as related to physiological aspects. In: FUJIMURA O, HIRANO, M. Vocal fold physiology. San Diego, Singular Publishing Group Inc., 1995.

HEGGER, R; KANTZ, H; SCHREIBER, T. Practical implementation of nonlinear time series methods: The TISEAN package. Chaos. Volume 9, Issue 2, pp. 413-435. 1999 
HENICK, DH; SATALOFF, R. Laryngeal Embryology and Vocal Development. In SATALOFF,RT. Professional Voice: the Science and Art of Clinical Care.2dn Edition. San Diego: Singular, 1997.

HERZEL, H; BERRY, D; TITZE, IR; SALEH, M. Analysis of vocal disorders with methods from nonlinear dynamics. Journal of Speech and Hearing Research, 37, pp 1001-1007. 1994.

HIRANO, M. Clinical examination of voice. New York: Springer Verlag, 1981.

HIRANO, M. Laryngeal Histopathology. In: COLTON, R; CASPER, J: Understanding Voice Problems, a Physiological Perspective for the diagnosis and Treatment. 2nd Edition. Baltimore: Williams \& Wilkins, 1996

HIRANO, M; BLESS, DM. Exame Videoestroboscópico da Laringe. Porto Alegre: Artes médicas, 1997.

HIRANO, M; KAKITA, Y. Cover-body theory of vocal fold vibration. In: DANILOFF, RG. Speech Science: recent advances. San Diego: College-Hill Press; 1985.

HIRANO, M; YOSHIDA, T; TANAKA, S; HIBI, S. Sulcus vocalis: functional aspects. Ann. Otol. Rhinol. Laryngol.; 99:679-83.1990

HORNERO, R; ALONSO, A; JIMENO, N; JIMENO, A; LOPEZ, M. Nonlinear analysis of time series generated by schizophrenic patients. IEEE Eng Med Biol Mag. ;3: pp. 84-90. 1999.

ISSHIKI, N. Recent advances in phonosurgery. Folia Phoniatrica. (Basel), 32:119-54, 1980.

JIANG, JJ; ZHANG, Y. Nonlinear dynamic analysis of speech from pathologic subjects. Electron Letters. 38:294-295. 2002.

JIANG, JJ; ZHANG, Y. Modeling of chaotic vibrations in symmetric vocal folds. J. Acoust. Soc. Am. 110 (4). 2001

JIANG, JJ; ZHANG, Y; MCGILLIGAN, C. Chaos in voice, from modeling to measurement. Journal of Voice. 20: pp. 2-17. 2006.

JIANG, JJ; ZHANG, Y; MACCALLUM, J; SPRECHER, A; ZHOU, J. Objective Acoustic Analysis of Pathological Voices from Patients with Vocal Nodules and Polyps. Folia Phoniatr Logop;61: pp. 342-349. 2009

KATZ M. Fractals and the Analysis of Waveforms. Comput Biol Med, 18(3):145-156, 1988. 
KANTZ, H; SCHREIBER, T. Nonlinear time series analysis. $2^{\text {nd }}$ ed. Cambridge University Press. 2003.

KARKOS, PD; MC CORMICK, M. The etiology of vocal fold nodules in adults Current Opinion in Otolaryngology \& Head and Neck Surgery: December Volume 17 - Issue 6 - pp. 420-423. 2009

KARNELL, MP; MELTON, SD; CHILDES, JM; COLEMAN, TC; DAILEY, SA; HOFFMAN, HT. Reliability of clinician-based (GRBAS and CAPE-V) and patient-based (V-RQOL and IPVI) documentation of voice disorders. Journal of Voice. 21(5):pp. 576-90, 2007.

KREIMAN, J; GERRATT, BR. Validity of rating scale measures of voice quality. J of the Acoustical Society of America. 104, pp. 1598-1608, 1998.

KUNDUK, M; McWHORTER, AJ. True vocal folds nodules: the role of differencial diagnosis. Curr Opin Otolaryngol Head Neck Surg 17:pp. 449-52. 2009.

LAVER, J. The phonetic description of voice quality. Cambridge University Press, Cambridge, 1980.

LE HUCHE, F.; ALLALI, A. La voz anatomía y fisiología patología terapéutica. Barcelona: Masson, 1993.

MAC CALLUM, JK; CAI, LI; ZHOU, L; ZHANG, Y; JIANG, JJ. Acoustic analysis of aperiodic voice: Perturbatin and nonlinear dynamic properties in esophageal phonation. Journal of Voice. Vol 3,N3 283-290. 2009.

MADRUGA, ECM; LEMOS, M; ARAGÃO, XFJ; SENNES, L; NASCIMENTO, PHS; TSUJI, DH. Distribution of collagen in the lamina propria of the human vocal fold. Laringoscope; 113 (12): 2187-19, 2003.

MAGRI, A; CUKIER-BLAJ, S; FRAGA E KARMAN, D; CAMARGO, ZA. Correlatos perceptivos e acústicos dos ajustes supraglóticos na disfonia. Rev CEFAC, São Paulo, v.9, n.4, 512-518. 2007

MARTIN, D; FITCH, J; WOLFE, V. Pathological voice type and the acoustic prediction of severity. J Speech Hear Res.; 38:765-771. 1995

MARTINS, RMG; FABRO, AT; DOMINGUES, MAC; CHI, AC; GREGORIO, EA Is Reinke's Edema a Precancerous Lesion? Histological and Electron Microscopic Aspects. Journal of Voice, Vol. 23, 722 No. 6, 2009

MARYN, Y; ROY, N; DE BODT, M; VAN CAUWENBERGE, P; CORTHALS, P. Acoustic measurement of overall voice quality: a meta-analysis. J. Acoust. Soc. Am. 126 (5), 2009. 
MATASSINI, L; HEGGER, R; KANTZ, H; MANFREDI, C. Analysis of vocal disorder in a feature space. Medical Engineering \& Physics 22: pp. 413-418; 2000.

MENDEL, W; HERZEL, H; WEMKE, K. Bifurcations and chaos in newborn infant cries. Phys Letters A. vol. 145, pp. 418-424, 1990.

MONTAGNOLI, AN. Análise Residual do sinal de voz. Dissertação (Mestrado em engenharia Elétrica), Depto de Engenharia Elétrica, EESC - USP Universidade de São Paulo - Campus de São Carlos, 1998.

MONTAGNOLI, NA; PEREIRA JC. [Análise de Voz, Versão 4.10]. Sistema de Auxílio à Análise Acústica da Voz. 2009.

NAYFEH AH, BALACHANDRAN B. Applied nonlinear dynamics. Wiley series in nonlinear Science. p.1-31. 1994

NUNES, MV; COSTA, LLR. Avaliação Acústica na Prática Fonoaudiológica. In: PINHO, S; TSUJI, DH; BOHADANA, SC. Fundamentos em laringologia e Voz. Ed. Revinter, Rio de Janeiro, 2006.

OATES, J. Auditory-Perceptual Evaluation of Disordered Voice Quality. Folia Phoniatr Logop;61: pp. 49-56. 2009

OTT, E; SAUER, T; YORKE, JA. Coping with Chaos. New York: Wiley eds. 1994.

PACKARD, NH; CRUTCHFIELD, JP; FARMER, JD, SHAW, RS. Geometry from a time series. Phys Rev Lett.;45:712; 1980.

PINHO, S; PONTES, P. Escala de avaliação perceptiva da fonte glótica: RASAT. Vox Brasilis - Ano $8-\mathrm{n}^{\circ}$ 3. 2002.

PONTES, P; BEHLAU, M; BRASIL, O. Minor structural alterations of the larynx: an attempt of classification. $6^{\text {th }}$ International Symposium of Phonosurgeons. Anais Veneza. 2000

POON, CS; MERRILL, CK. Decrease of cardiac chaos in congestive heart failure. Nature. ;389: pp. 492-495.1997.

RABINER, LRE; JUANG, BH. Fundamentals of Speech Recognition, Prentice Hall, Nova Jersey. 1993.

RAHN, DA; CHOU, M; ZHANG, Y; JIANG, JJ. Phonatory impairment in Parkinson's disease: Evidence from nonlinear dynamic analysis and perturbation analysis, Journal of Voice 21 pp. 64-71; 2007. 
RICHTER, M; SCHREIBER, T. Phase space embedding of electrocardiograms. Phys. Rev. E 58, pp. 6392 - 6398. 1998.

ROSEN, DP; SATALOFF, RT. Voice disorders; Psychological aspects; Patients; Rehabilitation; psychology. Singular Pub. Group; San Diego, 1997.

RUBIN, JS; MATHIESON, L; BLAKE, E. Posture and voice. Journal of Singing. ;60: pp. 271-275, 2004.

SATALOFF, RT. Professional voice: the science and art of clinical care. 2nd ed. San Diego, Calif: Singular Publishing Group; 1997.

SATALOFF, RT; HAWKSHAW, M. Chaos in Medicine: Source Readings. San Diego, CA: Singular Publishing Group. 2001.

SCALASSARA, PR; DAJER, ME; MACIEL, CD; CAPOBIANCO, R; PEREIRA, JC Relative entropy measures applied to healthy and pathological voice characterization Applied Mathematics and Computation 207 pp. 95-108, 2009.

SCHNEIDER, CM; DENNEHY, CA, SAXON, KG, Exercise physiology principles applied to voice performance: the improvement of postural alignment. Journal of Voice. 11:pp. 332-333. 1997.

SHRIVASTAV, R. Multidimensional Scaling of Breathy Voice Quality: Individual Differences in Perception. Journal of Voice, Volume 20, Issue 2, pp. 211-222, 2006.

SMITS, I; CEUPPENS, P; DE BODT, MS. A Comparative Study of Acoustic Voice Measurements by Means of Dr. Speech and Computerized Speech Lab. Journal of Voice, Vol. 19, No. 2, pp. 187-196. 2005.

SÖDERSTEN, M; LINDESTAD, PA; HAMMARBERG. Vocal fold closure, perceived breathiness, and acoustic characteristics in normal adult speakers. In: GAUFFIN, J; HAMMARBERG, B. Vocal fold physiology. Acoustic, perceptual and physiological aspects of voice mechanisms. San Diego: Singular; 1991.

TAKENS, F. Dynamical systems and turbulence, Lecture Notes in Mathematics. Berlin, Germany: Springer-Verlag, vol. 898, pp. 366-381; 1981.

TEAGER,H; TEAGER, S. Evidence for nonlinear sound production mechanisms in the vocal tract. In: Proc. NATO ASI on Speech Production and Speech Modeling, pp. 241-261, 1990.

TITZE, IR. Principles of Voice Production. 2nd ed. lowa City, IA: NCVS; 2000. 
TITZE, IR; BAKEN, R; HERZEL, H. Evidence of chaos in vocal fold vibration. New Frontiers in Basic Science, ed. Vocal Fold Physiology, Singular Publishing Group, San Diego, CA, 1993.

TOSI, O. Voice identification: theory and legal applications. University Park, Baltimor, 1979.

TSUJI, D; INAMURA, R; UBIRAJARA, LS. Fisiologia da laringe. In: PINHO, S; TSUJI, DH; BOHADANA, SC. Fundamentos em laringologia e Voz. Ed. Revinter, Rio de Janeiro, 2006.

TUCKER, H. Anatomy of the larynx. IN: TUKER, H. The Larynx. New York: Thieme, 1993.

UMAPATHY, K; KRISHNAN, S; PARSA, V; JAMIESON, DG. Discrimination of pathological voices using a time-frequency approach. IEEE. Transactions On Biomedical Engineering, Vol. 52, NO. 3, pp: 421- 430. 2005.

ZHANG, Y; JIANG, JJ. Chaotic vibrations of a vocal-fold model with a unilateral polyp. J Acoust Soc Am. 115: pp. 1266-1269. 2004.

ZHANG, Y; JIANG, JJ; BIAZZO, L; JORGENSEN, M; BERMAN, M. Perturbation and nonlinear dynamic analyses of voices from patients with unilateral laryngeal paralysis. Journal of Voice. 19(4): pp. 519-28I; 2005. 